Research Report

\title{
Consumer Decisionmaking in the Health Care Marketplace
}

Erin Audrey Taylor, Katherine Grace Carman, Andrea Lopez, Ashley N. Muchow,

Parisa Roshan, Christine Eibner 
For more information on this publication, visit www.rand.org/t/rr1567

Library of Congress Cataloging-in-Publication Data is available for this publication.

ISBN: 978-0-8330-9505-3

Published by the RAND Corporation, Santa Monica, Calif.

(C) Copyright 2016 RAND Corporation

RAND $^{\circledR}$ is a registered trademark.

\section{Limited Print and Electronic Distribution Rights}

This document and trademark(s) contained herein are protected by law. This representation of RAND intellectual property is provided for noncommercial use only. Unauthorized posting of this publication online is prohibited. Permission is given to duplicate this document for personal use only, as long as it is unaltered and complete. Permission is required from RAND to reproduce, or reuse in another form, any of its research documents for commercial use. For information on reprint and linking permissions, please visit www.rand.org/pubs/permissions.html.

The RAND Corporation is a research organization that develops solutions to public policy challenges to help make communities throughout the world safer and more secure, healthier and more prosperous. RAND is nonprofit, nonpartisan, and committed to the public interest.

RAND's publications do not necessarily reflect the opinions of its research clients and sponsors.

Support RAND

Make a tax-deductible charitable contribution at www.rand.org/giving/contribute

www.rand.org 


\section{Preface}

For this report, researchers conducted a literature review to better understand how consumers make choices about health insurance enrollment and to assess how website design can influence choice when consumers select plans online. The team also considered how such factors as imperfect information and bounded rationality can influence consumers' health plan choices and whether errors in decisionmaking caused by information failures or bounded rationality can be reduced with better website design. In addition to conducting the literature review, the team reviewed 20 health insurance websites, including 14 websites operated by state-based marketplaces, four private health insurance websites, and two public health insurance websites (the Medicare Plan Finder [Centers for Medicare \& Medicaid Services, undated (b)] and the California Public Employees' Retirement System website [California Public Employees' Retirement System, 2016]). In reviewing these websites, the team attempted to understand how the design of the sites might influence choices. After a review of the team's findings, the report concludes with a discussion about how websites could be improved to better support consumers' enrollment decisions. We conducted the literature review and the review of the websites in the spring of 2015.

This report will be of interest to policymakers and industry experts involved in designing health insurance websites and researchers who are interested in consumer choice. The work was sponsored by the U.S. Department of Health and Human Services, Office of the Assistant Secretary for Planning and Evaluation. However, the views, opinions, and findings presented here are ours and should not be construed as official government positions unless so designated by other documents. Questions concerning this report can be addressed to Christine Eibner (eibner@rand.org) or Erin Taylor (etaylor1@rand.org). This research was conducted within RAND Health. A profile of RAND Health, abstracts of its publications, and ordering information can be found at www.rand.org/health. 



\section{Contents}

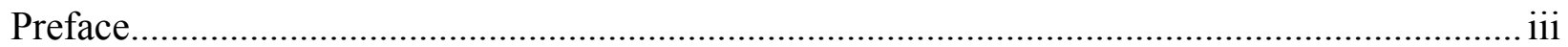

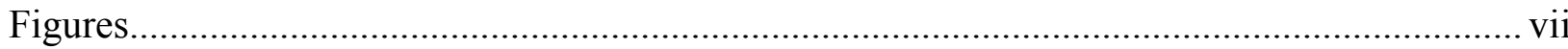

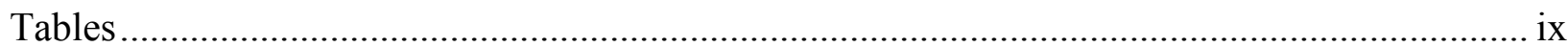

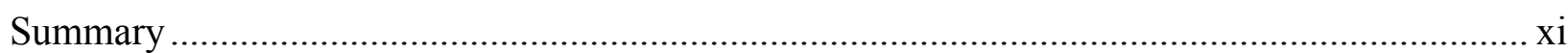

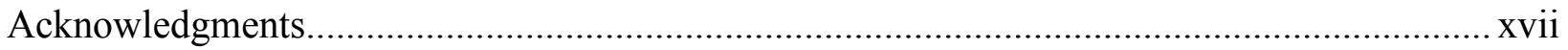

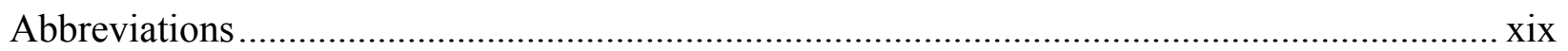

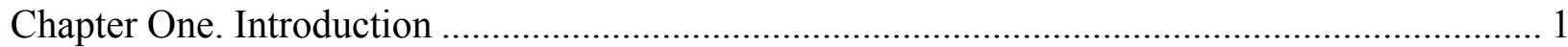

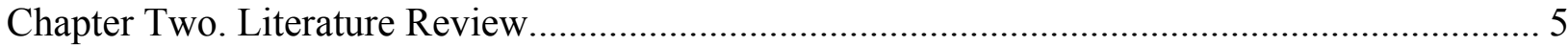

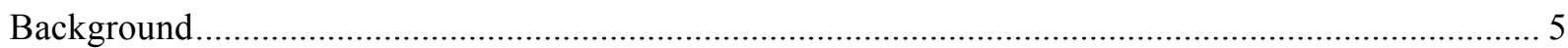

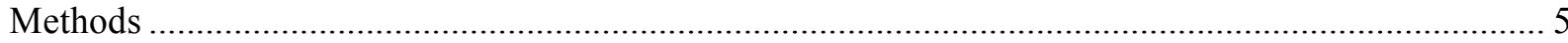

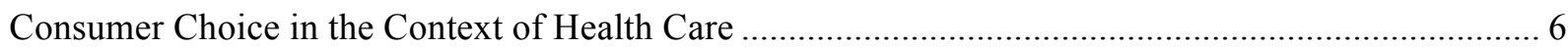

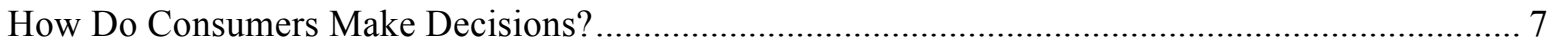

What Is the Appropriate Choice Architecture? Challenges to Effective Decisionmaking ............... 14

Previous Research on Health Insurance Website Design .................................................................. 22

Marketplace Regulations Affect Website Design and Choices....................................................... 22

Consumer Research Informed Website Design................................................................... 23

Health Insurance Choice Websites Sometimes Reflect Consumer Research Results....................... 24

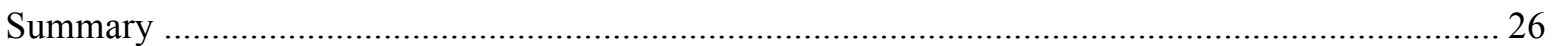

Approaches to Future Website Development from the Literature …................................................ 26

Consumers Might Incorrectly Calculate Cost or Put Undue Emphasis on Premiums ..................... 26

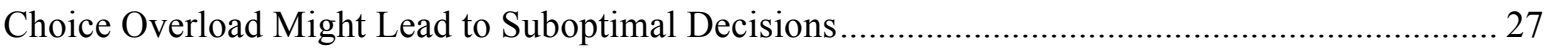

Consumers Might Have Difficulty Understanding Complex Health Insurance Information............. 28

Consumers Might be Subject to Inertia or Status Quo Bias ......................................................... 29

Limited Numeracy, Literacy, and Knowledge of Health Insurance Adversely Affect Individual

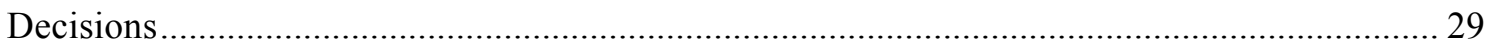

Standardization of Products Might Promote Competition ........................................................... 30

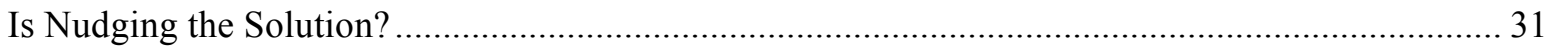

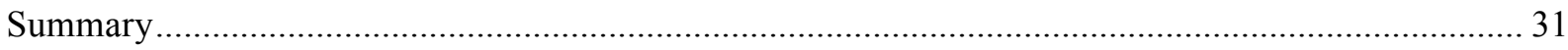

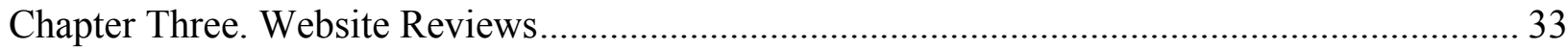

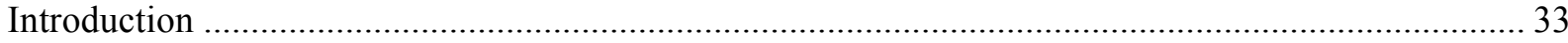

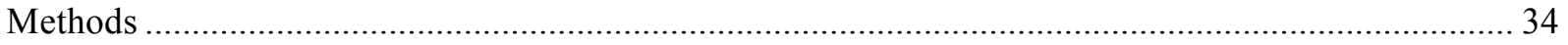

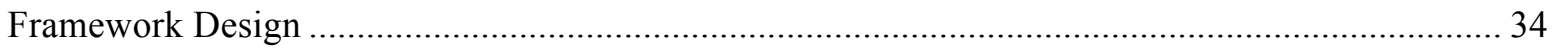

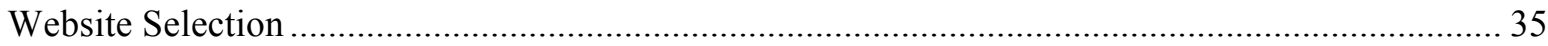

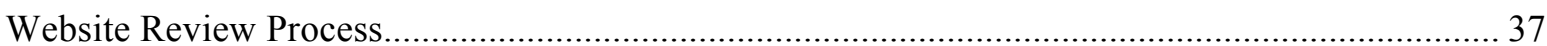

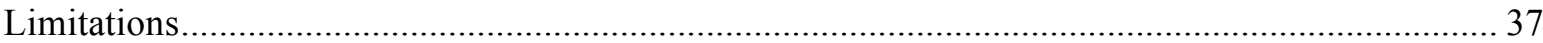

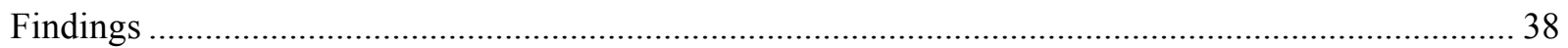

Many Pathways Exist to Navigate Sites ................................................................................ 38 


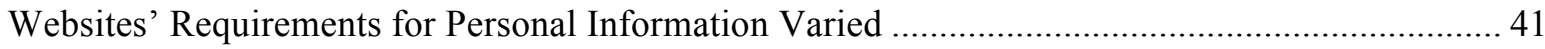

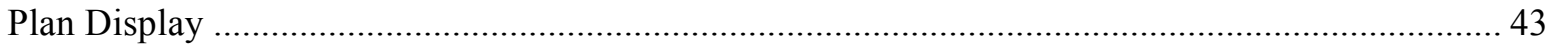

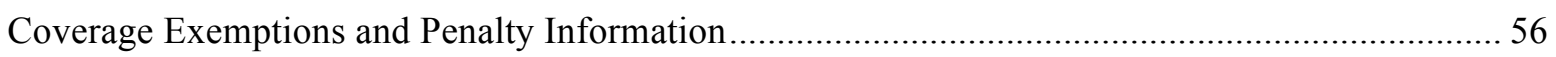

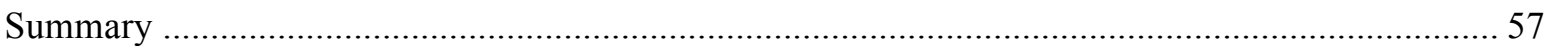

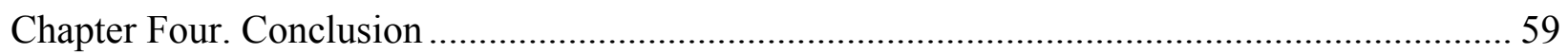

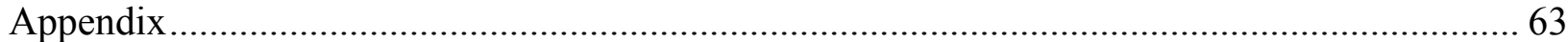

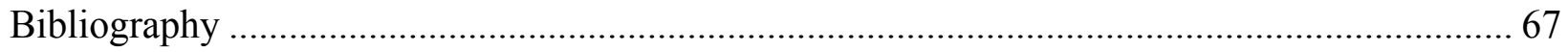




\section{Figures}

Figure 3.1. Screen Shot of the Covered California Home Page ............................................. 40

Figure 3.2. Screen Shot of Kentucky's Initial Result Display, Showing Premium Subsidies

Applied to the Low-Income Scenario Only ............................................................... 45

Figure 3.3. Minnesota's "My Preferences" Filter and Sort Options ........................................ 47

Figure 3.4. Washington Healthplanfinder's Physician Network Sort Option ........................... 55

Figure 3.5. kynect's Physician Network Filter Option ..................................................... 56 



\section{Tables}

Table 1.1. Example of a Dominant Plan's Expenses, in Dollars ................................................ 3

Table 2.1. State Actions to Simplify Consumer Choices in the Marketplace............................ 23

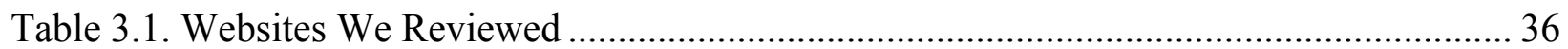

Table 3.2. The Amount and Types of Personal Information That Websites Requested or

Required

Table 3.3. Example of Premium and Cost-Sharing Subsidies in Initial Result Display, for Maryland, Kaiser Permanente Silver 1750/25-Percent Plan.

Table 3.4. Default Sorts and Filters Applied by Reviewed Websites for the Low-Income Scenario.

Table 3.5. Number of Sites Presenting Specific Design Elements in Initial Result Displays, for the Low-Income Scenario

Table 3.6. Information Collected by Websites That Offer Total Out-of-Pocket Cost Calculators 51

Table 3.7. Number of Sites That Offer User-Selected Sort and Filter Options .......................... 54

Table A.1. Sites That Request Specific Types of Personal Information .................................. 63

Table A.2. Sites Applying Default Sorts and Filters for the Low-Income Scenario ................... 64

Table A.3. Sites Presenting Specific Design Elements in Initial Result Displays, for the Low-Income Scenario 65

Table A.4. Sites That Offer Information on Provider Networks ............................................. 65

Table A.5. Sites That Offer User-Selected Sort and Filter Options...... 



\section{Summary}

\section{Overview of Study}

The Patient Protection and Affordable Care Act (ACA) (Pub. L. 111-148, 2010) introduced the health insurance marketplaces, new online clearinghouses for buying and selling insurance. One of the benefits of the marketplaces is that they enable consumers to compare a large number of health insurance plans and - ideally — select the plans that best suit their needs. In theory, the ability to shop through the marketplaces could both enhance the consumer experience by providing an easy way to comparison-shop across many plans and improve competition by making cost and quality differences across plans obvious to consumers. Consumers with low incomes might be eligible for subsidies for their insurance premiums and possibly for cost sharing, which could help reduce their out-of-pocket costs for coverage. In addition, the ACA encourages consumers to enroll in health insurance plans through an individual mandate that imposes penalties on those who do not have health insurance. Thus, consumers seeking insurance through the marketplaces have an additional incentive to comparison-shop because the status quo of nonenrollment might be an unattractive option.

However, a large body of evidence suggests that health insurance shopping might be overwhelming to consumers because of the complexity of products offered, limited health literacy and numeracy, inadequate decision-support tools, and an excessive number of choices. Consumers might be susceptible to the way choices are presented (e.g., they might be more likely to select plans that are presented first on the website). Limited health insurance literacy and poor numeracy could lead to flawed logic in making choices, such as focusing primarily on premiums without considering total anticipated spending. In some cases, having too many options could lead to fatigue, reducing the probability that a consumer will enroll in a plan at all. Furthermore, when consumers are myopic or not well informed, they might make suboptimal choices that could lead market outcomes to be inefficient.

Although little evidence exists so far regarding whether consumers in fact made poor choices in the marketplaces, there are several possible outcomes associated with poor choices. Consumers who enroll in plans with higher deductibles or other cost sharing than they can afford might forgo health care altogether. Consumers who are not aware of the potential for receiving subsidies for their premiums and cost sharing might choose not to enroll in coverage. And finally, consumers who enroll in plans with expected spending greater than alternative plans could end up spending far more on their health care during the year than they otherwise would have. Thus, website design can have a significant effect on consumers' ability to make good choices of health plans and avoid some of these adverse outcomes. 
Some of the challenges associated with online shopping for health insurance could potentially be alleviated by improving web design and enhancing decision support for consumers. For example, sites could eliminate health insurance jargon and explain key terms in plainer language, decision-support tools could nudge consumers to consider total costs rather than just premiums, and default settings could prioritize plans that best meet consumers' needs (e.g., by listing such plans first). For this study, we reviewed the literature on how consumers make choices in the context of health insurance enrollment to determine what plan characteristics matter most, what types of errors in decisionmaking are common, and what (if any) best practices exist for helping consumers make optimal (or at least improved) decisions. We considered in particular whether default settings and other nudges could be used to help enhance the consumer experience and improve the quality of plan choice.

In addition to the literature review, we reviewed 20 health insurance enrollment websites to determine what type of information is presented to consumers, how that information is presented, what types of decision-support tools are available, and how these factors might influence consumer choices. The websites we analyzed included those for the 14 states that operated their own online marketplaces in 2015 (California, Colorado, Connecticut, the District of Columbia, Hawaii, Idaho, Kentucky, Maryland, Massachusetts, Minnesota, New York, Rhode Island, Vermont, and Washington), four private organizations that operate websites that aggregate information from the marketplaces (Consumers' Checkbook, HealthSherpa, HealthPocket, and ValuePenguin), and two public agencies that operate websites (California Public Employees' Retirement System and the Centers for Medicare \& Medicaid Services [its Medicare Plan Finder website]). In selecting websites, we had a primary goal of analyzing all of the state-based marketplace websites and comparing these sites with a mix of other public and private health insurance comparison and enrollment websites. We selected the sites in conjunction with our client, the U.S. Department of Health and Human Services' Assistant Secretary for Planning and Evaluation. In addition to analyzing the design of the websites and the manner in which they presented choices to users, we assessed how the sites communicated information about subsidy eligibility, the ACA's individual mandate, and potential exemptions from the mandate.

\section{Findings from the Literature Review}

\section{Consumers Suffer from Bounded Rationality}

Behavioral economics research suggests that consumers can be affected by bounded rationality, in which they might make suboptimal choices because of difficulty processing complex information, fatigue, and other factors that limit critical thinking skills. Bounded rationality could be especially important in the context of health insurance given that products are complicated and the benefits of purchasing insurance are not immediately salient. That is, 
insurance protects people against future uncertain events but does not always provide an immediate tangible benefit.

The literature presents examples of bounded rationality that influence health insurance choices. Health insurance consumers are susceptible to choice overload. Particularly in experimental settings, the literature shows, the quality of plan selections falls as more options are added to the consumers' choice set. Consumers are also prone to status quo bias - they stick with initial choices even if prices change or if new, potentially better choices become available. When consumers are selecting plans, studies also show, the order in which choices are presented significantly influences consumers' decisions. Evidence from the Massachusetts Health Connector and elsewhere shows that a consumer is most likely to select the first plan presented on a website display. Additionally, consumers can be susceptible to framing biases, such that the manner in which choices are described can affect decisions. Of importance for the marketplaces is the fact that people prefer plans labeled "gold" even in experiments in which these plans had actuarial values and premiums similar to those of bronze plans.

\section{Consumers Have Limited Health Literacy and Numeracy}

Consumers are susceptible to biases stemming from bounded rationality, and their ability to make insurance choices might be hindered by a lack of understanding of key concepts. Studies have shown that many people lack familiarity with such terms as deductible, coinsurance rate, and provider network. Furthermore, low-income and uninsured consumers, the target populations for the marketplaces, have a more-limited understanding of these concepts than higher-income and insured consumers do.

More generally, consumers lack numeracy skills, such as the ability to calculate probabilities, which can be particularly important for understanding insurance. Insurance choices, by definition, require consideration not only of expected costs but also of risk. Even if expenditures were known in advance, calculating out-of-pocket spending requires mathematical reasoning to address the financial implications not only of premiums but also of deductibles, copayments, and other cost sharing. Studies have found that consumers tend to put undue emphasis on premiums in selecting plans, suggesting that they do not fully take into account the impact of cost sharing.

Studies have also found that conveying information on plan quality to consumers is difficult, an issue that is at least partly related to consumers' lack of familiarity with quality metrics, such as the Healthcare Effectiveness Data and Information Set and the Consumer Assessment of Healthcare Providers and Systems. In addition, there are many dimensions of quality, not all of which are important for every consumer, making summary measures relatively unhelpful for some consumers. At the same time, providing detailed information on multiple quality metrics can become overwhelming. Some studies have found that consumers might tend to view price as a proxy for quality. 


\section{Some Options to Improve Plan Selections}

The literature suggests that it might be possible to improve consumers' choices by simplifying the information presented to the greatest extent possible. Such simplifications could include eliminating jargon and removing extraneous text or information. Some studies have found that people make better choices when price and quality differences are ranked using symbols (e.g., $\$ \$$ or $* * *$ ) instead of actual dollar values or numbers. More generally, some studies have shown, people make better choices when information is presented graphically (as opposed to using text or numbers) and when key information, such as premiums, deductibles, and copays, can be compared side by side. In experimental settings, out-of-pocket cost calculators can improve choice.

Some consumer-oriented organizations and partnerships, including the Pacific Business Group on Health, Enroll UX 2014, and Consumers Union, have made recommendations for website design in the health insurance marketplaces. Suggestions include providing out-ofpocket cost calculators, incorporating provider directories into websites, allowing consumers to sort and filter plans based on key characteristics, and using defaults to strategically nudge consumers toward best-fit plans (e.g., listing such plans first in web displays). Ideally, best-fit plans would be identified based on multiple characteristics that the consumer rates as important, such as total costs, provider networks, and plan quality.

Although these recommendations seem sensible, they are based on evidence from small, experimental studies or extrapolated from such populations as Medicare enrollees. No studies have yet tested whether marketplace websites with these features lead to better outcomes in terms of plan selection.

\section{Findings from the Review of Websites}

Our website review documented the design and default settings used by 20 websites. For example, we note that about half the sites we reviewed listed plans with the lowest premiums first, an approach that might induce people to enroll in low-premium plans. However, only two of the 14 state marketplace sites directed subsidy-eligible people into a menu of silver-plan options. Because the value of a subsidy is benchmarked to the premium of the second-lowestcost silver plan, and because cost-sharing subsidies are available only to silver-plan enrollees, this type of default could improve choices for some consumers. Most sites presented clear and prominent information about individuals' eligibility for subsidies, and most sites included at least some informational materials and tools to allow consumers to learn more about health insurance and decide among various options. For example, the majority of sites provided glossaries of key terms and video tutorials to help consumers navigate the website and learn more about health insurance options. Most sites also allowed consumers to sort, filter, and compare plans on various characteristics. 
Three potentially useful tools — out-of-pocket cost calculators, directories of provider networks, and information on plan quality ratings — were only occasionally available on health insurance websites. Only one site, Minnesota's, attempted to assess consumers' preferences and use this information to prioritize plans. Specifically, the Minnesota website asked consumers questions about their health needs and preferences and sorted plans based on a composite metric as a default. Although all sites contained information on the individual mandate and potential exemptions to the mandate, this information was often difficult to find.

\section{Discussion}

The literature points to a variety of approaches to improve decisions on marketplace websites. Several recommended design features that we did not typically find in our website review included use of out-of-pocket cost calculators, incorporation of provider directories, provision of plan quality ratings, and use of tailored sorting approaches that allow consumers to identify best-fit plans, such as the "my preferences" approach used in Minnesota.

If well designed, such tools as out-of-pocket cost calculators, provider directories, and tailored sorting options could improve the consumer experience. However, these tools might be difficult to keep current and could be misleading if the information is outdated or incorrect. Among sites that included out-of-pocket cost calculators, most based these calculations on prior utilization, which might be a poor predictor of future utilization, particularly for the newly insured (who might use more care after becoming insured). Studies have found that algorithms used for cost calculators have varied widely. The Massachusetts Health Connector decided not to display out-of-pocket cost estimates on its website because site designers did not believe that there was an appropriate or accurate algorithm to create such a calculator.

The literature review showed that plan quality ratings were particularly difficult to convey to consumers, in part because there are many dimensions of quality, and a summary measure might be of limited use to consumers with specific health care needs. Some consumers were confused about the underlying concepts that quality ratings conveyed - such as the meaning of a high quality rating for vaccination (e.g., does this mean that these doctors provide better vaccines, that they vaccinate more patients, or something else?).

Although consumers often indicate that it is important to them that their doctor be in their provider networks, few websites currently provide integrated provider directories or enable consumers to sort and filter plans based on provider participation in network. Ideally, up-to-date provider directories could be extremely helpful to consumers. But such directories will be only as good as the underlying information supporting these tools. If these underlying data sources become quickly outdated or contain inaccuracies, adding such information might not improve the consumer experience.

The literature also supports using defaults and nudges to attempt to help consumers select the best plan. However, successful application of these tools requires that decisionmakers be able to 
identify best-fit plans for consumers. This might be difficult given the many parameters of potential importance and the difficulty of assigning weights to these parameters. For example, determining how much weight should be put on expected spending in a typical year compared with expected spending in a bad year requires an understanding of consumers' preferences for risk. Similarly, effective nudging might require decisionmakers to make an assumption about consumers' willingness to make trade-offs on such dimensions as cost, convenience, breadth of the provider network, and plan quality ratings.

Much of the literature draws from highly stylized experiments in which study participants are presented choices that researchers can easily rank. For example, participants might be presented with a set of plans that vary on only three or four financial dimensions (e.g., premium, deductible, and maximum out-of-pocket spending), and nonfinancial attributes, such as provider networks, are not considered. Consumers might also be told exactly how much health care expenditure they should expect to incur in a given year. With such an approach, it is possible for researchers to definitively determine the best plan for consumers by objectively calculating expenditure under the fixed set of plans. Optimal choices are far harder to determine in realworld settings, in which plans vary on nonfinancial dimensions and future expenditure is uncertain.

In addition, provider directories, quality rankings, out-of-pocket calculators, and nudges toward optimal plans will be only as good as the underlying data used to support these tools. In theory, ensuring that provider directors are up to date should be relatively straightforward because information on providers' participation in plans is necessary for billing. However, there is a lack of consensus regarding how best to convey plan quality information to consumers or how to design an ideal out-of-pocket cost calculator. Developing algorithms to identify best-fit plans might be even more complicated, particularly in the context of health insurance, in which there are many parameters and what is best for one person is not likely to be best for another. More research is needed to determine how to present information to consumers and how to develop plan rankings that are tailored to consumers' preferences and that account for multiple characteristics.

In addition, more research is needed to understand how features of website design influence consumers' decisions to enroll in marketplace plans and what types of plans they select. To date, no study has attempted to determine how specific features of marketplace websites influence consumers' enrollment decisions. Given that websites varied across states and over time, there might be opportunities to use quasi-experimental research designs to determine which features were most effective at nudging consumers to make good choices. 


\section{Acknowledgments}

We would like to thank several people for their contributions to this report. We appreciate the excellent comments and suggestions from the following people: Jill E. Luoto, Jonathan T. Kolstad, Peter S. Hussey, Paul Koegel, Ruth Katz, Teresa Manocchio, Christie Peters, Richard G. Frank, Arnold M. Epstein, Nancy De Lew, and David Yokum. We also thank Anita Szafran for her help searching and selecting articles for the literature review. Finally, thanks to Stacy Fitzsimmons for her excellent administrative assistance. 



\section{Abbreviations}

ACA Patient Protection and Affordable Care Act

APTC advanced premium tax credit

ASPE Assistant Secretary for Planning and Evaluation

CalPERS California Public Employees' Retirement System

$\mathrm{FAQ}$ frequently asked question

HMO health maintenance organization

ID identification

PBGH Pacific Business Group on Health

PPO preferred provider organization

SBM state-based marketplace 



\section{Chapter One. Introduction}

Two central goals of the health insurance marketplaces that the Patient Protection and Affordable Care Act (ACA) (Pub. L. 111-148, 2010) introduced are to empower consumers to make choices about their health insurance and to encourage competition among health plans. To accomplish these goals, the marketplaces make substantial changes to the way in which consumers shop for insurance. Traditionally, shopping for health insurance has involved selecting from a limited number of insurance plans available through an employer or on the individual market. Most people with employer coverage face extremely limited options; for example, 50 percent of workers at firms that offer health insurance have access to only one plan, and only 17 percent of covered workers have access to three or more plans (Claxton et al., 2014). Prior to enactment of the ACA, those seeking individual market coverage might have found more plans, but the ability to choose was limited by the underwriting process, which might have led to denials or unaffordable premiums for some shoppers. The ACA's rating and regulatory reforms in the individual market make the same plans available to all shoppers and provide substantial choice. For example, in 2014, the average consumer shopping in the marketplaces had more than 15 plan options from which to choose within the silver tier alone (Taylor et al., 2015). The ACA increases standardization of plans, introduces more choices, and restricts medical underwriting; together, these should make comparison-shopping easier for consumers.

However, the literature in behavioral economics, psychology, and decision sciences points to some important limitations in consumers' ability to engage in comparison-shopping. Behavioral economics departs from neoclassical economics by relaxing the assumption that people behave rationally. Behavioral economics brings together the findings of economics and psychology in hopes of better understanding the choices that people make. In particular, as Simon $(1955,1956)$ discussed, humans are limited in their ability to make fully rational choices, a limitation often referred to as bounded rationality. Similarly, many are limited by bounded willpower, a tendency to put undue weight on the present relative to the future. Although many behavioral biases have been discussed in the literature, the following are among the most important in the context of health insurance:

- the inability to process all information

- misperceptions of risk and optimism

- limited attention

- aversion to losses is stronger than attraction to gains (loss aversion)

- the tendency to remain in the current status (status quo bias)

- focus on the present as opposed to the future (present bias)

- framing effects (the idea that presenting choices in different ways can lead to different outcomes). 
These behavioral biases make consumers susceptible to nudges and make their choices highly contingent on the manner in which options are presented. In their seminal book Nudge, Thaler and Sunstein (2008) defined choice architecture as the context in which people make decisions and a nudge as

any aspect of the choice architecture that alters people's behavior in a predictable way without forbidding any options or significantly changing their economic incentives. To count as a mere nudge, the intervention must be easy and cheap to avoid. Nudges are not mandates. Putting fruit at eye level counts as a nudge. Banning junk food does not. (p. 6)

The precise design of a website is likely to influence consumer choice through the overall choice architecture, including both intended and unintended consequences. For example, the information displayed, the default sorting of options available, and the number of options will all influence the choices that consumers make. Careful choice architecture can be used to nudge people toward certain choices while still allowing consumers to make autonomous decisions. Thaler and Sunstein (2008) referred to this as libertarian paternalism, the idea that nudges are paternalistic because they are selected to push people toward the best option but libertarian because consumers still face the full set of options.

In the context of shopping for health insurance, the fact that many consumers have limited experience with the services that health insurance is intended to cover could exacerbate difficulties in making optimal choices. For example, most consumers do not make frequent visits to the hospital and therefore might have difficulties assessing the benefits that hospital coverage provides. Second, consumers often do not fully understand the terminology used to describe insurance policies and health care. If consumers do not know what a deductible is, the process of comparing insurance policies becomes more difficult, and they are unlikely to be able to make appropriate choices about health insurance. Furthermore, health insurance plans are expensive. For many, the costs might seem insurmountably high. Finally, low health literacy could limit individuals' understanding of the benefits provided. Because the marketplaces are geared toward previously uninsured households earning less than 400 percent of the federal poverty guidelines, the problems of low health literacy and limited knowledge of insurance are likely to be particularly severe.

A further complication for researchers studying health insurance choices is the difficulty in identifying the optimal choice: the one that maximizes the consumer's utility. This is because health insurance plans can vary the benefit structure on a wide variety of features, and consumers' preference might vary in an even wider variety of ways, including the plan features that matter to them, the relative importance consumers place on these features, and consumers' tolerance for risk. Researchers therefore often focus on dominant plans rather than optimal plans: If two plans are identical in all regards except for premiums and other forms of cost sharing, the one with the lowest out-of-pocket costs for all forms of cost sharing would be considered the dominant plan, while a plan with higher costs is referred to as dominated. For example, when 
comparing two plans from the same insurer covering the same network of providers, if one plan has a lower premium, deductible, copay, coinsurance, and maximum out-of-pocket costs, it would be considered dominant. Note that this requires that all other aspects of the plan, including the network of providers, are exactly the same. When dominant plans exist, they are plans that all consumers would prefer over the dominated plans, ex ante and ex post, regardless of their utility function. Much of the literature discussed here focuses on hypothetical choice experiments in which researchers can define hypothetical plans to be identical simply by stating, "assume that these plans are identical except for the following features." Table 1.1 provides a simple example of a dominant plan. If all other characteristics, such as benefit design and provider networks, are equivalent, consumers can choose the dominant plan based only on the characteristics shown. In this case, the last option would be dominant because all potential forms of out-of-pocket costs are less than or equal to those that other plans offer.

Table 1.1. Example of a Dominant Plan's Expenses, in Dollars

\begin{tabular}{lcccc}
\hline $\begin{array}{l}\text { Monthly } \\
\text { Premium }\end{array}$ & $\begin{array}{c}\text { Annual } \\
\text { Deductible }\end{array}$ & $\begin{array}{c}\text { Annual Out-of-Pocket } \\
\text { Maximum }\end{array}$ & $\begin{array}{c}\text { Doctor-Visit } \\
\text { Copay }\end{array}$ & $\begin{array}{c}\text { Generic-Medicine } \\
\text { Copay }\end{array}$ \\
\hline 290 & 2,000 & 3,000 & 25 & 20 \\
300 & 2,000 & 2,500 & 20 & 5 \\
310 & 1,200 & 3,000 & 25 & 20 \\
280 & 1,000 & 2,500 & 20 & 5 \\
\hline
\end{tabular}

In considering real plans, it might be hard to imagine that such dominant plans exist: Why would an insurer offer two plans if one strictly dominates another? However, as Bhargava, Loewenstein, and Sydnor (2015) discussed, this can happen. It is also important to point out that, when considering which options are optimal or dominant, plans are typically evaluated ex antethat is, at the time of purchase - to determine which plan is best.

Bounded willpower and present bias can also affect consumers' choices about health insurance. A large literature suggests that people focus on the present. This can lead people to overweight present gains or costs compared with those that occur in the future. This might manifest as procrastination, putting off costly effort, or disregarding future benefits entirely. This can have implications for health insurance, especially if present bias leads consumers to focus too much on premiums and not enough on other forms of out-of-pocket costs, such as deductibles and cost sharing, that are likely to occur in the future. However, the literature on health insurance choices has not addressed these issues.

In much of what follows, we focus on those consumers who were previously uninsured, but, even for those with a good understanding of insurance, calculating the total value of a given health insurance policy is difficult, requiring consideration of premiums, potential out-of-pocket spending, risk, potential eligibility for subsidies, and the value of any benefits that one might receive. In the short run, marketplaces will serve primarily poorer and subsidized consumers, so 
their experiences are particularly important. In the long run, the marketplaces could serve a broader population, especially as other marketplaces, including Small Business Health Options Program marketplaces, take off. Although the mix of consumers will change, it will continue to be important to keep in mind the needs of those with the lowest levels of numeracy and health literacy.

Designing choice architecture with these behavioral biases and consumer experiences in mind can help mitigate the potentially negative impact of these complex calculations. For example, providing consumers with the ability to sort and filter options to identify those plans that are most suited to their needs can help reduce the number of plans viewed and thus limit the amount of information consumers have to process. In addition, providing clear descriptions of key features of insurance, with examples, could help address limited knowledge of the jargon in the insurance industry. Some sites have provided total out-of-pocket costs under different scenarios so that consumers do not have to do complex calculations.

The report proceeds as follows: The next chapter describes and discusses the literature on consumer choice in health insurance. We then present the methods and results for the 20 websites we reviewed based on the review of the literature, and the final chapter offers conclusions. 


\section{Chapter Two. Literature Review}

\section{Background}

In this chapter, we review the literature on consumer choice in the context of health care, focusing on how people make decisions and the types of challenges involved. We highlight the existing literature on defaults, nudges, and choice architecture, as well as limitations on consumer knowledge and information. However, we do not limit our search to behavioral economics research; we also review papers that investigate consumer health insurance choices in general. To understand best practices and lessons learned, we also consider how websites and exchanges providing health insurance have been structured in other contexts. Finally, we discuss opportunities and challenges associated with improving online decisionmaking about health insurance plans going forward.

The research on consumer choice of health plans has used a variety of methodologies. Because the implementation of the ACA is still in its earliest stages, little research has been done to assess behavior in the new exchanges. As such, many of the papers discussed here are based on simple laboratory experiments; surveys (sometimes with convenience samples or very small samples); focus groups; qualitative interviews; or choices made in other contexts, such as employer-sponsored insurance, Medicare Advantage, or Medicare Part D. Although these settings are likely to differ from the marketplaces, many of the lessons are generalizable.

In this chapter, we first discuss the methods used for our literature review. Second, we discuss literature on consumer choices. Third, we discuss literature on website design. Finally, we present recommendations from other authors about how to best design choice architecture for health insurance websites.

\section{Methods}

We identified literature for this review through three main channels. First, we did a search of online databases, including gray literature. Second, we searched the references of these articles for additional relevant literature. Third, we drew on our own knowledge of the literature.

To obtain peer-reviewed literature, we searched four online databases: PubMed, EconLit, IDEAS, and PsycINFO. Our search covered the time period between January 1, 2005, and February 10, 2015. Search terms included decision tree, decision support, decision making, choice behavior, choice architecture, dominated option, default option, default choice, chooser tool, consumer tool, website, nudge, menus, health insurance, Medicare, Medigap, health plan, health insurance exchange, and Affordable Care Act. We also used the bibliographies in these articles to identify additional and relevant literature. 
Prominent topics in the literature include analyses of the number of choices affecting consumer behavior, consumers' ability to select the appropriate health insurance plan, and Medicare selection among the elderly.

We searched the gray literature using Google and the Grey Literature Report. We searched the Grey Literature Report using the terms choice behavior, choice architecture, menus, default choices, decision making, insurance, and health plans. We ran Google searches using the terms choice architecture, default choice, website, health insurance, and health insurance exchange.

We also used a snowball methodology, adding to our database relevant papers cited by those found through the above means. We identified relevant articles through the titles listed in the references and through our reading of the first group of articles.

Finally, some of the literature included in our review was based on our own knowledge of the literature on health insurance choice. We have also included some canonical papers in behavioral economics from other settings.

In this review, we have included the most-relevant articles. We excluded articles that did not explicitly address consumers' selection of plans or emphasize behavioral research. However, because this is nascent literature, much of the research is exploratory in nature. We have not limited our review to only those studies that used careful scientific design.

\section{Consumer Choice in the Context of Health Care}

Our review of the literature has pointed to some key factors that influence consumers' choices about health care. In what follows, we first discuss how consumers make decisions, focusing on the role of prices and product attributes, the number of choices, and the roles of the status quo and defaults. Next, we discuss challenges to effective decisionmaking in this domain, including the role of choice architecture and the presentation of information, consumer knowledge and awareness, and the complexity of the decision. Finally, we discuss recommendations from the literature on ways to address these challenges.

The literature discussed here has used a variety of different methodologies. First, some have focused on surveys measuring stated preferences, hypothetical choices, or comprehension and knowledge of insurance products to understand what contributes to consumer choice. Stated preference studies provide an opportunity to ask consumers to make choices in a controlled environment, allowing for careful testing of different alternatives. A stated preference survey allows for the opportunity to investigate what matters to consumers. However, these choices are rarely incentivized, so the results might not be generalizable to actual choices. Second, some papers have used incentivized laboratory experiments. Incentivized lab experiments have many of the benefits of hypothetical choice and stated preference surveys, but the results might be more generalizable because consumers are compensated based on the choices that they make. These incentives help to address the external validity of the results; however, if the stakes are very low, the results might not be generalizable. Finally, some papers study actual health 
insurance decisions as reported through surveys or administrative data. These papers have the distinct advantage of being based on actual choices; however, in the literature discussed here, few are true field experiments or even natural experiments, so results might represent correlation rather than causation. Furthermore, many take place in very specific settings, such as one employer. Therefore, the results from many of these papers might not be generalizable, which is an important limitation of the literature.

\section{How Do Consumers Make Decisions?}

Consumers' choices are, at the most basic level, a function of their preferences, the prices of goods, and those goods' attributes. However, when facing many options, consumers can struggle to make good choices or any choice at all and might be less satisfied with their choices than if they had fewer options. Furthermore, when given the opportunity to not make a choice, consumers have a tendency to stick with the status quo or the default. In this section, we discuss the literature on how consumers make choices in the context of health insurance.

\section{The Role of Prices and Product Attributes}

The literature on consumer choice begins in neoclassical economics. Out-of-pocket costs and product attributes influence rational consumers. Cutler and Zeckhauser (2000) provided an overview of the economics literature on health insurance that is still valid today. Although this is a broad literature and beyond the scope of this review, consumers are sensitive to out-of-pocket costs, especially premiums (Feldman et al., 1989; Cutler and Reber, 1998; Royalty and Solomon, 1999; Strombom, Buchmueller, and Feldstein, 2002; Nichols et al., 2004; Marquis, Buntin, Escarce, Kapur, et al., 2006; Marquis, Buntin, Escarce, and Kapur, 2007; Abraham et al., 2006; Buchmueller, 2006; J. Schwartz et al., 2013; Politi et al., 2014). Einav et al. (2013) found that consumers might even select into plans based on the potential sensitivity to cost sharing, to which the authors refer as selection on moral hazard. However, price is certainly not the only factor that influences choices. Consumers are also sensitive to providers included in the network (Shepard, 2015; Tumlinson et al., 1997; Nichols et al., 2004; Ericson and Starc, 2014), benefits (Tumlinson et al., 1997; Romley et al., 2012; Politi et al., 2014), benefit design (Polsky et al., 2005), and perceived quality (Rice et al., 2014; van den Berg et al., 2008).

Furthermore, consumer characteristics influence preferences. Naessens et al. (2008) found that consumers with worse health status are likely to choose costlier plans than those with better health status choose. In a series of focus groups with plan enrollees, Gibbs, Sangl, and Burrus (1996) found that Medicare, Medicaid, and commercially insured populations prioritized different plan characteristics. For example, Medicaid populations mentioned convenience of location as one of their primary considerations in choosing health plans. Medicare enrollees, in contrast, placed a relatively high value on provider choice. The privately insured population placed a higher priority on price than Medicare enrollees did, and they endorsed waiting times and customer service as important considerations in choosing health plans. 


\section{Too Much Choice Can Be Difficult to Navigate}

Although economic models typically assume that expanding the choice set can only improve welfare, many papers have found the opposite. Supporting the idea that having more options is better, Dafny, Ho, and Varela (2013), for example, showed that, when employees have more health insurance choices, they are more likely to face lower total costs than those with fewer choices do. Similarly, Dafny, Gruber, and Ody (2015) found that, in the first year of the federally facilitated marketplaces, prices were higher in areas with less competition. In contrast, the behavioral literature has focused on the problem of choice overload. The Paradox of Choice (B. Schwartz, 2004) discusses this literature, highlighting studies that have found that too much choice can lead to suboptimal decisionmaking and can even reduce consumers' satisfaction with the choices they make. One of the most-cited examples is by Iyengar and Lepper (2000). Consumers in an actual grocery store were given the opportunity to taste one of 24 different types of jam. On another day, they were given the opportunity to taste one of six types of jam. When facing more options, consumers were less likely to make any purchase at all. Choice overload, as it is often referred to, has now been documented in a variety of settings. Nearly all of the literature discussed here supports the results from other domains that choice overload reduces the quality of consumers' choices. Choice overload derives not only from the increasing cost of search as the number of options increases but also from the fear of making an incorrect choice. Many consumers exhibit loss aversion: They weight the costs of loss more than the benefits of gain. For example, they feel that it hurts more to lose $\$ 10$ than to gain a similar amount, which leads them to work harder to avoid losses than they would to achieve similar gains. Because of this, they might be paralyzed by the possibility of making the wrong choice, and this paralysis worsens as the number of available choices grows. In a less extreme form, consumers might procrastinate, putting off making a choice, because of the complexity of the choice. If consumers procrastinate too long, they might miss the opportunity to make a choice.

Choice overload can lead people to choose suboptimally or avoid making a choice altogether and can lead some consumers to regret their choices.

\section{Stated Preferences and Comprehension}

Several papers have used data from surveys asking consumers to evaluate different insurance plans, either to choose the best plan or to report which plans meet certain criteria.

Hanoch and coauthors conducted several related studies using examples based on Medicare Part D. Hanoch, Rice, Cummings, et al. (2009) surveyed 192 people of all ages and asked respondents to review three, ten, or 20 plans and then select the one that met specific criteria, such as lowest cost, and answer other factual questions about the plans. Increasing the number of plans significantly reduced the number of correct answers. Hanoch, Wood, et al. (2011) used a computer-based program to assess how people compare information and plans. The survey asked 150 respondents of all ages to assess either three or nine plans for a hypothetical friend.

Respondents had to click on different boxes to reveal each attribute of each plan. Increasing the 
number of choices decreased the likelihood that consumers selected the lowest-cost plan, for an average loss of nearly $\$ 50$ per month. Furthermore, consumers investigated a smaller share of the available information as the number of plans increased. Hanoch, Rice, Cummings, et al. (2009) and Hanoch, Wood, et al. (2011) found that the quality of answers declined with age. Wood et al. (2011) conducted a similar experiment to the two above, with 121 adults of all ages, adding a detailed cognitive battery. The survey asked each participant to choose a plan that was either the lowest-cost plan or lowest-cost plan that included a mail-order option for prescriptions. The authors found that the number of participants who found the correct option decreased as the number of choices increased and that, like in the other studies, the quality of the answers declined with age. After controlling for cognitive function, they found that age no longer influenced the quality of choice but that numeracy continued to affect choices.

Bundorf and Szrek (2010) conducted a hypothetical choice experiment with 295 members on an online Internet panel. The survey asked respondents to select Medicare Part D plans and answer key questions about these plans in settings with two, five, ten, or 16 plans. Although the authors did not find evidence that the number of choices led to paralysis (choosing not to choose, like in Iyengar and Lepper, 2000), they did find that the number of options reduced the quality of choice. In a similar study, Szrek and Bundorf (2014) investigated the role of numeracy and choice-set size. The authors found that more-numerate adults make better choices when faced with smaller choice sets than less numerate adults do but that these differences disappear when the size of the choice set increases.

Barnes, Hanoch, and Rice (2015) conducted a hypothetical choice experiment with 276 techsavvy uninsured people who use Amazon's Mechanical Turk ${ }^{1}$ and 161 uninsured rural Virginians. The survey included information about health status, health care utilization, numeracy, risk and time preferences, and a hypothetical choice task. The authors found that a larger choice set increases the likelihood of choosing a plan that costs $\$ 500$ or more than the lowest-cost plan and that comprehension of insurance mediates these effects.

Johnson, Hassin, et al. (2013) conducted six experiments to assess consumers' ability to make health insurance choices. In each experiment, the authors compared the quality of decisions when given four or eight options and found that decision quality improves when the number of options is limited to four.

Mikels, Reed, and Simon (2009) surveyed 53 college students and 53 older adults recruited at senior centers to measure their willingness to pay for access to five, ten, 25, or 55 Medicare Part D plans. The authors found that older adults place a lower value on having more options

\footnotetext{
1 Amazon's Mechanical Turk is an online marketplace in which requesters can hire workers to complete small tasks. Although most of the tasks are actual tasks, such as coding or sorting files, researchers are increasingly using the setting to field surveys and conduct experiments. The advantages of using Mechanical Turk include the ability to quickly recruit subjects and very low costs. Barnes, Hanoch, and Rice paid respondents a total of \$1.25. One concern is that Mechanical Turk workers are unlikely to be similar to a general population.
} 
than younger adults do. However, these results could be related to familiarity with the product; few college students are likely to be well informed about Medicare Part D and therefore might not appreciate the complexity of the choice.

Tanius et al. (2009) randomized a group of 192 adults to one of two Medicare Part D plan choice conditions: The first group received six plan choices, including one strictly dominant and one strictly dominated plan, and the second group received 24 plan choices, including one strictly dominant and one strictly dominated plan. People randomized to the first group were more likely to select the strictly dominant plan than people in the second group.

An important weakness of each of these studies is that they based their results on unincentivized choices. Furthermore, in the exchanges, the average consumer faces 15 plans in the silver tier alone. Thus, the choices that participants had in these experiments involved far fewer options than consumers have in the ACA exchanges.

\section{Incentivized Experiments}

Improving on these methods, several studies have used incentivized experiments to assess choice overload. Johnson, Hassin, et al. (2013) added incentives to one of the experiments to assess whether compensating people for making better choices improves their decisionmaking in a setting that mimics health insurance choices, but the authors found that incentives did not improve outcomes. This could be due to the size of the incentives; those choosing the most costeffective plan earned an additional dollar and a chance at $\$ 200$. Although small incentives can improve decisions in experiments, these incentives are significantly smaller than the potential cost savings associated with choosing a better option in the health insurance exchanges.

Schram and Sonnemans (2008) studied the effect of increasing the number of choices among Dutch consumers. The researchers asked 148 respondents to review four or ten policies. Like Hanoch, Wood, et al. (2011), Schram and Sonnemans allowed participants to reveal information about each policy by clicking on a separate box for each attribute, allowing the researchers to observe precisely how much information they used. A unique feature of this study is that the plan attributes were based on the costs associated with five different potential health outcomes of varying degrees of risk and cost. The survey asked respondents to select insurance over the course of 35 periods, with the probability of the different health outcomes varying over time. In each period, a health outcome was selected randomly. The authors found that increasing the number of options reduces the fraction of information boxes that participants clicked and decreases the quality of their decisions. They also found that consumers are less likely to switch plans, exhibiting status quo bias that we discuss in more detail below.

A limitation of many of the experimental studies (both with incentivized and hypothetical choice designs) is that, when comparing consumer choice with a small or large number of options, an implicit assumption of the research is that both the large and small choice sets will contain the so-called best plan. In reality, a larger choice set might be more likely to contain the 
optimal plan for a given individual because larger choice sets can include a wider variety of options.

\section{Real-World Settings}

Confusion over too much choice has been found in real-world settings, as well as the survey and experimental settings above. Informed by on interviews with 33 young adults who were navigating the HealthCare.gov website in real time, Wong et al. (2014) found that respondents were overwhelmed by the amount of information provided. The Massachusetts health reform experience also revealed that consumers might prefer fewer choices and standardization of plan benefits. Accordingly, regulators in the state reduced the number of plans offered on the Massachusetts Health Connector over time; simultaneously, plan benefit designs were increasingly standardized (Day and Nadash, 2012).

McWilliams et al. (2011) examined the effect that the increase in the number of plan options and plan generosity has on the likelihood of Medicare beneficiaries to enroll in a Medicare Advantage plan, using real-world data on enrollment and plan numbers for U.S. counties. An increase of fewer than 15 plans in a county significantly increased enrollment in Medicare Advantage, while an increase of more than 15 plans was associated with no significant (16 to 30 plans) or negative (more than 30 plans) enrollment effects. Plan generosity did significantly increase enrollment for beneficiaries with high cognitive function but had no effect for those with low cognitive function.

For a new paper, Bhargava, Loewenstein, and Sydnor (2015) assessed the quality of health insurance decisions made by more than 50,000 employees of a single firm who were permitted to build their own health plans based on a standardized menu that included a significant share of financially dominated options. Employees were given the opportunity to select options along four cost-sharing dimensions (deductible, out-of-pocket maximum, copay, and insurance), such that the 48 options presented to them differed in terms of cost sharing and premiums but were otherwise equivalent across all remaining dimensions, including the network and services covered, and, in that sense, constituted a comparatively simple choice set. The choice architecture that all employees saw included the use of visual nudges, real-time learning tools, and deliberate design decisions to increase the ease of comparing plans. The authors found that the majority of employees chose dominated options. By choosing a dominated plan, these employees spent an extra $\$ 373$ per year on average. Using several hypothetical choice experiments, the authors also found that the structure, size, and complexity of a choice set significantly affect the quality of health insurance decisions but that health literacy and numeracy are arguably more important indicators of individual decisions.

The results presented in this section suggest that consumers struggle when faced with too many choices. Many of the papers report that consumers are more likely to make suboptimal decisions as the number of choices goes up. This is in contrast to the standard economic models that predict that more options should improve welfare because more people will be able to find a 
product that suits their preferences. Taken together, these results suggest the need for careful choice architecture that helps consumers sort and filter to reduce the number of options that they must consider.

\section{Status Quo Bias and Default Bias}

When facing a complex choice, many seek to minimize their effort. One way to do that is to make no choice at all. This behavior can result from one of two closely related biases documented in the behavioral economics literature. The first is status quo bias, the idea that, rather than making a new choice, one sticks with the current status. Samuelson and Zeckhauser (1988) first defined this phenomenon. One of the authors' main examples was in the context of the health insurance choices that Harvard University employees made. The authors noted that, when new health insurance plans were offered and other plans were retained, the choices that new employees made differed from the choices made by incumbent employees, who had first enrolled in insurance several years prior. Some refer to status quo bias as inertia. Status quo bias can result from loss aversion: People perceive that the losses associated with a change would have a greater impact on them than the gains would. Status quo bias might also be the result of procrastination: People might intend to make a change but never get around to implementing it. In practice, it is difficult to disentangle different explanations for the tendency to prefer the status quo; in particular, consumers might face switching costs that limit their willingness to change insurers. Researchers might perceive that consumers are unwilling to switch to a dominant plan, when, in fact, the reason for not favoring the dominant plan is that the switching costs are too high. These switching costs can result from access to specific providers.

The second related bias is the default bias. Default bias also arises from making no choice but does not rely on the previous status. The most-famous examples of default bias are in the contexts of organ donation and 401(k) saving plans. Johnson and Goldstein (2003) showed that, in countries where people have to opt in to organ-donation programs, organ-donor rates are significantly lower than in countries where people have to opt out. Similarly, Madrian and Shea (2001) described an employer that changed the default for 401(k) enrollment. Rather than actively choosing to join the $401(\mathrm{k})$, employees had to actively choose to not join. This raised participation rates dramatically and was found to be so powerful that many companies now automatically enroll employees in 401(k) saving plans. Default bias might be particularly common in situations in which consumers experience choice overload. Default bias can also be a consequence of fear of regret: People are so concerned that they will make a bad choice and regret it that they prefer to make no choice at all.

Status quo bias and default bias are not always distinguished in the literature; this is in part because, in many cases, the default is to stay in the status quo. However, there is no requirement that the status quo and the default be the same. Consumers who are defaulted away from the status quo might still prefer to stick with the status quo. Furthermore, defaults can exist even when there is no status quo. 
Each of these two biases can influence health insurance choices. Many already enrolled in insurance plans might stay enrolled in dominated plans as new plans become available. This could be due to status quo bias or default bias. In many settings, the default is that, if no active choice is made, one remains enrolled in the same insurance plan. There might be status quo bias even when active choice is required; many will stick with the same plan or insurer. For those not currently enrolled, the default is to remain unenrolled.

Most of the work in this area relies on real-world data; however, we found one incentivized laboratory experiment that investigates status quo bias in health insurance choice (Krieger and Felder, 2013). In one arm of the experiment, participants were defaulted into their insurance choice from the previous round; in the other arm of the experiment, they had to make a new choice each round. The authors did find evidence of a status quo bias, but this bias diminished over time. However, these results might differ from those in the real world because participants in an experiment learn much faster, making four choices in 90 minutes, rather than one choice per year. Additionally, after repeating the same game, they might seek novelty and switch plans just for the sake of switching.

Strombom, Buchmueller, and Feldstein (2002) studied insurance choices made by employees of the University of California system. The authors found that new and incumbent employees make substantially different health insurance choices. However, they found that new and incumbent employees are similarly price sensitive, suggesting that "many individuals pay closer attention to enrollment materials when they first sign up for coverage" (p. 114). We interpret this to suggest a default bias: Employees are less likely to make choices when they are defaulted into their existing plans.

Frank and Lamiraud (2009) studied the effect that the number of choices available has on insurance-plan switching in Switzerland. In Switzerland, consumers are required to purchase health insurance on the private market. Insurance policies are standardized in many ways, which should allow for frequent switching between plans based on cost. Over the period of the study, the average number of options for health insurance grew from 39 per canton to 52 . This could potentially increase choice overload. The authors identified very low switching rates, typically less than 5 percent. They considered several possible explanations for consumers switching or not switching policies. First, consumers might seek to maximize expected utility taking into account the costs of search and thus switch when the benefits of lower-cost insurance outweigh the costs of search. Second, choice overload, either due to the costs of choosing or the fear of choosing the wrong option, could lead consumers to stick with the default option. Finally, status quo bias might limit switching. The authors found that switching is more common in areas with fewer health insurance options, suggesting that status quo bias and choice overload might interact. They also found that consumers new to a particular market make very different decisions from those who have lived in the area for a while.

Sinaiko and Hirth (2011) studied health insurance choices at the University of Michigan following the introduction of a new plan that strictly dominates an existing plan. Like Samuelson 
and Zeckhauser (1988), the authors found that new employees make very different choices from those of incumbent employees, with incumbent employees much more likely to stick with the status quo and new employees more likely to choose the dominating options.

Handel (2013) built on the papers above; the author looked at a company where employees are observed in periods in which they can default into the status quo and periods in which they must make an active choice. As in the other papers, he observed that, when incumbent employees can stick with the status quo, they make very different choices from those of the new employees. Using a structural model, he estimated that people forgo, on average, more than $\$ 2,000$ per year because of inertia.

Ericson (2014) looked at Medicare Part D choices in which the author found that many consumers stick with the initial defaults for long periods of time. The inertia makes consumers susceptible to paying higher premiums over time because insurers might raise the price of their products, possibly in response to consumers' inertia.

All of these papers find very low switching rates between insurance plans. Status quo bias, as well as switching costs and choice overload, is likely to keep switching rates low over time. Although consumers might be better off switching plans, this behavior is rare.

\section{What Is the Appropriate Choice Architecture? Challenges to Effective Decisionmaking}

A central premise of Nudge (Thaler and Sunstein, 2008) is that choice architecture, or how options are presented, matters. In designing health insurance marketplace websites, one must be aware of how consumers respond to different information. Although no one paper has carefully studied all of the choices that go into designing the choice architecture for health insurance marketplaces, there are some important areas to keep in mind. The presentation of risk, quality information, and cost structure can all influence choices, as can the total amount of information being conveyed.

Appelt et al. (2014) found that consumers choose health insurance plans that meet more of their stated preferences when presented with plan options in a manner that simplifies the options available than when choices are presented without a specific choice architecture. However, the authors also found that consumers prefer the choice architecture that presents more information, in direct contradiction to the fact that they chose the better option in the simplified environment.

Uhrig et al. (2006) conducted a hypothetical choice experiment that attempts to address many of the issues of choice architecture surrounding health insurance. The experiment compared three information settings that differ in terms of color and the use of pictures, quotes, stars, or graphs to convey information about health plan costs and quality. Although the authors found that one of their settings helps people to make better choices, their experiment is difficult to interpret. There are so many differences between their three treatments that it is difficult to know what to recommend. This paper speaks to the difficulty of designing an appropriate choice architecture for such a complex product. So many factors can be varied, and the factors can interact with each other. Careful experimentation is necessary to draw meaningful conclusions. 


\section{Framing and Labeling Affect Consumer Choices}

The way in which information is presented can influence consumers' choices. Presenting numbers rather than symbols, the choice of words to describe product, and even the time frame for calculating premiums can all influence choices.

In a recent paper, Ubel, Comerford, and Johnson (2015) pointed to the importance of labels and the way in which price information is reported. In their first experiment, the authors asked consumers to make an unincentivized hypothetical choice between gold, silver, and bronze plans; however, for half the consumers, the authors switched the labels on the gold and bronze plans, so that gold plans were less expensive and provided lower actuarial value. They found that respondents with low numeracy are more likely to choose gold plans regardless of the actuarial value. Second, they investigated whether displaying premiums at a monthly or weekly level affects price sensitivity, again in an unincentivized hypothetical choice experiment. They found that respondents were more sensitive to equivalent price differences when prices were presented at a weekly level.

Barnes, Hanoch, Wood, and Rice (2012) conducted a hypothetical choice experiment using a sample of 126 adults of all ages that investigated the effects that price framing, brand names, and choice-set size have on the selection of Medicare Part D plans. When prices were represented by symbols ( $\$$ to $\$ \$ \$$, with $\$$ indicating a low-cost plan and $\$ \$ \$$ indicating a high-cost plan), the authors found that more people selected the lowest-cost plan than when the dollar amount of the price was presented.

\section{Order Matters}

The default sort on a marketplace website is likely to influence consumers' choices. Citing Brockington (2003) and Lynch and Ariely (2000), Ubel, Comerford, and Johnson (2015) noted that the ordering of information on a page significantly affects choice. Brockington (2003) looked at the effect that ordering has on political ballots; the author found that those at the top of the ballot are more likely to win. Lynch and Ariely (2000) looked at on the ordering of wine on a wine list; the authors found that people are more likely to select the first wine.

In the context of health care, Ericson and Starc (2012) found that, in Massachusetts, many select the first plan. The authors point out that plans are sorted by premium. However, we note that it is not possible to tell whether people are selecting the cheapest option or the first on the list. Furthermore, sorting on premium might suggest to some consumers that premium is the most relevant factor to consider in choosing a health insurance plan, minimizing the role of outof-pocket expenditures and other factors.

\section{Information on Plan Quality Is Difficult to Convey to Consumers}

Effectively providing information on quality can prove to be very difficult. In the case of health insurance and health care, quality can be measured on many attributes. Quality of both insurers and providers can influence consumers' choices, but that information must be displayed 
in a way that is easy to understand. Providing too many quality measures can increase choice overload. Using symbols can help consumers better comprehend quality information, as discussed above in the context of Barnes, Hanoch, Wood, and Rice (2012) and below in Peters, Dieckmann, et al. (2007).

Kolstad and Chernew (2009) reviewed the literature on quality and consumer choices of health insurance and health care. Although the authors' reading of the literature suggests that conveying quality information can help consumers to make better choices, they point out that these effects are concentrated among a subset of the population. They point to two papers, by Jin and Sorensen (2006) and Dafny and Dranove (2008), that suggest that consumers seem to make choices on the basis of quality information that is not explicitly provided, perhaps because they are seeking quality information on their own or because the formal measures of quality are correlated with consumers' perceptions of quality.

However, other studies have found that people have difficulty understanding and effectively using information on quality, even when it is directly presented to them. For example, Gibbs, Sangl, and Burrus (1996) found that focus-group respondents had concerns that information conveyed could be biased, especially if the health plans had provided the information. Consumers also noted challenges with ratings that are too closely grouped-e.g., if every plan gets four or five stars, the information is not particularly valuable. Finally, in some cases, consumers interpreted information differently from how it was intended. For example, Medicare beneficiaries raised a concern that plans with low rates of hospitalization for pneumonia were failing to admit patients in need of care. Consumers perceived other indicators, such as childhood immunization rates, as being primarily determined by the patient rather than the plan or provider and therefore not informative.

Using data from the United Kingdom, Hanoch and Rice (2011) reported that few patients use hospital quality information to make decisions. Possible reasons include difficulty in understanding the information, lack of standardized measures, and poor communication of information. Harris-Kotejin et al. (2007) described a similar issue in the United States, noting that Medicare beneficiaries have traditionally shown limited interest in using comparative quality information when selecting health plans.

Several papers on quality of health care, rather than health insurance, point to the importance of how quality information is presented in a related context. Peters, Dieckmann, et al. (2007) described several experiments that change how quality information is presented. The authors' overall conclusion is that less is more: Limiting quality information to the most-relevant measures and using clear symbols to make information easier to interpret can help people to better comprehend quality information. In one experiment, they used simple symbols to rate hospitals based on the number of registered nurses per 100 patients. Without a reference point, it was difficult for consumers to decide whether 21 nurses per patient was excellent, adequate, or subpar. Because a symbolic rating was included, consumers could easily interpret this information. 
Also in the context of quality of health care, Hibbard, Greene, et al. (2012) pointed out that many consumers interpret cost as a signal of quality. Extrapolating from this, we would not be surprised if consumers interpreted low costs for insurance as a signal of low-quality insurance as well. If consumers evaluating particularly low-cost health insurance plans assume that the low cost is obtained by contracting with low-cost providers, they might be less likely to select these plans.

Spranca et al. (2007) presented a cautionary tale about providing too much information. The authors conducted a hypothetical choice experiment in which they investigated the effects of providing detailed quality information from Healthcare Effectiveness Data and Information Set and Consumer Assessment of Healthcare Providers and Systems, as well as information about the number of plan participants who disenroll. They found that providing information on disenrollment can cause consumers to underweight important quality measures from the Consumer Assessment of Healthcare Providers and Systems and the Healthcare Effectiveness Data and Information Set. Quality measures are particularly susceptible to overprovision because there are many possible measures of quality, each of which might be valuable to different consumer types. Therefore, it is crucial to balance providing helpful information with the possibility of providing too much information.

\section{Consumers Lack Awareness and Understanding of Health Insurance Concepts}

Choosing a health insurance plan requires consumers to compare plans based on such characteristics as deductibles and copays. To compare plans this way, consumers must understand these concepts. However, research suggests that they do not.

Using survey data from the RAND American Life Panel, Barcellos et al. (2014) found that 42 percent of Americans ages 18 to 64 could not correctly describe a deductible, and 62 percent did not understand key differences between health maintenance organizations (HMOs) and preferred provider organizations (PPOs). Health insurance knowledge was lower among lowincome people than among other populations.

Loewenstein et al. (2013) found similar results in a survey of insured adults; in particular, many do not understand coinsurance. The authors found greater levels of knowledge than Barcellos et al. (2014) did, likely because Loewenstein et al. surveyed only those with insurance, while Barcellos et al. surveyed a representative sample. Using these results, Loewenstein et al. designed a simplified health plan that involved only copays, eliminating coinsurance and deductibles, and used a stated preference survey to estimate potential demand for such a product. Their results suggest that consumers would better understand these simplified plans but that there might be limited demand for them. We suspect that this limited demand might be the result of the simplified plan's unfamiliarity to respondents and because even the simplified plan was complex, with different prices for different types of services.

Consumers Union conducted a series of focus groups and in-depth interviews about consumer knowledge (Quincy, 2012a). It similarly found that many consumers do not understand 
the jargon used to describe health insurance plans or how to combine the information available to make a good choice.

Politi et al. (2014) reported, following a small survey of uninsured, predominantly lowincome people in St. Louis, significant confusion about such terms as coinsurance, deductible, out-of-pocket maximum, prior authorization, and formulary. Lack of knowledge was particularly pronounced among people who had never had insurance. Barnes, Hanoch, and Rice (2015) reported that those with greater health insurance comprehension are likely to choose lower-cost plans.

Older surveys of the Medicare-eligible population have found similar challenges related to health insurance literacy. For example, among a sample of Medicare beneficiaries living independently, Hibbard, Jewett, et al. (1998) found, 30 percent had no understanding of the difference between Medicare HMOs and traditional Medicare. Even among respondents who understood this basic difference, only 16 percent had adequate knowledge to effectively choose between an HMO and traditional Medicare.

Given this broad evidence on the difficulties many have understanding health insurance, it is important that consumers be provided with easy-to-understand explanations. Although many can identify the correct definition of deductible, for example, explaining terms clearly and keeping in mind low levels of literacy among some subsets of the population is crucial. Furthermore, these problems must be kept in mind when designing choice architecture; providing information might not be sufficient.

\section{Consumers Need to Understand Probability and Risk}

Understanding health insurance options might also require people to make numerical calculations and to understand and assess the value of avoiding risk. Yet many Americans lack the basic math skills needed to make these comparisons. In a summary paper commissioned by the Institute of Medicine, Peters, Meilleur, and Tompkins (undated), reported major deficiencies in numeracy in general and health numeracy in particular. For example, the majority of Americans cannot translate a 1-in-1,000 chance into a percentage (Galesic and Garcia-Retamero, 2010). Numeracy rates are lower among those who are uninsured, with only 8.6 percent estimated to be proficient in basic math (Peters, Meilleur, and Tompkins, undated; Apter et al., 2008). Bundorf, Mata, et al. (2013) conducted a hypothetical choice experiment in which researchers asked a representative panel of respondents to choose between two Medicare Part D plans for a hypothetical friend. The task was repeated two times. The experiment had a $2 \times 2$ design: Some saw a graphical representation of risk, while others received text-based information, and some received an abstract description of the friend's health, while others received a specific diagnosis. In each task, respondents could choose between plans that offered more or less protection from risk. They then measured whether choices were consistent across the two tasks. Although most people were consistent, more were consistent with the graphical 
version of the task than with the textual one. When communicating complex risk, a graphical depiction might help some consumers.

\section{The Decision Is Complex}

If consumers understand the jargon used to describe insurance, then, to fully determine which is the best option in terms of cost, consumers might want to know how much the plan would cost under different scenarios. Although comparing premiums is relatively simple, to calculate total expected out-of-pocket costs, one must combine estimates of the probability of illness and the potential costs of treatment. Furthermore, to fully compare plans, consumers must decide how to weight provider networks and quality ratings, which can be difficult for many people. More broadly, health insurance plans differ on many characteristics, further complicating the comparisons consumers must make and adding to the difficulty in weighting the various dimensions of coverage.

Greene et al. (2008) conducted a hypothetical choice experiment to test different ways of presenting information to consumers about high-deductible health plans and PPOs. Some saw a side-by-side comparison, while other saw a table that explained how the plans were similar and how they were different. Some participants were provided a framework to help them understand the advantages and disadvantages of the high-deductible plan. The survey asked participants six knowledge-based questions about the plans, which plan they would be more likely to choose, and how easy it was to understand the information about the plans. The authors also measured participants' numeracy and literacy. The side-by-side comparison led both the highly numerate and less numerate people to get more answers correct on the knowledge question than the table explaining similarities and differences. However, the more numerate reported greater subjective understanding of the material with tables. The framework provided information on a limited number of attributes of plans. Providing the framework improved comprehension of those attributes covered but reduced comprehension of those attributes not covered, suggesting that it led people to focus on the attributes covered in the framework. The authors concluded that the study highlighted "the difficulty many consumers have in understanding comparative plan information and making informed health care choices" (Greene et al., 2008, p. 369).

Johnson, Hassin, et al. (2013) added a cost calculator in two of their experiments and found that this improved choices. In another experiment reported in the same article, the authors provided just-in-time education on health insurance choices in conjunction with calculators. Justin-time education is targeted to consumers when they most need it rather than providing education with the expectation that it will prove valuable at some point in the future. The authors found that just-in-time education did not improve choices but that cost calculators did.

Handel and Kolstad (2015) used detailed administrative data on health insurance choices and claims with survey data to estimate a structural model of how consumers make choices. The data came from a large employer. This allowed the authors to separate risk attitudes, information, and perceived hassles associated with different plans. Previous research suggests that consumers are 
very risk averse; however, by building a model with all of these features, the authors found that risk aversion is capturing consumers' limited information. So many factors enter into consumers' choices that it is difficult not only for consumers to make choices but also for modelers to accurately model the decision process. In particular, the authors found that, in this setting, consumers' limited information about high-deductible health plans causes them to underutilize these plans.

Ericson and Starc (2013) took advantage of a policy change in the Massachusetts Health Connector that required insurers to standardize the characteristics of the plans they offered and limit the plans to seven defined options based on such characteristics as copays and deductibles. After the reform, plans were still free to set their own premiums and define the network of providers covered. This reform not only altered the plans offered but also changed how plans were sorted; prior to the reform, all plans were sorted by premium, and, since the reform, the consumer picks a tier of insurance and then sees plans. Following this reform, consumers selected more-generous health insurance plans. These results suggest that simplifying the choice set changed the way in which consumers compared plans. With plan standardization, consumers were better able to compare plans, and the types of plans they selected changed. The authors point out, "standardization may alter decision utility because it shifts consumers attention (DellaVigna, 2009) or changes the salience of product characteristics (e.g., as in Bordalo, Gennaioli and Shleifer, 2012)" (Ericson and Starc, 2013, p. 3).

Some papers have examined the choices Medicare beneficiaries make in the context of either the Medicare prescription drug benefit (Part D) or Medicare Advantage programs. These programs offer Medicare beneficiaries a variety of options for their medical and prescription drug coverage, run by private insurers. The benefit design and variations across plans in both Medicare Advantage and Part D create a complex choice for Medicare beneficiaries deciding on a plan.

Economists focus on minimization of out-of-pocket costs as the determinant of whether a consumer selects the best plan. Abaluck and Gruber (2011) used prescription drug claims data matched to Part $\mathrm{D}$ plan benefit design information to examine whether beneficiaries chose the Part D plan with the lowest out-of-pocket costs. Results indicated that only a small proportion of beneficiaries ended up choosing the lowest-cost plan in their areas. Further, the authors ran a multinomial choice model to estimate the effect that individual and plan characteristics have on Part D plan choices. The authors found that Medicare beneficiaries placed more weight on premium than they did on the expected out-of-pocket costs associated with the plan and that they placed too much emphasis on plan characteristics (e.g., deductible and plan quality) as opposed to considering their individual cases and requirements for coverage. This suggests that Medicare beneficiaries are making their Part D plan enrollment decisions based on incomplete information, a situation the authors suggest could be remedied by providing additional information about expected plan costs. 
Heiss et al. (2013) used Medicare claims data to estimate beneficiaries' total out-of-pocket costs (premium plus cost sharing) for both the plan in which they are enrolled and alternative plan options. The authors found that beneficiaries usually did not choose the lowest-cost plan and, as a result, spent an average of $\$ 300$ more per year than they would have had they chosen the lowest-cost plan. The lowest-cost plan in this case was the option that would have been presented on the Medicare Plan Finder had the beneficiary taken time to enter his or her drugs into the online tool. As a result, the authors suggested that encouraging the use of the Plan Finder tool and its associated out-of-pocket estimates might help beneficiaries select the best plans in terms of expected out-of-pocket costs.

Another aspect of the choice complexity problem is the process that Medicare beneficiaries and consumers in general use to screen and then select their plans. Li and Trivedi (2012) examined Medicare beneficiary choices of Medicare Advantage plans using a screening model that assumes that every beneficiary goes through a stage whereby he or she screens all available plans. From the screening phase, a beneficiary reduces the choice set by including only those plans that fulfill the beneficiary's requirements on all plan characteristics. The authors found that Medicare beneficiaries tended to screen the full choice set based on premium, drug coverage, and vision coverage (in that order) but that, once the choice set is established, these characteristics do not play an important role in the final choice of plan. Because screening is an important part of the choice process in a market in which many choices are available with lots of information and attributes, presentation and marketing of plans can have an important impact on the ultimate choice of plan.

Kling et al. (2012) conducted an experiment designed to determine whether Medicare Part D enrollees chose to switch to lower-cost Part D plans when mailed printouts showing their expected out-of-pocket costs in their current plans compared with the lowest-cost plans in their areas. The authors found that 28 percent of beneficiaries switched plans when mailed the expected cost information, while only 17 percent of beneficiaries who received only mailings with the link to the Medicare Plan Finder tool switched plans. Because the same cost information could be obtained from the Plan Finder tool, these results suggest that reducing the costs associated with comparing alternative options (called comparison friction) might assist beneficiaries in making better decisions about their health plans.

For a report similar to the work on Medicare, in the context of employer-sponsored insurance, Atanasov and Baker (2014) investigated the barriers to selecting high-deductible plans using a survey of employees from a single large employer. Although many realized that the highdeductible plan could save them money, only 3 percent of employees selected this plan. The most significant barrier was the perception that the network of providers would be limited with the high-deductible plan, when in fact the providers were the same. This result suggests that many lack information about the details of the plan and that, in lacking that information, they miss out on the opportunity to save money. 


\section{Summary}

Overall, effective decisionmaking when purchasing health insurance is challenging in many ways. Consumers are easily swayed by the framing of information and the sorting of plans. Many lack the knowledge needed to understand the products being offered. Furthermore, the choices are complex, involving many possible scenarios and the need to understand risk and probabilities. Keeping these challenges in mind when designing choice architecture is crucial.

Furthermore, because of the numerous challenges discussed in this section, it is possible that insurers might take advantage of consumers' bounded rationality or limited information. In a general context, Gabaix and Laibson (2006) developed a model of "shrouded attributes" in which firms can exploit consumer myopia and complexity of the decision. They do this by obscuring (or shrouding) attributes that might be particularly important in selecting a product. Some consumers might not realize that these characteristics are important and might unwittingly purchase a suboptimal product. The authors showed that this could lead to allocation-related inefficiencies. If this is the case, competition might not succeed in producing efficient market outcomes with low prices for consumers. Markets for health insurance are potentially at risk for this behavior because of the complexity of the product.

\section{Previous Research on Health Insurance Website Design}

Two aspects of the health insurance market have influenced website design for the marketplaces. The first are regulations, at either the state or federal level, that impose requirements on the design of the insurance market in the state or nation. These requirements can affect the number of choices available and the design of the plans offered and can therefore influence the consumer's decisionmaking process. The second aspect is consumer research on specific design aspects for the websites. This section briefly describes some key regulations that can affect choice in the marketplaces, then discusses the development and evaluation of marketplace plan websites.

\section{Marketplace Regulations Affect Website Design and Choices}

Regulations placed on marketplaces at the state and federal levels can affect website design or choice sets. Monahan et al. (2013) detailed some of the regulations that states operating their own marketplace websites have implemented to simplify consumers' choice environments. Table 2.1 shows the states that have taken three types of actions. Nine states have limited the number of plans or benefit designs that insurers can offer, six states have standardized benefit design, and eight states have required that each of an insurer's plans differ substantially from its own other plans offered in a given market. Each of these regulations is designed to make it easier

for consumers to compare plans. Limiting the number of options helps to avoid choice overload. Standardized benefit designs limit the number of attributes of a plan that consumers have to 
compare. Finally, requiring substantial differences between plans should make differences more salient to consumers.

Table 2.1. State Actions to Simplify Consumer Choices in the Marketplace

\begin{tabular}{lccc}
\hline State & $\begin{array}{c}\text { Limited the Number of Plans or } \\
\text { Benefit Designs }\end{array}$ & $\begin{array}{c}\text { Standardized Benefit } \\
\text { Designs }\end{array}$ & $\begin{array}{c}\text { Adopted Meaningful-Difference } \\
\text { Standards }\end{array}$ \\
\hline California & $\mathrm{x}$ & $\mathrm{x}$ & $\mathrm{x}$ \\
Colorado & $\mathrm{x}$ & $\mathrm{x}$ & $\mathrm{x}$ \\
Connecticut & $\mathrm{x}$ & & $\mathrm{x}$ \\
Kentucky & $\mathrm{x}$ & $\mathrm{x}$ & $\mathrm{x}$ \\
Maryland & $\mathrm{x}$ & & $\mathrm{x}$ \\
Massachusetts & $\mathrm{x}$ & $\mathrm{x}$ & \\
Nevada & $\mathrm{x}$ & $\mathrm{x}$ & $\mathrm{x}$ \\
New York & $\mathrm{x}$ & & $\mathrm{x}$ \\
Oregon & & $\mathrm{x}$ & $\mathrm{x}$ \\
Utah & $\mathrm{x}$ & & \\
Vermont & & & \\
Washington, & & & \\
D.C. & & & \\
\hline
\end{tabular}

SOURCE: Monahan et al., 2013.

NOTE: Not every state here ran its own state-based marketplace (SBM) as of 2015.

\section{Consumer Research Informed Website Design}

A variety of different activities were undertaken prior to the launch of the marketplaces in order to design consumer-friendly websites that assist in plan selection and enrollment. These activities included consumer research, website development and refinement, and the launch of a prototype website for marketplaces to use as a model. This section describes some of these activities and the findings and recommendations from the preparatory work.

Enroll UX 2014 (Enroll UX 2014, undated [a]) was formed as a public-private partnership with the federal government, 11 state governments, and private foundations, with the goal of developing a "design reference for states and federal health insurance exchanges" (Enroll UX 2014, undated [b]). The partnership spanned multiple years, during which time web developers and partners met to discuss the design, conduct testing on consumers, and make refinements. A prototype web tool was then launched. Some of the materials on the Enroll UX 2014 website describe lessons learned from the process of developing the website. These include the difficulties of designing easy-to-understand questions to elicit income information from consumers; consumer testers' appreciation of filters and other questions designed to help the selection process; and consumers seeing the ability to remain on the same page while comparing 
plans as a positive. In addition, the visual design of the website was an important aspect of the development; maintaining consistency of hierarchies, providing easy access to help, and supporting multilingual options were all described as important aspects of the design. The final prototype is included as a possible private website for review using the framework.

The Pacific Business Group on Health (PBGH) conducted a series of experiments designed to better understand how consumers who were likely to enroll in exchange plans would respond to different web design options (PBGH, 2012). As a result of this research, PBGH (2013) issued five recommendations for website design; PBGH selected the five recommendations that would have a significant impact on the choice process and ultimate choice of health plan:

- Provide consumers with an estimate of the total out-of-pocket costs under the plan.

- Organize the initial result page to first present plans that are the so-called best fit for the individual consumer, and allow the consumer to sort and filter after seeing the initial page.

- Allow the consumer to take shortcuts based on how quickly the consumer wants to select a plan and how many different attributes the consumer wants to consider.

- Provide information in such a way that highlights the attributes that have been found to be most important to consumers (for example, costs and whether a doctor is included in the plan).

- Incorporate a provider directory so consumers can see plans in which their doctors participate.

PBGH also includes recommendations for how to approximate the above tools given the short time frame available to implement the health exchange websites.

\section{Health Insurance Choice Websites Sometimes Reflect Consumer Research Results}

Once the exchange plan websites were up and running, researchers began examining the design of those websites to see how well they reflected the research results and principles described above. Some researchers also offered suggestions for improvement for some of the websites reviewed. This section describes the website review research conducted after ACA implementation.

Using the five PBGH recommendations as a guide, Baker et al. (2014) reviewed HealthCare.gov and all of the state-based websites during the first 15 days of the openenrollment period in 2014. In general, the reviewers found that sites had implemented some of the easier recommendations. For example, six of the state-based websites incorporated tools that allowed consumers to determine which providers participated in plans. However, only a couple of websites provided estimates of total costs or organized result pages to present best-fit plans first, and no sites allowed for shortcuts for those who wished to see the results more quickly.

Quincy (2012b) reviewed six web tools designed to help consumers choose health insurance plans and conducted interviews with key informants at the organizations sponsoring those tools. The author focused on the initial (default) set of plan options presented to consumers because the default becomes the anchor or baseline for consumers' decision processes. The results of the 
reviews and interviews informed the design of the framework for this project. The author found that the websites differed in their display of the initial page of results, based on three key aspects: (1) emphasis on total expected costs, (2) whether all plans or only a subset are displayed, and (3) the types of plan characteristics displayed in the results (for example, premium, total costs, and quality ratings).

Some websites she reviewed did make use of an estimated out-of-pocket cost calculator, but the algorithm used to calculate total expected costs varied by site. Some sites asked only a few questions about the consumer and then matched those questions to an actuarial estimate of costs, while others asked more-detailed questions about the consumer's desired level of risk and expected utilization. The Massachusetts Health Connector did not display total out-of-pocket costs because the designers did not feel that there was an appropriate, accurate algorithm for predicting costs (Quincy, 2012b).

Quincy found a range of opinions on the most appropriate set of choices to present to consumers. Some sites did not limit the initial results displayed but allowed consumers to filter options either before or after the initial results appeared. The Massachusetts Health Connector filtered based on the actuarial value of the coverage (level of insurance coverage) and presented the results based on the level that the consumer selected. Other sites presented only what they called "best sellers," as they defined them, or three plan options selected based on consumer responses to screening questions.

The types of plan attributes presented in the initial result page included premium, deductibles, copayments, estimated out-of-pocket costs, and plan quality measures. Not all websites displayed all of the above information. Quincy also explored three plan attributes in more detail because of their known importance to the plan selection process. The first attribute is cost, which we discussed above in terms of how the expected costs are displayed on the different sites. The second is whether the consumer's provider is in the plan's network. Some websites incorporate the provider directory into the tool, so a consumer could see whether a particular doctor is included in the plan's network as part of the plan screening process. Finally, plan quality ratings can provide cognitive shortcuts for the consumer by summarizing a variety of quality data into one overall rating. All sites reviewed display some type of quality rating for each plan, but the measures included in those quality ratings differ by site.

Consumers are usually given the option to sort or filter their results or both. Sometimes, the filtering occurs as part of the initial screening questions, and the website presents results based on the answers to those questions. Other times, all results are displayed, and the consumer can either sort or filter options based on preferred plan attributes. In some cases, the filters are nested, meaning that consumers can filter based on more than one plan characteristic at a time. Quincy (2012b) points out that the ability to filter on multiple characteristics at once makes filters "more powerful than sort options in terms of engaging consumers and customizing the display to meet their needs" (p. 16). 
Quincy also found that websites used some design elements that might make the experience more user-friendly for consumers. These included the use of pop-up tools to define health insurance terms, such as premium and deductible; video tutorials; glossaries; lists of frequently asked questions (FAQs); and rollover definitions, for which a consumer need only place the mouse over the word to see the definition.

Other studies that have explicitly reviewed the ACA's marketplace websites have noted several opportunities for improvement, including a need to more clearly convey which types of services are exempted from cost-sharing requirements (Wong et al., 2014), a need for clearer and more-readily accessible information on provider networks (Baker et al., 2014), and a need to more clearly convey the value of the ACA's cost-sharing reductions and the applicability of these reductions to silver plans (Wong et al., 2014; Baker et al., 2014).

\section{Summary}

When it comes time to implement decision-support tools designed to help consumers make good health insurance choices, state regulations restricting both the number of plans offered and design of websites can play an important role in the ultimate website design. In addition, findings from website reviews conducted after the ACA was implemented indicate variation in the use of recommended tools and approaches. This variation highlights the complexity inherent in designing websites to help consumers choose health plans that are good fits for them.

\section{Approaches to Future Website Development from the Literature}

In addition to the research on consumer decisionmaking and choice architecture, some authors have been synthesizing these results and making recommendations for future health insurance marketplace website development. In what follows, we present some of the key recommendations discussed in the literature to address the biases and challenges discussed above. We have organized the recommendations under headings identifying the primary problems they intend to resolve.

In a recent New England Journal of Medicine article, Ubel, Comerford, and Johnson (2015) made several unique suggestions. First, they suggest deemphasizing the metal labels because the labels suggest a rank ordering that might not be appropriate for all consumers. Second, they recommend that policymakers and designers partner with researchers to design experiments that can help to better identify best practices in this setting.

\section{Consumers Might Incorrectly Calculate Cost or Put Undue Emphasis on Premiums}

Quincy (2012b) noted that the major next steps for the websites reviewed include improved expected-cost calculations and helping consumers better understand the total costs in a plan, as well as better integration of the provider network directories. Medicare is planning changes to 
the Plan Finder web tool to better enable beneficiaries who are new to Medicare to navigate the system and find plan options.

One possible way to make the choice process easier is to provide consumers with easy-toread printed information detailing their expected costs for different plans in their areas. Thaler and Sunstein (2008) proposed this type of approach.

However, a potential pitfall with providing consumers with information on expected costs is that this approach minimizes the role of insurance in reducing exposure to unexpected, catastrophic risk. In a Health Affairs blog post (Krughoff, Francis, and Ellis, 2012), the architects of Consumers' Checkbook argue that using patients' past spending to populate out-of-pocket calculators will not necessarily convey the costs a consumer might incur in the event of a serious accident or unanticipated illness. One of insurance's primary functions is to protect consumers against exactly this type of catastrophic risk. The authors suggest that a better approach would provide consumers with expected spending under typical, best-case, and worst-case scenarios using data from a population with similar demographic characteristics (e.g., age, family size). Ubel, Comerford, and Johnson (2015) also recommended reporting costs under several scenarios. In addition to better conveying potential financial risks under an extreme scenario, this approach has the benefit of requiring less detail on individuals' personal health spending history. The concern that calculators might not accurately convey information about worst-case spending scenarios is underscored by the fact that insurance counselors reported that consumers often fail to understand insurance's function as a hedge against catastrophic financial risk (Paez et al., 2014).

\section{Choice Overload Might Lead to Suboptimal Decisions}

Bundorf and Szrek (2010) suggested that, in a multiattribute, multichoice environment, such as that of health insurance, errors in decisionmaking are more likely because people will develop a heuristic (or simple rule of thumb) to simplify the decision process at the risk of possibly removing valuable options from their choice sets. As described in more detail above, in some cases, excessive choice can increase the probability that a consumer gives up and makes no choice at all.

One obvious solution to the problem of choice overload is to limit the number of options available to consumers. This approach has been adopted in some contexts, such as in the Massachusetts Health Connector. However, limiting the choice set can detract from consumer well-being if desirable options are excluded from the choice set (Dafny, Ho, and Varela, 2013). As an alternative, filtering and sorting can limit the number of options any given consumer has to consider, without limiting the entire choice set. Quincy (2012b) pointed out that the ability to filter on multiple characteristics at once might make filters more beneficial to consumers than sort options.

To address the problem of choice overload, Maher (2012) and King et al. (2013) recommended being more strategic about default settings. The marketplaces could establish 
default settings to correlate with public policy goals set by the U.S. Department of Health and Human Services to generate both individual and public value in the long term. Some studies illustrate that people often wish to choose not to choose, preferring to delegate decisionmaking to a trusted person (e.g., their employers) to help them select a health insurance plan (Maher, 2012; Day and Nadash, 2012; Marquis, Buntin, Escarce, Kapur, et al., 2006). In the current setting, the default is that people are uninsured, which might not be in the best interests of the consumer or public policy goals.

\section{Consumers Might Have Difficulty Understanding Complex Health Insurance Information}

In addition to using modified design to reduce the burden of choice, the exchanges could deploy decision-support tools to facilitate more-effective, higher-quality decision processes and outcomes. Hibbard and Peters (2003) made some recommendations. One possibility is to use a computer-aided decision tool to help consumers structure their decision processes. Consumers would be asked simple questions that help to identify their preferences. This tool would then use a consumer's reported preferences to point him or her toward the choices that best fit his or her needs. The authors also recommend advisers, such as navigators, either in person or through an online live chat tool, who can help consumers make choices. Alternatively, websites could include personal narratives or vignettes that describe anecdotal experiences with insurance. These narratives can help some consumers better understand the options they face. Pop-ups and rollover definitions of terms, like Quincy (2012b) described, could also reduce the burden of making a choice.

To improve consumers' experiences in the complex health insurance choice environment and optimize their decisions, the government and the exchanges could look to non-Internet-based support mechanisms as well. Although more people are finding information online, certain segments of the U.S. population remain unconnected and fall outside the reach of modern technologies. For some consumers, information about their options (and the defaults embedded in said information) would likely have to be disseminated via hard-copy materials, in person, or by telephone (Maher, 2012).

Prior studies on Medicare and Medicaid acknowledged the role that different support mechanisms could have in promoting health insurance take-up, especially among subgroups that have limited access to or comfort with the Internet. Wood et al. (2011) noted that Internet sites and toll-free hotlines are available to Medicare beneficiaries but that both are underused. Hanoch and Rice (2006) commented on the misinformation that customer service representatives provided to seniors who did use the toll-free hotline. Although there are divergent views on the usefulness and reliability of toll-free hotlines, for some consumers, human support might be necessary to make choices in the complex health plan environment. Navigators can also serve as an important resource (Maher, 2012). Baicker, Congdon, and Mullainathan (2012) argued that counseling from employer administrators and human resource departments could reduce the burden of decisionmaking and that these third parties could supplement marketplaces' efforts to 
properly articulate the benefits of being insured and the risks of being uninsured, thereby promoting take-up. Third parties could be employer-based, or they could be hospital-based, such that they would be able to share information and enroll people at the time and point of service (Baicker, Congdon, and Mullainathan, 2012).

\section{Consumers Might be Subject to Inertia or Status Quo Bias}

Often cited as a key element in decisionmaking, status quo bias and default bias often lead people to make no active choice. This might be rooted in choice overload, or in some cases, inadequate literacy or numeracy on the part of the individual consumer (Barnes, Hanoch, Wood, and Rice, 2012; Day and Nadash, 2012). The default settings that are established on a website can be wielded as powerful nudges, leading people to make better decisions that serve the individual as well as public interest, especially if defaults can be tailored to an individual's characteristics. However, some websites might prefer to require active choice. In this case, consumers could be required to actively select health insurance plans each year; however, they would be free to reenroll in the same plans. If they did not actively enroll, they could be uninsured and face a penalty. If consumers are loss averse, penalties rather than rewards can help to spur action. That is, introducing a risk message and associating a certain penalty with noncompliance or inaction are likely to have a greater influence on individual behavior than a reward-based incentive scheme would (King et al., 2013; Baicker, Congdon, and Mullainathan, 2012; Hanoch and Rice, 2006). Even if consumers are risk averse, penalties can help to spur active choice.

Ericson and Starc (2014) developed a model of dynamic defaults. Dynamic defaults can be used to ensure that insurers do not take advantage of status quo biases by raising prices for those who do not change plans. In this case, when plan prices increase significantly, a consumer could be defaulted to a lower-cost plan that includes the consumer's doctor and has similar out-ofpocket costs to those of the previous plan. When plan prices do not rise significantly, the consumer could be defaulted to renew the existing plan.

\section{Limited Numeracy, Literacy, and Knowledge of Health Insurance Adversely Affect Individual Decisions}

Although exchange design and decision-support tools can help reduce the burden of choice, some argue that choice overload is not the central problem. Rather, they argue that poor numeracy and literacy, as well as a general lack of familiarity with health insurance, are the driving forces behind individuals' suboptimal health insurance decisions. One policy solution would be to invest in improving both literacy and numeracy in general, although such a change is beyond the purview of those developing marketplace websites.

For a more practical solution, Maher (2012) recommended making the system "simple and transparent": It should not take a consumer long to make a choice (simplicity), and, after making a choice, a consumer should feel confident that he or she has made the right choice 
(transparency). A review of Medicare Advantage, O'Brien and Hoadley (2008), similarly concluded that standardizing, simplifying, and streamlining comparison across different options would force plan providers to actually compete on the dimensions that are most important to the beneficiaries, as opposed to the dimensions that are easiest to identify and compare in a complex information environment. Using symbols, such as five-star ratings, to convey cost and quality information could also help to minimize choice overload (Barnes, Hanoch, Wood, and Rice, 2012; Peters, Meilleur, and Tompkins, undated).

In addition, some studies have suggested moving away from health insurance jargon in presenting choices and focusing instead on practical implications (Harris-Kojetin et al., 2007; Krughoff, Francis, and Ellis, 2012). As discussed above, presenting consumers with expected costs under several scenarios (e.g., average or worst case in the event of a common condition, such as pregnancy) might be more helpful than simply describing deductibles and copays. Gibbs, Sangl, and Burrus (1996) recommended that information be presented to consumers in a layered manner, so that people can choose how much detail is conveyed. For example, an overall consumer satisfaction score could be provided as a top-line assessment of the plan, with the ability to access satisfaction rankings on specific dimensions (e.g., through a click menu) should the consumer desire more information. Similarly, Hibbard, Jewett, et al. (1998) suggested presenting "big ideas" first, to help consumers narrow choices, before moving on to morecomplex differences. For example, some plans offer tighter network restrictions in exchange for lower premiums and out-of-pocket costs. This type of big-picture trade-off could be presented before describing more-specific differences in plan design. In presenting plan distinctions, it might be more informative to present clear differences (e.g., does the plan allow patients to see specialists without referral?) than to present labels, such as $H M O s$ or $P P O s$. This is especially true if distinctions can be hazy across plan types - for example, if some HMOs require referrals for specialists and other HMOs do not (Harris-Kojetin et al., 2007).

\section{Standardization of Products Might Promote Competition}

As shown in their paper on shrouded attributes discussed above, Gabaix and Laibson (2006) noted that, in markets with complex products, competition might not lead to efficiently functioning markets. White (2011) suggested that health insurance markets are likely to suffer from these problems. The author stated that, although some consumers will focus on price, others will select insurance randomly. Furthermore, some consumers will make mistakes and realize these mistakes only ex post. White stated, "Standardization can help promote price competition by reducing the number of dimensions on which plans can differ, simplifying comparisons among plans and helping guarantee that all plans meet minimum standards" (White, 2011, p. 2). There is a trade-off, however, because increased standardization of plans limits how innovative insurers can be in developing new insurance products. A well-known example of standardization is the Medigap insurance option, which has been reformed multiple times in the past few 
decades. These reforms have resulted in ten standardized plan options from which Medicare beneficiaries can choose (Jacobson, Huang, and Neuman, 2014).

\section{Is Nudging the Solution?}

Nudges could hold great promise: They are a simple way to help people to make choices without limiting their freedom to choose. But, for nudges to work as intended, there must be consensus about which product or set of products is optimal for the consumer. For example, in the context of health insurance, a nudge that pointed consumers to plans that included their current providers might lead to very different outcomes from those produced by a nudge that pointed consumers to plans with the lowest costs. McWilliams (2013) pointed out that nudging is a form of agency and notes that the interests of the agent doing the nudging (e.g., an employer, provider, health plan, or government) might not necessarily be aligned with the interests of the consumer. Furthermore, unless different nudges can be applied to different people, choice architects run the risk of helping some consumers at the detriment of others. The process of making health insurance choices might be so complex that those with particularly low knowledge of health insurance might not be able to identify whether the products toward which they are being nudged are appropriate for their own circumstances. In this context, libertarian paternalism, which offers nudges but still requires the consumer to choose a plan, might be insufficient to lead to optimal choices. For those who find it overwhelming to make an adequate choice, a stronger approach might be required, such as default enrollment into a health insurance plan.

In conclusion, a broad literature has noted the difficulties that are likely to arise in designing choice architecture for health insurance decisions. These papers have pointed to suggestions that might help consumers make more-effective choices, such as out-of-pocket cost calculators, limits to the number of choices, decision-support tools, and appropriate nudges or defaults.

\section{Summary}

There is clear evidence that consumers have trouble with making choices about health insurance plans. They often fail to select the best options, especially when facing many options; they lack necessary knowledge about health insurance; sometimes, they take no action at all (status quo and default bias); and choice architecture can easily sway their choices. At the same time, allowing consumers to make their own choices provides them with autonomy and allows them to select the option that matches their own personal circumstances from the set of available choices. Furthermore, markets with many options can enhance social welfare if people can adequately sort through the options, understand the implications, and make optimal choices. When more options are available, each consumer can get closer to his or her own optimal product; the products that Bhargava, Loewenstein, and Sydnor (2015) discussed attempted to do this by allowing consumers to customize their insurance plans in terms of cost sharing. If priced 
in an actuarially fair manner and if consumers are capable of making these choices, this sort of customization could help consumers purchase optimal insurance plans. Additionally, with more options in the market, there is more competition between insurers, which has led to lower prices. 


\section{Chapter Three. Website Reviews}

\section{Introduction}

The application of choice and behavioral economics research to real-life website design involves many decisions regarding how to present the available information. From a consumer's perspective, the manner by which the information on marketplace insurance websites is presented might affect his or her ability to understand the options available and might nudge the consumer toward a specific plan or type of plan. In addition, web tools that enable the potential enrollee to calculate estimated out-of-pocket costs, see whether his or her preferred provider is in a plan's network, and sort plans based on available quality ratings might further assist the consumer in understanding the differences between the plan choices available. Finally, the availability of information about the consumer's eligibility for an exemption from insurance coverage likely affects the consumer's decision to enroll or not enroll in a plan.

We used the findings from the literature review to develop a framework for reviewing SBM websites, as well as federal, state, and other private websites related to choice of health insurance. The framework captured information on the choice architecture, defaults, and decision-support tools that are presented to consumers seeking information about health insurance options. Broadly speaking, the framework addressed the following areas of interest:

- whether the websites used any defaults (e.g., offering consumers only silver plans, or presenting the silver plans as the first options) or nudges

- whether any websites used web tools (e.g., out-of-pocket cost calculators) to help consumers, navigators, or assisters

- the type of information that the website provided related to eligibility for exemptions and how to apply for exemptions.

With the exception of the third area, which no past research has explicitly addressed, the framework generally tried to capture whether the websites reflected the recommendations that arose from the literature review. Using the draft framework, we conducted a review of 20 websites selected in conjunction with the U.S. Department of Health and Human Services' Assistant Secretary for Planning and Evaluation (ASPE). This chapter describes the methods used to develop the framework and conduct the reviews and presents the findings from those reviews. Overall, we found that all websites reviewed did make use of at least some of the recommendations that arose from the literature review, but the most common tool to assist consumers in making decisions was the application of sorts and filters to help consumers focus on and narrow their options. 


\section{Methods}

\section{Framework Design}

We developed a framework for the website reviews based on the key lessons learned in the literature review. We divided the draft framework into specific sections, which generally reflected the pathway a consumer would take to navigate the given site: personal information, plan display (including default settings and sort and filter options), informational materials, and exemptions and penalty information. The framework was in a Microsoft Excel spreadsheet and generally required the website reviewers to enter data in a $0 / 1$ (no/yes) format.

Websites can use personal information to provide consumers with tailored information on the available plan options. In the personal-information section, we captured the amount and type of information a website requested or required consumers to enter in order to see plan options. These types of information included age, gender, smoking status, pregnancy status, income, health status, and information on other members of the consumer's household.

The use of specific design elements (a website's choice architecture) can focus users' attention on certain plans and nudge them to select specific options that are highlighted or appear more prominently on the page. To see the plan options, we entered personal information for a sample consumer, who was a single female, age 28 , nonsmoker, and not pregnant. For each site, we entered the personal information twice, using two income levels in order to determine how and whether websites displayed information differently depending on whether the consumer was eligible for the premium or cost-sharing subsidies created by the ACA. The first annual income was $\$ 18,000$ (low-income scenario, approximately 155 percent of the federal poverty guideline), which is an income eligible for both premium and cost-sharing subsidies in all states and for all ages of potential enrollees. The second income level was $\$ 40,000$ (high-income scenario, approximately 340 percent of the federal poverty guideline), which is not eligible for costsharing subsidies but might be eligible for premium subsidies if the consumer's expected annual spending on the premium is above 9.5 percent of the second-lowest cost silver-plan premium in his or her area. This might occur if the consumer is older and in a rating area with a secondlowest-cost silver-plan premium that is above $\$ 3,800$ (9.5 percent of $\$ 40,000$ ). For the sample consumer we used, the $\$ 40,000$ income level was eligible for premium subsidies for four of the websites and insurance plan rating areas we reviewed (in Hawaii; New York; Vermont; and Washington, D.C.).

Reviewers captured information on the plan display, including whether the consumer was asked whether he or she wanted to view only a subset of plans before seeing the result display; whether the consumer was automatically routed to a filtered group of plans; how the website sorted initial results; the types of plan information that were explicitly presented as part of the initial results; and whether the consumer could sort and filter on specific design elements.

One key lesson from the literature review is that consumers have difficulty understanding the concepts associated with insurance. As a result, the provision of informational materials on 
websites can help consumers make a more informed choice of plan. We captured whether sites provided consumers with additional information on plan benefit design, glossaries of key insurance terms, FAQs on aspects of the ACA marketplace and the coverage options available, and other relevant information. Finally, we also captured whether and how well websites presented information on the possibility of receiving an exemption from the coverage requirement and the possibility of having to pay a penalty if the consumer does not meet the individual coverage requirement (mandate).

We incorporated comments from ASPE staff and two quality assurance reviewers into the draft framework. In addition, each of the four website reviewers tested the draft framework on one site (Maryland). The reviewers met to compare their results, resolved any differences, and updated the framework to make clarifications and add questions that arose during the testing phase. We also asked reviewers to take qualitative notes on interesting or unique aspects of the websites, which we also used in summarizing the findings.

\section{Website Selection}

In consultation with ASPE, we selected 20 websites for review (see Table 3.1). 
Table 3.1. Websites We Reviewed

\begin{tabular}{|c|c|c|}
\hline Type & Site & Jurisdiction \\
\hline \multirow[t]{14}{*}{ SBM } & Covered California (undated) & California \\
\hline & Connect for Health Colorado (undated) & Colorado \\
\hline & Access Health CT (undated) & Connecticut \\
\hline & DC Health Link (undated) & District of Columbia \\
\hline & Hawai'i Health Connector (undated) & Hawaii \\
\hline & Your Health Idaho (undated) & Idaho \\
\hline & kynect (undated) & Kentucky \\
\hline & Maryland Health Connector (undated) & Maryland \\
\hline & Massachusetts Health Connector (undated) & Massachusetts \\
\hline & MNsure (undated) & Minnesota \\
\hline & NY State of Health (undated) & New York \\
\hline & HealthSource RI (undated) & Rhode Island \\
\hline & Vermont Health Connect (undated) & Vermont \\
\hline & Washington Healthplanfinder (undated) & Washington \\
\hline \multirow[t]{4}{*}{ Privately run aggregator } & HealthSherpa (undated) & \\
\hline & ValuePenguin (undated) & \\
\hline & HealthPocket (undated) & \\
\hline & Consumers' Checkbook (2016) & \\
\hline \multirow[t]{2}{*}{ Other public insurance } & CaIPERS (2016) & CaIPERS \\
\hline & Centers for Medicare \& Medicaid Services (undated [b]) & Medicare \\
\hline
\end{tabular}

NOTE: CalPERS = California Public Employees' Retirement System.

They can be broken down into three groups: SBM sites, aggregator sites, and public insurance sites. The SBM sites are the 14 websites run by individual states that chose to offer SBMs for individual coverage under the ACA. The aggregator sites are privately run sites that aggregate marketplace and other types of insurance information from various sources and present the options to consumers. Three of the aggregator sites cover the entire country and allow the consumer to explore plan options regardless of the state in which the consumer lives. One site, Consumers' Checkbook, presents an example of a marketplace website, using Illinois as its illustration for how such a site could work. Some of these sites (e.g., HealthSherpa) also allow the consumer to select and enroll in a plan via the site, while others (e.g., HealthPocket) require the consumer to call an insurance broker to learn more and enroll in a plan. The last two websites we reviewed were sites presenting options to a subset of Americans eligible for specific types of public insurance: CalPERS and Medicare. CalPERS is available to all California public employees and retirees, and Medicare is available to Americans who are either disabled or 65 years of age or older. We reviewed plan options for Medicare Advantage (Part C of 
Medicare) in order to capture how the website presented information on medical benefit, as opposed to just pharmacy benefit (Part D) coverage.

\section{Website Review Process}

Three of the four reviewers each reviewed six sites, and one reviewer examined two sites. Each reviewer selected a specific geographic location for a given website; usually, this selection process was done at random. For example, if a site required the consumer to select a county to see plan options, the reviewer might select the first county in the list. For sites requiring ZIP Codes, sometimes a reviewer would enter his or her own ZIP Code or a ZIP Code for the state or area the reviewer happened to know. For the three aggregator sites offering information nationwide, we searched for plans in California (ValuePenguin and HealthPocket) and Virginia (HealthSherpa). We have no reason to believe that the result display or website design would change based on different geographic areas.

The initial site reviews took approximately one to one and a half hours to complete per site. After the initial review of all sites, we conducted data cleaning and quality checks to verify the results. The quality checks consisted of an additional two website reviews by each of the three reviewers; results were compared to the original reviewer's results, and the original reviewer resolved any discrepancies. The lead reviewer tabulated the initial results and asked individual reviewers to make clarifications and edits where discrepancies and questions arose.

We also conducted some additional reviews to address questions that arose after the framework was completed and the initial reviews had begun. These additional reviews addressed two specific questions: (1) whether a person eligible for Medicaid would receive information to that effect when entering his or her income (\$10,000 for this scenario) and (2) the general appearance of each website, in terms of the types of photos (if any) used.

\section{Limitations}

There are a few limitations to these reviews. First, many of the sites had different pathways, or routes a person can follow, in order to obtain the desired information. This led to some disagreements among the reviewers that arose during the quality check reviews, which the team resolved through discussion. Given some of these findings, the review team also returned to some of the sites for which quality checks were not conducted, in order to double check and make changes to the answers in the framework as necessary.

A second limitation is that it was difficult at times for reviewers to capture all of the information and nuances of a site. Some of the reviewed sites differed substantially from the others, so the information captured by the framework was not necessarily sufficient to adequately describe the site's choice architecture. To address this limitation, the website review team took notes on unusual or different website appearances. In our findings, we highlight some of the sites that offered distinctly different experiences. 
Third, we reviewed these sites on computers, not on mobile devices. It is possible that a consumer using a mobile device would have a different experience navigating the websites from those reported here.

Finally, because we did not have accounts with these sites, we could not see how and whether the websites presented a different display of options based on prior year's enrollment. This is a limitation because the manner by which a consumer's current plan is compared with other plan options could lead to different enrollment choices. We therefore conducted our reviews from the point of view of a consumer thinking about enrolling in a marketplace plan for the first time.

\section{Findings}

\section{Many Pathways Exist to Navigate Sites}

In general, the reviewer first went to the site's home page and searched for the option to compare plans or browse plan options. The reviewer was then prompted to enter personal information, was sometimes told whether he or she was eligible for a subsidy, and was then shown the available plans in his or her area (the initial result display). Separately from the process to view plan options, the reviewer also searched for the types of informational materials available on the site, as well as information on the possibility of receiving exemptions from the coverage requirement and the consequences of noncompliance with the individual mandate (penalty).

However, the websites often presented different navigation options, which could affect the consumer's experience. This section describes some aspects related to the overall experience of navigating the sites, in terms of the distinction between account creation and browsing for plans, the different tools websites used to convey plan and subsidy eligibility information, the appearance of the websites, and the informational materials that the sites provided in order to educate consumers about their coverage options.

As noted in the "Limitations" section above, there were often different pathways through a given site. The lack of a clear road map through sites sometimes led the website reviewers to different conclusions about the presence or absence of a given piece of information on the site (for example, whether a site requested the consumer's income in order to see plan options). When reviewers returned to the websites to resolve these differences, they sometimes discovered that the sites offered different tools designed to meet different consumer needs and that one reviewer had found or used one tool, while the other reviewer had used the other.

Of note is the fact that three pairs of websites used similar site platforms, which meant that the user would have a very similar experience on each pair of sites. These pairs were the sites for Connecticut and Maryland; Massachusetts and Colorado; and Washington, D.C., and Minnesota. Also worth noting, some private organizations have their own sites that offer consumers the 
ability to search for marketplace and other plans for specific states. Consumers could mistake these sites for a state's official marketplace site, and they would likely have different search experiences on the private and public sites.

\section{Some Sites Required Account Creation While Others Permitted Just Browsing}

A key feature of most sites was the distinction between account creation and the ability to browse for plan options. It was possible to create an account with most sites; account creation facilitates enrollment into a marketplace plan and sometimes facilitates the plan selection process. However, requiring the consumer to create an account can create an additional barrier to those interested in learning about options without going through the additional steps of creating an account. Many sites allowed the consumer to browse without creating an account in order to see the plan options available. The browse option often allowed for the entry of some personal information in order to see tailored results.

Websites approached the use of accounts and the browse option differently. Nine of the 14 state sites defaulted the consumer to browsing for plans and allowed for later account creation. Four state sites gave the option to either create an account or browse for plans up front. One site, DC Health Link (undated), was the only one to require account creation. All of the aggregator sites allowed for browsing as a default.

Medicare (undated) allowed the consumer to browse plans in his or her area using only a ZIP Code. If the consumer wished to see more-tailored information, he or she had to enter a Medicare identification (ID) number, birth date, and other personal information. On its initial page, CalPERS presented both the option to create an account and a browse option.

In general, we captured the findings presented below using the browse feature. However, because browsing was not possible on DC Health Link (undated), we created an account to access information from that site. We were also able to obtain Medicare ID information from a beneficiary in order to review the site; therefore, the results for Medicare reflect what a Medicare beneficiary with a Medicare ID would see.

\section{Websites Used a Variety of Tools to Provide Information}

The first type of tool, which was separate and distinct from the standard browse feature of a site, was a subsidy-estimator tool. This tool, which had different names on different sites, existed solely to allow the consumer to enter his or her household income and see whether he or she might be eligible for the premium or cost-sharing subsidies in the marketplace. These tools, which were available on five state websites (but not on any of the aggregator sites), requested only household size and income and did not ask for any additional personal information. Some of these five state websites also had a separate browse feature for plans, some of which requested personal information and presented results based on that personal information.

One site, Covered California (undated), also had multiple browse tools available, which asked for similar personal information up front but did so in a different way (for example, one 
tool had the user select their age from a dropdown box, while another tool allowed the user to type age into a box). Consumers who went to the Covered California home page and selected "Preview Health Plans" at the top of the page were directed to a tool that provided detailed information on plan options, including estimated out-of-pocket costs and plan cost sharing. Consumers who chose "Shop and Compare" near the bottom of the page, however, saw a plan result page that included only basic plan information (for example, insurance carrier, premium, and metal level) and a button to initiate the enrollment process. Figure 3.1 shows a screen shot of the Covered California website with the two options at the top and bottom of the page. The plan selection experience appears to vary significantly depending on the path the consumer chose. These different choice architectures could lead consumers to very different perceptions about the best plans available, but whether consumers who are browsing choose "Preview Health Plans" or "Shop and Compare" seems arbitrary. Even members of our team selected different options for how to browse plans.

Figure 3.1. Screen Shot of the Covered California Home Page

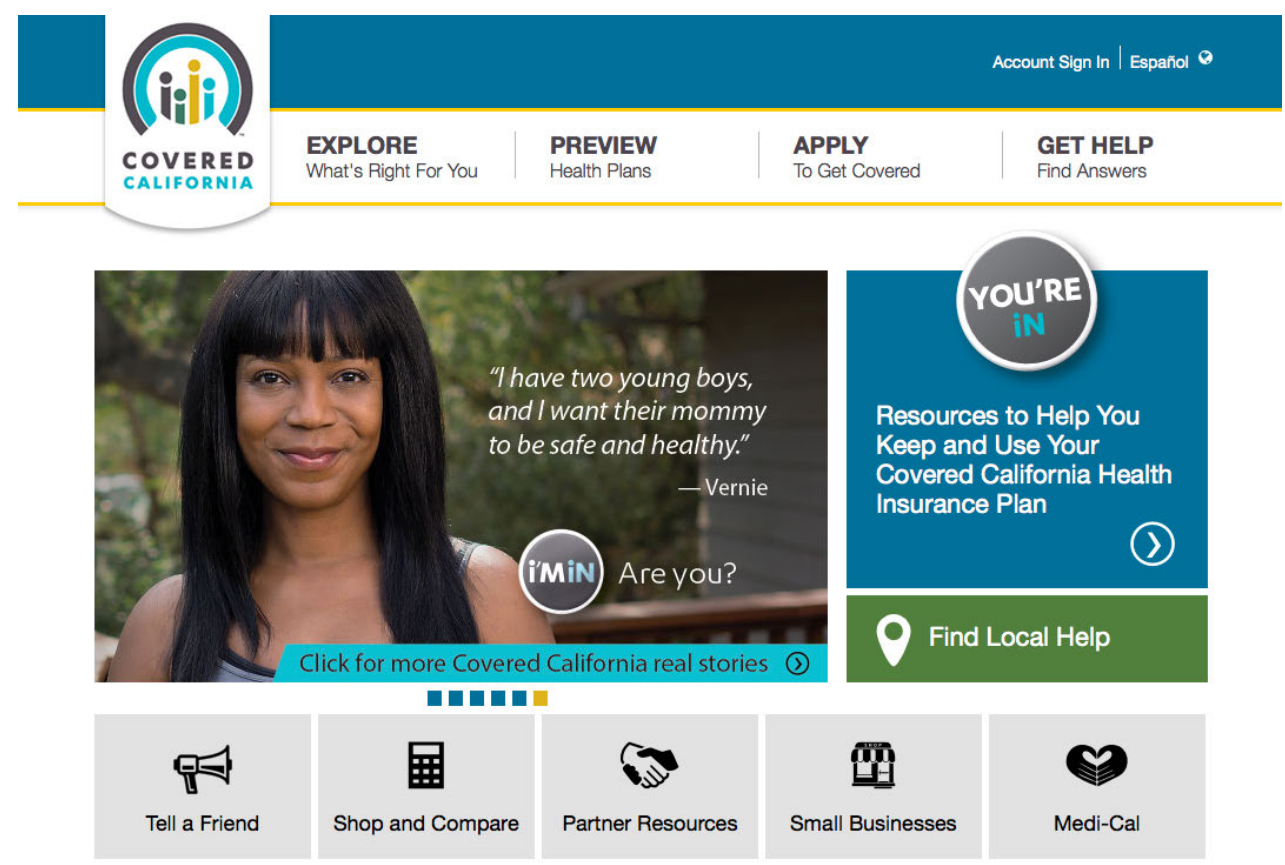

SOURCE: Covered California, undated. Screen shot taken April 2015.

For the purposes of this report, the website reviewers focused on the browse-plans options, and not the subsidy-estimator tools, when answering the questions contained in the framework. For Covered California, reviewers used the "Preview Health Plans" browse option for all results presented in this report, but it is important to keep in mind that other options are available. 
Websites Varied in Appearance

More than half of the websites reviewed made use of pictures or other visual tools on the home page and other pages. Eleven state sites and one aggregator site (HealthPocket, undated) included pictures of people; these people were usually smiling and happy, and many sites also included photos of families, some of which reflected diverse backgrounds. Two sites (kynect, undated, and Your Health Idaho, undated) did not use pictures but instead made use of animation to draw people into the site. Three of the four aggregator sites did not have any pictures but instead focused users directly on the entry of personal information to see plan options.

\section{Informational Materials Varied}

Research has shown that consumers have a great deal of trouble understanding the concepts related to health insurance (Barcellos et al., 2014; Loewenstein et al., 2013). If easily accessible, informational materials can help consumers make more-informed choices. All 14 state sites had FAQs and provided plan summaries of benefits and coverage. Twelve state sites, one aggregator site, and both public sites provided glossaries of terms, while seven state sites provided personal narratives as additional means of orientation. Eleven state sites and one other site allowed the user to view the site in another language, usually Spanish. Seven state sites, three aggregator sites, and one other site were mobile friendly, which provides another means by which consumers can access the information they need to make decisions. Finally, seven state sites, two aggregator sites, and two other sites provided video tutorials to help consumers learn about insurance and their coverage options.

\section{Websites' Requirements for Personal Information Varied}

Collecting personal information from consumers, such as age, income, and geographic location, is essential to providing accurate information about the plans available and the premiums a consumer could expect to pay. However, requesting this information can also create a burden on consumers, who might prefer an easy browsing experience or to not provide such information. Thus, sites must balance the need to provide consumers with accurate information with the potential burden.

The first framework category captured the amount and types of personal information the website requested or required a consumer to enter in order to see plan options. Sites can use personal information to tailor plan results and help focus the consumer on plans that might be a good fit. Table 3.2 shows the number of sites that required or requested that consumers enter specific types of personal information. All sites, with the exception of HealthSource RI (undated) and Vermont Health Connect (undated), required users to enter some type of geographic location information, such as ZIP Code or county. Each of these two states has only one rating area for the entire state, so there is no variation in plan offerings within certain areas of the state. 
Table 3.2. The Amount and Types of Personal Information That Websites Requested or Required

\begin{tabular}{lcccccc}
\hline & \multicolumn{2}{c}{ Number of Sites That Require } & \multicolumn{3}{c}{$\begin{array}{c}\text { Number of Sites That Request but } \\
\text { Do Not Require }\end{array}$} \\
\cline { 2 - 6 } $\begin{array}{l}\text { Type of Personal } \\
\text { Information }\end{array}$ & $\begin{array}{c}\text { State } \\
\text { Sites }\end{array}$ & $\begin{array}{c}\text { Aggregator } \\
\text { Sites }\end{array}$ & Other $^{\mathrm{a}}$ & $\begin{array}{c}\text { State } \\
\text { Sites }\end{array}$ & $\begin{array}{c}\text { Aggregator } \\
\text { Sites }\end{array}$ & Other $^{\mathrm{a}}$ \\
\hline $\begin{array}{l}\text { Gender } \\
\text { Age }\end{array}$ & 1 & 0 & 0 & 1 & 0 & 0 \\
$\quad$ & & & & & & \\
$\quad$ Date of birth & 5 & 0 & 0 & 1 & 1 & 1 \\
$\quad$ Year of birth & 0 & 0 & 0 & 0 & 0 & 0 \\
$\quad$ Age (number) & 6 & 2 & 0 & 0 & 1 & 0 \\
Smoking status & 2 & 2 & $\mathrm{n} / \mathrm{a}$ & 5 & 2 & $\mathrm{n} / \mathrm{a}$ \\
Pregnancy status & 2 & 1 & $\mathrm{n} / \mathrm{a}$ & 3 & 0 & $\mathrm{n} / \mathrm{a}$ \\
Household income & 5 & 1 & $\mathrm{n} / \mathrm{a}$ & 4 & 3 & $\mathrm{n} / \mathrm{a}$ \\
Average number per site $^{\mathrm{b}}$ & 1.7 & 1.5 & 1.5 & 1.1 & 2.3 & 1.0 \\
Range across sites $^{\mathrm{b}}$ & $0-6$ & $0-3$ & $0-3$ & $0-5$ & $0-3$ & $0-2$ \\
\hline
\end{tabular}

NOTE: $\mathrm{n} / \mathrm{a}=$ not applicable to Medicare and CaIPERS. Table A. 1 in the appendix shows the specific sites providing each of these pieces of information.

${ }^{a}$ Because Medicare and CalPERS do not provide information on marketplace plans but instead relate to other insurance products, the types of information they collect is not always the same as that for the marketplace plans.

${ }^{\mathrm{b}}$ These summary statistics also include the types of personal information collected related to health care utilization and health status. We discuss these types of information in the "Out-of-Pocket Cost Calculator" section below.

Sites used a variety of approaches to requiring versus requesting information from consumers. Some sites left a field blank but included a star next to the field indicating that it was a required entry (i.e., the field provided no default value, so the consumer had to fill it in before proceeding). Other fields were left blank but the user did not have to fill them in to see the plan options available (i.e., the fields were blank but the consumer did not have to fill them in before proceeding). Sites also made use of auto-fill options, in which a response was shown by default for a question (for example, a "no" response related to pregnancy or smoking status), but the user had the option to change the response. Reviewers treated the first case as personal information that was required to see plan options and the last two cases as optional personal information.

The three different site types (states, aggregators, and other) required, on average, similar amounts of personal information; some sites did not require consumers to enter any personal information in order to see plan results, while others required as many as three (aggregators and other sites) or six (one state site, Kentucky's kynect, undated) pieces of personal information.

The most frequently required piece of information was age (a key factor in determining premiums), which was usually captured via date of birth or simply the numerical age. Eleven of the 14 state sites and two aggregator sites required some entry of age. Some sites also requested information on smoking status, which can affect out-of-pocket premium costs under the ACA, and pregnancy status, which can affect Medicaid eligibility. Few sites requested information 
(required or optional) about estimated utilization of health care services; those sites that did request this information generally provided estimates of out-of-pocket costs in a given plan. We discuss these pieces of information and the out-of-pocket cost calculators below.

Income information is essential to calculating whether a consumer is eligible for premium or cost-sharing subsidies within the marketplace. Consumers who are eligible for the subsidy and who can see the estimated final costs (including the subsidy) that they will incur if they enroll in a marketplace plan might be more likely to enroll than those who do not see final costs that take into account the subsidy. As noted above, all state websites had some method for consumers to enter their incomes and receive estimates as to whether they were eligible for the subsidy. However, although all four aggregator sites captured income information (either required or optional) via the browse feature, only nine state sites did so. This suggests that consumers viewing plan options on those state sites that did not collect income information were seeing plan options that did not take into account their likely lower subsidized premium.

\section{Plan Display}

Sites Provided Tools to Determine Subsidy Eligibility, but Not All Applied Eligibility Results to Plan Displays

As mentioned above, it is important for consumers to know whether they are eligible for premium or cost-sharing subsidies because their costs might be significantly lower with the subsidy. Given that a consumer's costs might be lower, knowing the final amount that he or she might pay for a plan could increase the likelihood that a subsidy-eligible consumer chooses to enroll in a plan. All websites (both state-based and aggregator sites) provided information on the possibility of receiving a subsidy for premiums or cost sharing. However, the sites varied in the extent to which an eligibility calculator, based on income, was incorporated into the plan results in the browse feature. Nine state sites and the four aggregator sites incorporated income into the browse feature, while five state sites had a separate subsidy-estimator tool that requested the consumer's income. Of note, some of the state sites that incorporated income into the browse feature also had separate subsidy-estimator tools; results presented here focus on the browse feature as opposed to these other tools.

Of the sites that displayed subsidy eligibility based on income as part of the browse feature, most notified the consumer of his or her potential eligibility. Under our $\$ 18,000$ scenario, in which the consumer was eligible for both the premium and cost-sharing subsidies, nine state sites and all four aggregator sites applied the estimated subsidy to lower the premiums shown on the initial result page. In addition, five state sites and three aggregator sites also applied the subsidy to lower the cost-sharing estimates displayed. Of note, Covered California lowered the premiums because of subsidy eligibility but did not display cost sharing at all for the low-income person, simply noting that, because the person was likely eligible for the cost-sharing subsidies, the cost sharing would likely be lower than the information contained in the plan finder. 
Table 3.3 shows an example comparing the high- and low-income scenarios for the same plan on Maryland Health Connector (undated). For the low-income scenario, the premium subsidy has been applied to the estimate for the Kaiser Permanente plan, and the cost-sharing subsidy, which serves to reduce the consumer's out-of-pocket maximum costs, deductible, and cost sharing for specific services (for example, emergency room and primary care), has also been applied.

Table 3.3. Example of Premium and Cost-Sharing Subsidies in Initial Result Display, for Maryland, Kaiser Permanente Silver 1750/25-Percent Plan

\begin{tabular}{lccccc}
\hline & $\begin{array}{c}\text { Estimated } \\
\text { Monthly } \\
\text { Premium, in } \\
\text { Dollars }\end{array}$ & $\begin{array}{c}\text { Annual Out-of- } \\
\text { Pocket } \\
\text { Maximum, in } \\
\text { Dollars }\end{array}$ & $\begin{array}{c}\text { Emergency Room, } \\
\text { Percentage, After } \\
\text { Deductible }\end{array}$ & $\begin{array}{c}\text { Primary Care } \\
\text { Copayment, } \\
\text { Percentage, After } \\
\text { Deductible }\end{array}$ & $\begin{array}{c}\text { Annual } \\
\text { Deductible, in } \\
\text { Dollars }\end{array}$ \\
\hline $\begin{array}{l}\text { Low income } \\
(\$ 18,000)\end{array}$ & 62.50 & 2,250 & 10 & 10 & 500 \\
$\begin{array}{l}\text { High income } \\
(\$ 40,000)\end{array}$ & 192.55 & 5,000 & 25 & 25 & 1,750 \\
\hline
\end{tabular}

Kentucky's kynect (undated) provides another example of the application of the subsidy to lower the premium but not the cost sharing (see Figure 3.2). The Kentucky site presents the same total monthly premium estimate on the far left of the initial result display and, next to that premium, shows the "Premium with APTC Applied." The site does not provide a definition of $A P T C$ via a rollover definition or other simple-to-access source, but, when comparing the lowincome scenario with the high-income scenario, our reviewers found that this is the premium with the tax credit subsidy applied: The low-income scenario shows a far lower premium. For consumers trying to choose among plans and see the total costs, this display might be confusing because they will first note the total, higher premium on the left side and must look for the lower premium next to it (and understand what "APTC" means). ${ }^{2}$

${ }^{2}$ APTC stands for advanced premium tax credit (Centers for Medicare \& Medicaid Services, undated [a]). 
Figure 3.2. Screen Shot of Kentucky's Initial Result Display, Showing Premium Subsidies Applied to the Low-Income Scenario Only

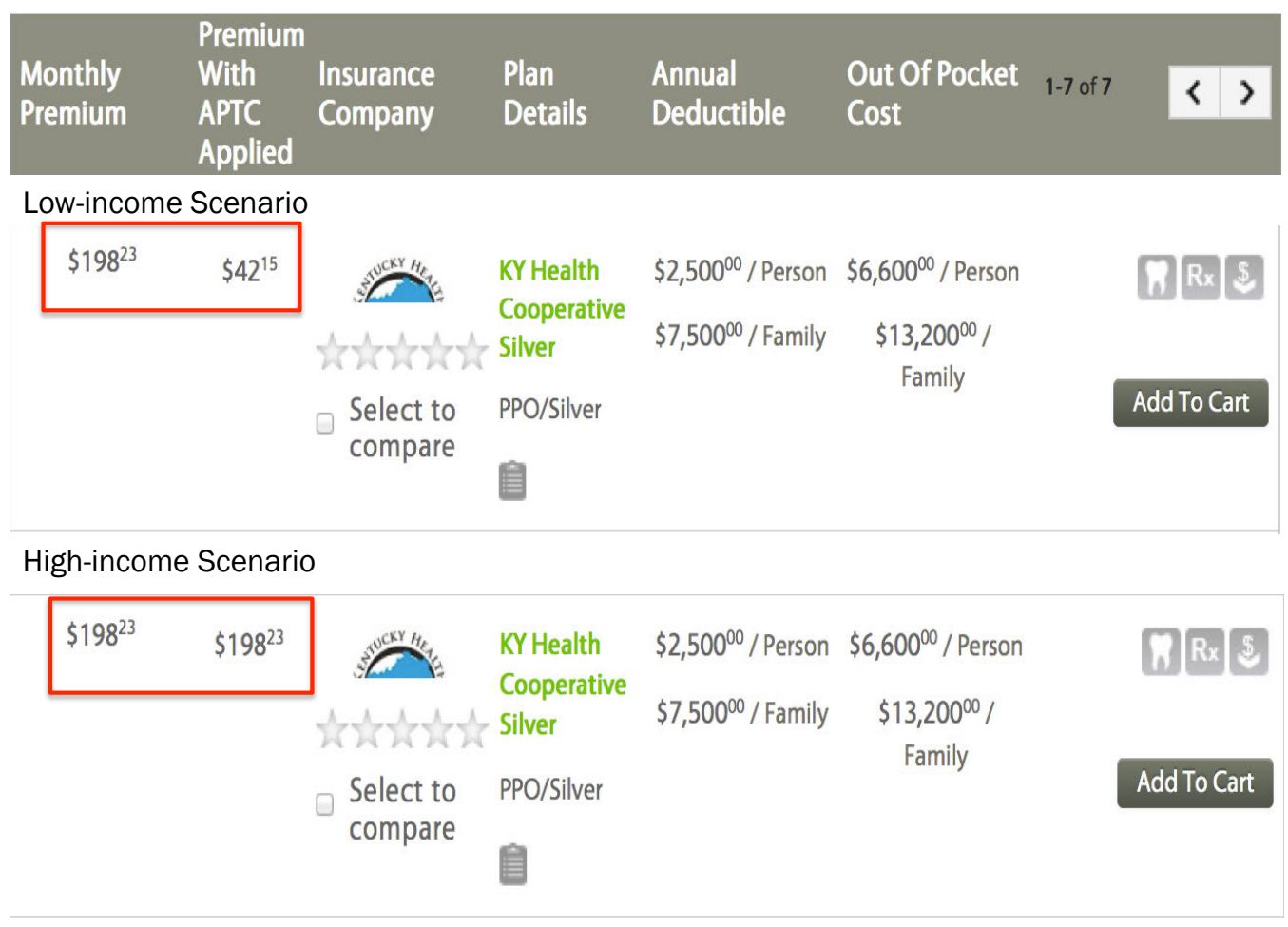

SOURCE: kynect, undated. Screen shot taken March 2015.

\section{Default Filtering and Sorting Varied}

One manner by which websites and other decision-support tools can help a consumer select a plan is by automatically sorting or filtering the results the consumer sees on the initial result page. Filtering in particular can be beneficial because choice overload is likely to occur in these markets, where more than ten and sometimes as many as 136 plans are available. We have termed this automatic sorting or filtering approach default sorting and filtering because the website usually takes this approach without the user selecting it. Default result displays can have an important effect on plan choice because they focus the consumer on specific plans. Such defaults can be beneficial if tools are well designed and accurately select the best (for that consumer) plan options to display. However, if tools select poorly or focus on plan design elements that are not conducive to selecting a good fit, such defaults could do more harm than good.

Table 3.4 shows the number of sites that applied specific types of default filters or sorts to the initial result display. Default filtering, or the reduction of displayed plan options via some algorithm, was applied only in the low-income scenario. Two state sites (those for Connecticut and Maryland) and one aggregator site (ValuePenguin's) filtered low-income consumers to the silver-tier plans. For the high-income consumer, only ValuePenguin automatically filtered to 
silver plans. Both state sites notified the consumer in advance that the filtering would occur, while the aggregator site simply filtered the plans and did not notify the user. Both state sites gave the user the option to see the full list of results, both before and after seeing the initial result display. The aggregator site filtered on metal tier but did not allow the consumer to see all of the options available at once; the consumer had to intentionally select other metal tiers in order to see plans offered within that tier.

Table 3.4. Default Sorts and Filters Applied by Reviewed Websites for the Low-Income Scenario

\begin{tabular}{lccc}
\hline & \multicolumn{3}{c}{ Number of Sites Applying Default Sorts or Filters } \\
\cline { 2 - 4 } & State Sites & $\begin{array}{c}\text { Aggregator } \\
\text { Sites }\end{array}$ & Other \\
\hline Plan Design Element & 2 & 1 & n/a \\
\hline $\begin{array}{l}\text { Default filter (metal tiers only) } \\
\quad \text { Silver }\end{array}$ & & & \\
Default sort & 1 & 0 & 0 \\
$\quad$ Metal tier, then premium & 8 & 3 & 0 \\
Premium & 1 & 1 & 2 \\
$\quad$ Total out-of-pocket costs & 2 & 0 & $\mathrm{n} / \mathrm{a}$ \\
$\quad$ Metal tier & 1 & 0 & 0 \\
"My Preferences" & & & \\
\hline
\end{tabular}

NOTE: $\mathrm{n} / \mathrm{a}=$ not applicable because Medicare and CalPERS insurance plans do not have metal tiers. Table A.2 in the appendix shows the specific sites providing each of these pieces of information.

Every site used some type of default sorting approach. It was possible to determine the sorting approach for all but one site (Kentucky's kynect, undated). One site (Washington state) used a nested sorting approach for low-income consumers, in which they sorted first to silver-tier plans and then on premium. Other sites used different default sorting approaches; the two most common were premium (eight state sites and three aggregator sites) and total estimated out-ofpocket costs (one state site, one aggregator site, and both other sites). Minnesota presented results sorted based on user-provided answers to questions; we discuss this approach more below. Two sites (Vermont Health Connect, undated, and Rhode Island's HealthSource RI, undated) sorted on metal tier alone.

Although default filtering and sorting can be a website-initiated option to focus consumers on specific plans, three sites (Medicare's Centers for Medicare \& Medicaid Services, undated [b]; Minnesota's MNsure, undated; and DC Health Link, undated, for Washington, D.C.) allowed consumers to apply filters prior to seeing the initial results. This could have a different effect from user-selected filters, which we describe below and occur after the initial results are displayed. Medicare in particular allowed consumers to apply a significant number of filters before seeing plan results, including insurance carrier, premium, drug coverage, deductible, plan 
quality rating, and whether the plan offered nationwide coverage. Minnesota and Washington, D.C., allowed consumers to apply filters, such as plan type, metal tier, and deductible, before seeing the initial results.

Minnesota's MNsure (undated) is an example of a unique sorting approach. The website asks users to enter responses to screener questions ranking the importance of various aspects of insurance (for example, premium or deductible). The website then requests information on expected utilization, then filters the initial results based on the user-entered responses to the questions. Results are also sorted based on those best matching the consumer's expressed preferences, with the best matches at the top of the page. Figure 3.3 shows how the process works on the Minnesota website. This type of approach is similar to what experts suggest would help people choose a plan, in that Minnesota has attempted to implement a decision-support tool that elicits information from the consumer regarding the relative importance of various plan features and then presents results that are tailored to those responses. However, reviewers could not determine how well the Minnesota tool actually performed. Thus, it is difficult to say whether the approach should be replicated elsewhere.

Figure 3.3. Minnesota's “My Preferences" Filter and Sort Options

1. Consumer enters basic demographic information

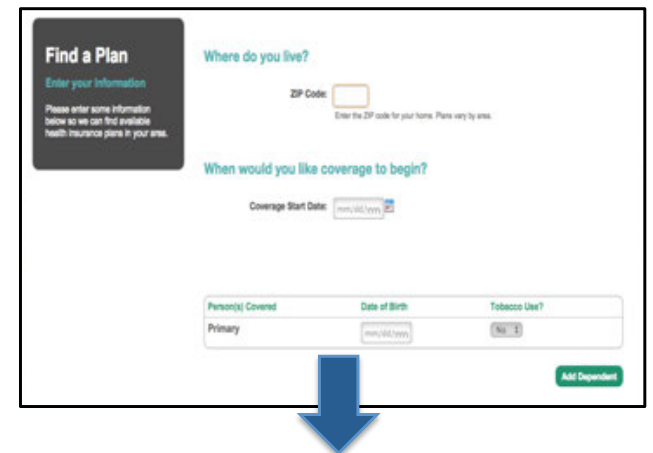

2. Then consumer is prompted to answer questions on medical visits and medications
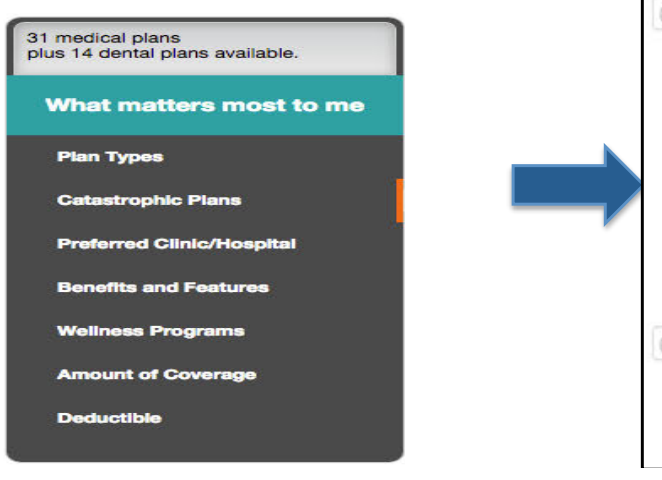

3. Results are displayed

SOURCE: MNsure, undated. Screen shot taken March 2015. 
Sites Consistently Presented the Same Plan Design Elements in the Initial Result Display

The information that websites initially display in plan results will make those elements most salient to consumers. This can help focus consumers on specific aspects of coverage that might be an important part of their decisionmaking. However, there are two important caveats. First, those characteristics might not be the characteristics that a given consumer values most. If that is the case, that consumer could end up selecting a plan that is not appropriate for him or her. For example, if websites focus on premiums but provide limited or no information about expected out-of-pocket costs, some consumers could end up picking a suboptimal plan that leads to higher expected out-of-pocket costs. Second, the quality of the data behind the information provided is extremely important, and the quality varies significantly by type of information. For example, premium, deductible, and insurance carrier are fairly simple plan design elements and are easily verified. By contrast, the inclusion of specific physicians or hospitals in a plan's network can be difficult to confirm; in addition, the physician network can change frequently, so databases containing plan network information might not only be incorrect but quickly out of date. In addition, the out-of-pocket estimators included on some sites (discussed in greater detail below) vary significantly in terms of the types of information used to calculate the out-of-pocket costs and the quality of the estimate itself.

Although choices can increase competition and lower prices, the number of available options on the websites we reviewed suggests that choice overload is highly possible. Of the sites we reviewed, four state sites, three aggregator sites, and one other site (that for CalPERS) displayed all of the plans available in the area on the initial page, which ranged from 11 (CalPERS) to 136 (HealthPocket). It is important to note that the number of plans displayed, for the sites that display all available plans, varies by rating area; thus, the range presented here is dependent on the rating areas we selected for entry on the individual sites. Six state sites displayed ten options on the initial result page, and four state sites displayed from three to five options. Restricting the number of options displayed on the first page might reduce the initial burden on consumers but at the cost of focusing consumers only on those plans that are listed first. If the best plan for a given individual shows up on the third or fourth screen, some consumers might never find the best plan for them.

One method by which consumers can narrow and compare choices is the ability to select a certain number of plans for comparison and then to see those plans displayed in a separate window in a manner that facilitates comparison. Twelve state sites, two aggregator sites, and both other sites allowed consumers to select a certain number of plans for comparison; the most common number of plans a consumer could select was three (11 state sites and one other site). The other state site (Rhode Island's HealthSource RI, undated) allowed consumers to select four plans for comparison.

Table 3.5 presents the number of sites that presented specific plan design elements in the initial result display. Of note is the fact that all sites displayed the insurance carrier, premium, and metal tier for a plan (all easy data elements to verify and ensure accuracy). Most sites also 
displayed the plan's deductible and maximum out-of-pocket costs. About half of the sites displayed cost-sharing information, and seven sites presented some information on the drug coverage that the plan offered.

Table 3.5. Number of Sites Presenting Specific Design Elements in Initial Result Displays, for the Low-Income Scenario

\begin{tabular}{lccc}
\hline Plan Design Element & State Sites & Aggregator Sites & Other \\
\hline Insurance carrier & 14 & 4 & 2 \\
Premium & 14 & 4 & 2 \\
Metal tier & 14 & 4 & $\mathrm{n} / \mathrm{a}$ \\
Deductible $^{\text {a }}$ & 12 & 3 & 2 \\
Maximum out-of-pocket costs $^{\mathrm{a}}$ & 10 & 1 & 2 \\
Cost sharing $^{\text {a }}$ & 6 & 1 & 2 \\
Total estimated out-of-pocket costs $_{\text {Plan quality rating }}$ & 4 & 1 & 2 \\
$\quad$ Based on established metrics & 1 & 2 & 1 \\
$\quad$ Based on surveys & 1 & 0 & 0 \\
$\quad$ Other method & 3 & 1 & 0 \\
Drug coverage information $_{\text {Whether physician is in network }}$ & 5 & 0 & 2 \\
Average number per site & 0 & 1 & 0 \\
Range across sites & 6.0 & 5.5 & 8.0 \\
\hline
\end{tabular}

NOTE: Table A.3 in the appendix shows the specific sites providing each of these pieces of information.

${ }^{a}$ California does not display these three elements for those with low incomes who are eligible for cost-sharing subsidies but does display them for high-income consumers.

${ }^{b}$ The numbers do not add to the total of eight sites that included quality ratings because one aggregator site used two methods for calculating quality ratings-based on established metrics and some other algorithm.

\section{Sites Sometimes Include Notable Elements Requiring Significant Additional Data}

Plan quality ratings, estimated out-of-pocket costs, and physician networks are all notable pieces of information that can provide a consumer with important additional information to aid in plan choice but were included in less than half of the reviewed sites. Information that is not salient might be ignored in the decisionmaking process. This could lead consumers to select suboptimal insurance plans. For example, although premiums are most salient, expected out-ofpocket costs have a larger impact on consumer welfare; if consumers are made aware only of premiums and not expected out-of-pocket costs, they could end up choosing less-comprehensive insurance coverage. In some cases, those who become insured with less-comprehensive coverage might avoid seeking needed health care because of concerns about out-of-pocket costs. Of note is the fact that these three elements are among those for which the data are particularly difficult to 
obtain and verify; in addition, the first two require significant additional analysis and calculation in order to generate the final information for use on the site. We discuss how sites treat each of these elements in turn.

\section{Plan Quality Ratings}

Five state sites, two aggregator sites, and one of the other sites (Medicare's Centers for Medicare \& Medicaid Services, undated [b]) included plan quality ratings in the initial result display. Reviewers were able to find basic explanations of plan quality ratings for all but two sites. Among the six sites for which it was possible to interpret the quality rating, two sites used established quality measures (one state site and one other site), three sites used surveys of previous enrollees (possibly conducted by the plan itself), and one site (Maryland Health Connector, undated) compared plans to what it called a national benchmark but did not indicate the source of this benchmark. One aggregator site combined the established quality metrics with an additional measure of quality that was opaque to the reviewer. Of note, some of the plans displayed on some of the sites did not yet have a quality rating; therefore, the rating for that plan was grayed out. In addition, two sites (Kentucky's kynect, undated, and Minnesota's MNsure, undated) included quality ratings in the site design but had not yet populated the ratings with data.

\section{Out-of-Pocket Cost Calculators}

Information related to the amount a consumer might expect to pay over the course of the year for health care in a specific plan can be very valuable in the decisionmaking process. Out-of-

pocket cost calculators, which can use a variety of different methods to calculate estimates of the expenses a consumer can expect to incur when using a given plan's benefits, are sometimes included in the reviewed sites. Seven sites (four state sites, one aggregator site, and both other sites) present estimated total out-of-pocket costs as part of the display. This is an important piece of information because many consumers are likely to focus only on premiums, especially if the consumer does not understand the different characteristics of insurance. The sole focus on premium can lead to suboptimal choices on the part of the consumer. Where out-of-pocket cost estimates can be provided, they can provide another valuable piece of information to the consumer that could enable more-informative comparisons of plans. However, these calculators should be tested to ensure that the estimates are as informative as possible, and, as noted above, it is difficult to construct these estimates.

The sites that present out-of-pocket cost estimates use different pieces of information from the consumer, some or all of which can be used to estimate these costs. Of note, we could not always determine the methodology that the site used to estimate costs; therefore, although some pieces of information likely contribute to out-of-pocket costs for an individual, we could not always determine whether the specific site took them into account when presenting the estimates. The sites do appear to use different approaches to estimating these out-of-pocket costs, and it is 
not possible to determine the accuracy of these cost estimates. As a result, it is difficult to assess whether the inclusion of out-of-pocket cost estimates is beneficial to consumers.

Table 3.6 shows the information that these sites requested that might contribute to the calculation of estimated out-of-pocket costs. Five sites ask consumers to estimate their medical utilization (usually based on number of doctor's visits) for the coming year; four sites ask for estimates of the number of prescriptions the consumer (and household members) take per month. The Medicare and Consumers' Checkbook sites (Centers for Medicare \& Medicaid Services, undated [b]; Consumers' Checkbook, 2016) also allow consumers to enter their health status, while two sites (those for Rhode Island and CalPERS) ask users to specify chronic and medical conditions, and Consumers' Checkbook also asks users to select specific procedures they anticipate having during the coming year. Four of the sites that present estimated out-of-pocket costs request users to enter their pregnancy status; however, we cannot tell whether this information is requested to estimate out-of-pocket costs or solely to identify women who might be eligible for Medicaid.

Table 3.6. Information Collected by Websites That Offer Total Out-of-Pocket Cost Calculators

\begin{tabular}{|c|c|c|c|}
\hline Website & Information Collected & $\begin{array}{c}\text { Additional Information That } \\
\text { the Cost Calculator Might } \\
\text { Use }\end{array}$ & $\begin{array}{c}\text { Website-Provided } \\
\text { Information About the Cost } \\
\text { Algorithm }\end{array}$ \\
\hline $\begin{array}{l}\text { California's Covered } \\
\text { California, undated }\end{array}$ & $\begin{array}{l}\text { Age, household size, } \\
\text { pregnancy status, and } \\
\text { disability }\end{array}$ & $\begin{array}{l}\text { Medical service use and } \\
\text { medication use }\end{array}$ & $\begin{array}{l}\text { Estimate based on user- } \\
\text { provided medical-visit and } \\
\text { medication information }\end{array}$ \\
\hline $\begin{array}{l}\text { Kentucky's kynect, } \\
\text { undated }\end{array}$ & $\begin{array}{l}\text { Age, gender, household } \\
\text { size, pregnancy status, } \\
\text { smoking status, and } \\
\text { disability }\end{array}$ & Medical service use & None \\
\hline $\begin{array}{l}\text { Your Health Idaho, } \\
\text { undated }\end{array}$ & $\begin{array}{l}\text { Age, pregnancy status, } \\
\text { and smoking status }\end{array}$ & $\begin{array}{l}\text { Medical service use, } \\
\text { medication use, and key } \\
\text { services }^{a}\end{array}$ & $\begin{array}{l}\text { Estimate based on user- } \\
\text { provided medical-visit and } \\
\text { medication information }\end{array}$ \\
\hline $\begin{array}{l}\text { Rhode Island's } \\
\text { HealthSource RI, } \\
\text { undated }\end{array}$ & Age, and household size & $\begin{array}{l}\text { Medical service use, chronic } \\
\text { conditions, and preferences for } \\
\text { lower premiums versus lower } \\
\text { cost sharing }\end{array}$ & Unclear \\
\hline $\begin{array}{l}\text { Consumers' Checkbook, } \\
2016\end{array}$ & $\begin{array}{l}\text { Age, household size, } \\
\text { pregnancy status, and } \\
\text { smoking status }\end{array}$ & $\begin{array}{l}\text { Perceived health status and } \\
\text { anticipated procedures }{ }^{b}\end{array}$ & $\begin{array}{l}\text { Calculates "typical" costs for } \\
\text { people like the consumer, } \\
\text { assuming use of preferred } \\
\text { providers }\end{array}$ \\
\hline CaIPERS, 2016 & Household size & $\begin{array}{l}\text { Medical service use, } \\
\text { medication use, key services }{ }^{a} \text {, } \\
\text { and medical conditions }\end{array}$ & None \\
\hline $\begin{array}{l}\text { Medicare's Centers for } \\
\text { Medicare \& Medicaid } \\
\text { Services, undated (b) }\end{array}$ & Age & $\begin{array}{l}\text { Medication use } \\
\text { Perceived health status }\end{array}$ & $\begin{array}{l}\text { Calculates costs based on } \\
\text { actual Medicare beneficiary } \\
\text { service utilization }\end{array}$ \\
\hline
\end{tabular}


Although reviewers could determine the types of information the sites might have used to inform the out-of-pocket cost estimates, in general, the method by which these costs were estimated was unclear. This is likely because the information that the site provided to consumers was presented in a way that those with low or limited health literacy could understand. Where we could find some information regarding the information used in the algorithm, we include it in Table 3.6.

The out-of-pocket estimates provided on these seven sites are usually a dollar estimate based on average expected spending, with two notable exceptions. First, the Idaho site (Your Health Idaho, undated) presents an estimate expressed as low, average, or high, with a colored flag next to the estimate (green, yellow, or red, respectively). This provides the consumer with a rough idea of whether his or her costs will be low or high in a given plan but does not attach a specific dollar estimate to the information. The other exception is Consumers' Checkbook (2016), which presents costs in an average year and in a bad year. The site also provides the consumer with the probability (based on user-provided information) that the bad year will occur.

\section{Provider Networks}

Finally, the ability to enroll in a plan that includes a specific provider or hospital in its network can be extremely important to consumers. However, as mentioned, the quality of the data used to inform consumers as to whether or not their providers are in the plan's network is extremely important and varies. Most sites offered some means by which consumers could see the plans' provider networks (12 state sites, three aggregator sites, and both other sites), but the ease of access to that information varied significantly by site. Of the 17 sites offering provider network information, 12 (eight state sites, two aggregator sites, and both other sites) simply linked to the plan's website, requiring the consumer to go to another website to obtain the information. Five sites (four state sites and one aggregator site) had built-in tools for the consumer to enter a provider's name to check on network status. Three of these sites (all state sites) also included hospitals in the search option. (Table A.4 in the appendix lists the specific sites referenced here.)

\section{Distinctive Plan Result Displays}

A few sites had plan result displays that were worth highlighting. California's site displays three plans on the initial page, with each plan appearing as a separate box next to another. Below each plan box is a list of several characteristics that the user can click. When the user clicks those boxes, additional information about each plan is revealed. The user has the option to hide some or all of the boxes at once, which could help the user focus on specific plan design elements at different times. Your Health Idaho (undated) also uses the plan box approach but displays additional information in the initial box (i.e., does not require a dropdown click to display the information) and includes 12 plans on each page (displayed as a grid). Focusing on a limited 
number of plans could help consumers avoid choice overload but only because they do not consider all choices.

The CalPERS site includes a table that has five separate tabs, allowing users to view different plan characteristics and rate the level of fit for those characteristics. The tabs allow users to rate or remove plans based on four different plan characteristics that include estimated costs (e.g., premium contributions, estimated out-of-pocket costs based on expected medical service and prescription use levels selected by the user on the preceding information entry page); provider networks; health plan features (e.g., HMO and PPO network characteristics, referral requirements, special assistance or disease-management programs); and a detailed cost comparison of copays, deductibles, annual maximums, coinsurance, and drug copays for services that include hospital care, doctor visits, drugs, home health, vision, and mental health. The final result tab colors each plan based on the preference ratings that the user entered in the preceding tabs.

Two of the aggregator sites take a different approach to plan displays and the entry of personal information. Both HealthSherpa (undated) and HealthPocket (undated) ask the user to enter only a ZIP Code or geographic area on the main page, then immediately show the plans available in the user's area. On the top of the result page, users have the option to change the default information that the website prepopulates (for example, age, income, and location), and the plan options are automatically updated based on the new information.

Finally, Rhode Island's HealthSource RI (undated) allows the consumer to select up to four plans to compare, then exports the results to a Portable Document Format document that the consumer can save and review later.

\section{User-Selected Sort and Filter Options}

Once the consumer reaches the initial result page, the ability to sort and especially filter plan results can help reduce the problem of choice overload. Table 3.7 shows the number of sites that allow for sorting or filtering on different types of options. Premium and deductible were the most-common sort and filter options, with insurance carrier and metal tier also being fairly common filters. On average, sites incorporated anywhere from 3 to 3.8 different sort options, and 4.5 to 4.8 filter options (note that the CalPERS site did not have any sort or filter options). Medicare's Centers for Medicare \& Medicaid Services (undated [b]), allowed for nine filters, as discussed above, because the user was able to apply the filters before seeing the initial results. 
Table 3.7. Number of Sites That Offer User-Selected Sort and Filter Options

\begin{tabular}{lcccccc}
\hline & \multicolumn{3}{c}{ Sorting } & \multicolumn{3}{c}{ Filtering } \\
\cline { 2 - 7 } Plan Design Element & $\begin{array}{c}\text { State } \\
\text { Sites }\end{array}$ & $\begin{array}{c}\text { Aggregator } \\
\text { Sites }\end{array}$ & Other & $\begin{array}{c}\text { State } \\
\text { Sites }\end{array}$ & $\begin{array}{c}\text { Aggregator } \\
\text { Sites }\end{array}$ & Other \\
\hline Premium & 11 & 3 & 1 & 7 & 2 & 1 \\
Insurance carrier & 3 & 2 & 0 & 11 & 3 & 1 \\
Deductible & 9 & 2 & 1 & 9 & 2 & 1 \\
Estimated out-of-pocket costs & 3 & 1 & 1 & 2 & 1 & 0 \\
Maximum out-of-pocket costs & 2 & 1 & 0 & 2 & 1 & 0 \\
Cost sharing & 0 & 0 & 0 & 0 & 0 & 0 \\
Plan quality rating & 4 & 2 & 1 & 3 & 2 & 1 \\
Metal tier & 3 & 1 & $\mathrm{n} / \mathrm{a}$ & 14 & 4 & $\mathrm{n} / \mathrm{a}$ \\
Plans that include a specific & 1 & 0 & 0 & 2 & 0 & 0 \\
physician or hospital & & & & & & \\
Average number per site & 3.0 & 3.8 & 3.0 & 4.7 & 3.0 & 4.5 \\
Range across sites & $0-6$ & $0-7$ & $0-6$ & $1-8$ & $0-6$ & $0-9$ \\
\hline NOTE: n/a & & & & & & 0 \\
\hline
\end{tabular}

NOTE: $\mathrm{n} / \mathrm{a}=$ not applicable because Medicare and CalPERS do not have metal tiers. Table A.5 in the appendix shows the specific sites providing each of these pieces of information.

One site (Washington Healthplanfinder, undated) allowed consumers to sort based on plans that did or did not include a specific physician or hospital, while two sites (Connect for Health Colorado, undated, and Kentucky's kynect, undated) allowed consumers to filter based on inclusion in a physician network. Figures 3.4 and 3.5 show how the sort for Washington and the filter option for Kentucky work for the physician network tools. 
Figure 3.4. Washington Healthplanfinder's Physician Network Sort Option

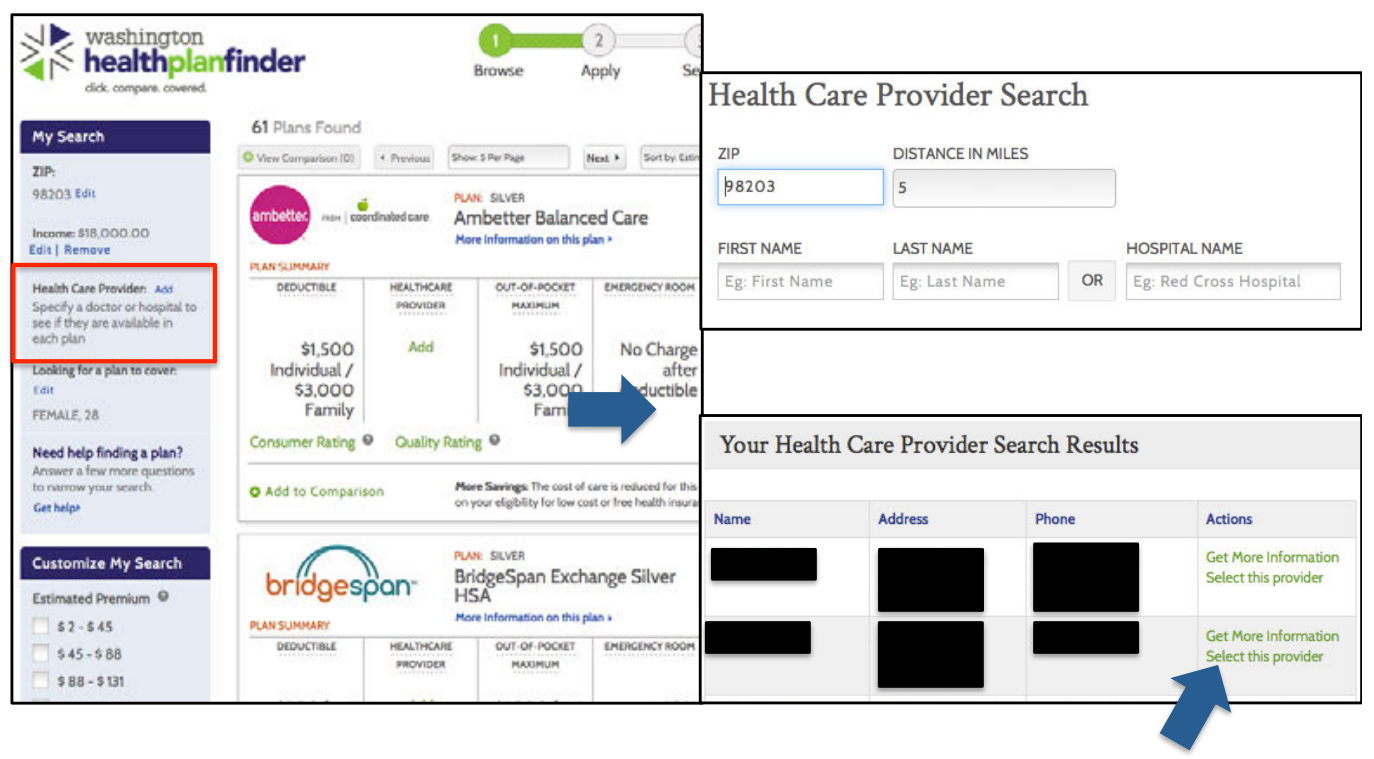

1. Consumer selects add my doctor or hospital to my search

2. Prompted to search and select provider/hospital

3. Results are sorted by provider/hospital

SOURCE: Washington Healthplanfinder, undated. Screen shot taken March 2015. 


\section{Figure 3.5. kynect's Physician Network Filter Option}



SOURCE: kynect, undated. Screen shot taken March 2015.

\section{Coverage Exemptions and Penalty Information}

Some key aspects of the ACA do not pertain to specific insurance plan design features but instead to requirements to obtain coverage or an exemption from coverage. The ACA includes an individual coverage mandate, which requires most consumers to obtain health insurance coverage or pay a penalty. However, there are some exemptions to this requirement. The consumer's ability to access information both about the possible penalty he or she might pay, as well as the possibility of receiving an exemption from the mandate, can also help the consumer decide whether to enroll in a marketplace plan.

In general, we found that consumers are likely to find information on mandate penalties and exemptions only if they actively look for it. This means that the consequences of not obtaining health insurance might not be apparent to uninformed consumers.

Of the 18 sites that offer information on marketplace plans (excluding Medicare and CalPERS, which provide information on other insurance programs), all state sites and one aggregator site provided information on the possibility of receiving an exemption from the 
coverage requirement. This information often appeared on a marginal area of the page or required the reviewer to search through multiple pages to find it.

Although reviewers could not test the browse feature to see whether it informed users of the possibility of receiving an exemption from coverage for all types of exemptions, we did test whether someone with an income low enough to be Medicaid eligible $(\$ 10,000)$ would be advised of possible eligibility. Although 13 state sites and three aggregator sites provided notification of a consumer's potential eligibility for Medicaid, Your Health Idaho (undated) did not notify the consumer of potential Medicaid eligibility. It simply informed the consumer that she was not eligible for subsidies and then presented the full-cost plan options.

Similar to the exemption information, most sites (13 state sites and two aggregator sites) acknowledged the possible consequences of noncompliance with the coverage mandate. However, this information was generally difficult to find and often required searching through various web pages in order to find it.

\section{Summary}

Our findings indicate that state, aggregator, and other insurance sites use choice architecture to assist consumers with plan choice. This choice architecture takes a variety of forms, such as the collection of personal information to present tailored results; default filtering and sorting to focus consumers on specific plans; initial result displays that provide information on specific aspects of plan benefit design that might be most important to consumers; and additional pieces of information (for example, plan quality ratings and estimated out-of-pocket costs) designed to help consumers make a good choice.

All websites we reviewed provide at least some informational materials and tools designed to help consumers learn about coverage and decide among the various options available. About half of the sites default-sort only on premium, but most sites allow for other types of sorting and filtering of results once they are displayed. Only two sites encourage low-income people to focus on silver plans via default filtering, but both sites do allow consumers to see all of the options available if they so desire.

Websites generally provide clear and prominent information on potential eligibility for premium and cost-sharing subsidies, but some sites do not apply the subsidy to the premium and cost sharing displayed in the initial results. Failing to apply subsidies could confuse subsidyeligible consumers who think that the premium they see is what they will pay (when it could be much lower). 

Our review of the literature has suggested some ways to overcome roadblocks to optimal choices that consumers' behavioral biases and limited knowledge created. However, when we look to actual website design, we find that these theoretical best practices are often not implemented. One reason for this disconnect is that health insurance choices are quite complex. In the literature reviewed, many papers use hypothetical choice experiments in which it is easy to say that all characteristics of the plans, except those listed, are equivalent. In practice, there are many features of health insurance plans, and plan standardization is not the norm. Even those papers that have considered actual insurance choices have considered settings with more plan standardization or fewer insurance options than found in the existing health insurance marketplaces. Although coming up with suggestions to improve choice architecture is relatively easy, implementing them can be difficult in practice.

Our findings suggest that there are a variety of ways to apply behavioral economics and choice research results to real-life decision-support tools. Our reading of the literature suggests the following best practices:

1. Provide sorting and especially filtering tools, which will eliminate some options and can help consumers narrow down the set of options and reduce choice overload. Decision-support tools that use easy-to-answer questions to apply filters might be even more beneficial. The vast majority of websites offer these tools already, but there might be room to improve these tools and add features based on further research on actual consumer behavior on the marketplace websites.

2. Provide accurate out-of-pocket calculators that estimate several possible outcomes, including consumers' expected spending under typical and worst-case scenarios. This type of tool might help people better compare health insurance plans that differ in terms of premiums, deductibles, coinsurance, and copays. Less than half of websites currently offer this tool; of those that do, only one presents expected spending under different scenarios.

3. Provide clear and accurate information about provider networks. Provider lists should be easily accessible on websites, and the data behind the lists should be accurate and up-to-date. Ideally, consumers would be able to sort plans based on whether their preferred providers are in network. Although most of the reviewed websites provide access to information on provider networks, most (13 of 18) simply link to the plans' websites.

4. Display plan and network quality in a simple, easy-to-understand format. This need must be balanced with the risk of providing too much information about each option.

5. When optimal choices can be identified, list them first. As noted previously, however, determining the optimal choice for a given consumer can be a complicated task. Decision-support tools could help to identify these plans. 


\section{Base the default — what happens when consumers make no choice - on either the}

status quo or the optimal choice. In some contexts, people become so overwhelmed that they simply do not make a choice. Default enrollment can be a solution to address this issue. However, again, if defaults are used, it is important that there be some consensus about which choices should be prioritized. Furthermore, if initial choices are suboptimal, a status quo default might keep people in suboptimal plans; in that case, a dynamic default might be preferable.

We believe that the literature supports these conclusions, but there are important caveats. First, many of the studies described here rely on unincentivized choices or small convenience samples. The results from these papers might not apply when choices have real consequences or in larger, more-representative samples. Second, most of the studies based on actual insurance choices presented here have not considered the marketplaces specifically. Some have considered settings, such as employer-sponsored insurance, in which the set of options varies dramatically from those available in the marketplaces. Although the general conclusions are likely to apply, there might be unforeseen differences. Importantly, the marketplaces involve premium tax credits and cost-sharing subsidies, which could complicate the decisionmaking process. Additionally, the data needed to support the proposed website functions might be costly to obtain and prone to inaccuracies. For example, provider directories are useful only if they are accurate and up-to-date. Similarly, out-of-pocket cost calculators could be misleading if they are supported by inaccurate data. Our analysis did not explore the feasibility of obtaining accurate data to support these tools or the cost-benefit of improving such tools.

To better understand the implications of website design in the context of health insurance choice, Ubel, Comerford, and Johnson (2015) suggested, carefully designed randomized field experiments would be beneficial. This would overcome the problems of unincentivized hypothetical choice experiments and would avoid potential problems with generalizability that come from studying choices in other settings in which choice architecture might differ.

In addition, with the ACA and the continued progress of technology, the experience of purchasing insurance online is continually evolving. Consumers are becoming more Internet savvy and, over time, might demand different types of web navigation tools. Technologies are also changing, with more and more people using smartphones as their primary way to access the Internet. Because of these changes, web design features that make sense now might not make as much sense in the future. Therefore, conclusions drawn from the literature here, most of which is less than ten years old, might be already out of date. People over 65 ten years ago might have had significant trouble with online decisionmaking, but this might be less true today. Furthermore, consumers will learn more about health insurance and about the ACA over time. As we learn more about how to display information and as technology changes, we might develop new ways to communicate choices to people.

Finally and most importantly, the use of a default or a nudge is effective only if consumers are nudged toward the optimal, or at least not clearly dominated, outcome. However, this is 
problematic in the context of health insurance, in which there are so many parameters and what is best for one person is not likely to be best for another.

We found that, to reduce the number of choices available or allow the user to focus on specific options, most sites provided consumers with the ability to sort and filter their plan options. However, few sites provided out-of-pocket cost calculators or built-in tools enabling consumers to see whether their preferred providers were in a plan's network. In addition, few sites provided information on plan quality, and some of those that did had yet to populate the display with data.

Given the complexity and number of plan options available in most marketplaces, our findings suggest that the websites available to help consumers sort through their options could be improved. However, the quality of the data behind all of these sites is extremely important: Any tool is only as good as the data behind it. The consumer needs high-quality, easy-to-use tools that can help him or her choose a plan that is a good fit. 



\section{Appendix}

Table A.1. Sites That Request Specific Types of Personal Information

\begin{tabular}{|c|c|c|c|c|c|c|}
\hline \multirow[b]{2}{*}{$\begin{array}{l}\text { Type of Personal } \\
\text { Information }\end{array}$} & \multicolumn{3}{|c|}{ Sites That Require } & \multicolumn{3}{|c|}{ Sites That Request but Do Not Require } \\
\hline & State Sites & $\begin{array}{l}\text { Aggregator } \\
\text { Sites }\end{array}$ & Other & State Sites & $\begin{array}{l}\text { Aggregator } \\
\text { Sites }\end{array}$ & Other \\
\hline Gender & Kentucky & 0 & 0 & Washington & 0 & 0 \\
\hline Date of birth & $\begin{array}{l}\text { Colorado; Idaho; } \\
\text { Massachusetts; } \\
\text { Minnesota; and } \\
\text { Washington, D.C. }\end{array}$ & 0 & 0 & Washington & HealthPocket & Medicare \\
\hline Age (number) & $\begin{array}{c}\text { California, } \\
\text { Connecticut, } \\
\text { Hawaii, Kentucky, } \\
\text { Maryland, and } \\
\text { Rhode Island }\end{array}$ & $\begin{array}{c}\text { Consumers' } \\
\text { Checkbook } \\
\text { and } \\
\text { ValuePenguin }\end{array}$ & 0 & 0 & HealthSherpa & 0 \\
\hline Smoking status & $\begin{array}{l}\text { Kentucky and } \\
\text { Minnesota }\end{array}$ & $\begin{array}{c}\text { Consumers' } \\
\text { Checkbook } \\
\text { and } \\
\text { ValuePenguin }\end{array}$ & $\mathrm{n} / \mathrm{a}$ & $\begin{array}{c}\text { Colorado, } \\
\text { Hawaii, Idaho, } \\
\text { Massachusetts, } \\
\text { and Washington }\end{array}$ & $\begin{array}{l}\text { HealthPocket } \\
\text { and } \\
\text { HealthSherpa }\end{array}$ & $\mathrm{n} / \mathrm{a}$ \\
\hline Pregnancy status & $\begin{array}{l}\text { California and } \\
\text { Kentucky }\end{array}$ & $\begin{array}{l}\text { Consumers' } \\
\text { Checkbook }\end{array}$ & $\mathrm{n} / \mathrm{a}$ & $\begin{array}{l}\text { Connecticut, } \\
\text { Maryland, and } \\
\text { Washington }\end{array}$ & 0 & $\mathrm{n} / \mathrm{a}$ \\
\hline Household income & $\begin{array}{l}\text { California, Hawaii, } \\
\text { Idaho, Kentucky, } \\
\text { and } \\
\text { Rhode Island }\end{array}$ & ValuePenguin & $\mathrm{n} / \mathrm{a}$ & $\begin{array}{l}\text { Connecticut, } \\
\text { Maryland, New } \\
\text { York, and } \\
\text { Washington }\end{array}$ & $\begin{array}{l}\text { HealthPocket, } \\
\text { HealthSherpa, } \\
\text { and } \\
\text { Consumers' } \\
\text { Checkbook }\end{array}$ & $\mathrm{n} / \mathrm{a}$ \\
\hline
\end{tabular}

NOTE: $\mathrm{n} / \mathrm{a}=$ not applicable because Medicare and CaIPERS do not use metal tiers. 
Table A.2. Sites Applying Default Sorts and Filters for the Low-Income Scenario

\begin{tabular}{|c|c|c|c|}
\hline \multirow[b]{2}{*}{ Plan Design Element } & \multicolumn{3}{|c|}{ Sites Applying Default Sorts and Filters } \\
\hline & State Sites & Aggregator Sites & Other \\
\hline \multicolumn{4}{|l|}{ Default filters (metal tiers only) } \\
\hline Silver & $\begin{array}{l}\text { Connecticut and } \\
\text { Maryland }\end{array}$ & ValuePenguin & $\mathrm{n} / \mathrm{a}$ \\
\hline \multicolumn{4}{|l|}{ Default sorts } \\
\hline Metal tier, then premium & Washington & 0 & 0 \\
\hline Premium & $\begin{array}{l}\text { Colorado; Connecticut; } \\
\text { Hawaii; Idaho; } \\
\text { Maryland; } \\
\text { Massachusetts; New } \\
\text { York; and Washington, } \\
\text { D.C. }\end{array}$ & $\begin{array}{l}\text { HealthPocket, } \\
\text { HealthSherpa, and } \\
\text { ValuePenguin }\end{array}$ & 0 \\
\hline Total out-of-pocket costs & California & $\begin{array}{l}\text { Consumers' } \\
\text { Checkbook }\end{array}$ & $\begin{array}{c}\text { CalPERS and } \\
\text { Medicare }\end{array}$ \\
\hline Metal tier & $\begin{array}{c}\text { Rhode Island and } \\
\text { Vermont }\end{array}$ & 0 & $\mathrm{n} / \mathrm{a}$ \\
\hline "My Preferences" & Minnesota & 0 & 0 \\
\hline
\end{tabular}

NOTE: $\mathrm{n} / \mathrm{a}=$ not applicable because Medicare and CalPERS do not use metal tiers. 
Table A.3. Sites Presenting Specific Design Elements in Initial Result Displays, for the LowIncome Scenario

\begin{tabular}{|c|c|c|c|}
\hline $\begin{array}{l}\text { Plan Design } \\
\text { Element }\end{array}$ & State Sites & Aggregator Sites & Other \\
\hline Insurance carrier & All sites & All sites & All sites \\
\hline Premium & All sites & All sites & All sites \\
\hline Metal tier & All sites & All sites & $\mathrm{n} / \mathrm{a}$ \\
\hline Deductible & $\begin{array}{l}\text { California; Colorado; Connecticut; Idaho; Kentucky; } \\
\text { Maryland; Massachusetts; Minnesota; Rhode Island; } \\
\text { Vermont; Washington; and Washington, D.C. }\end{array}$ & $\begin{array}{l}\text { Consumers' Checkbook, } \\
\text { HealthPocket, and } \\
\text { HealthSherpa }\end{array}$ & All sites \\
\hline $\begin{array}{l}\text { Maximum out-of- } \\
\text { pocket costs }\end{array}$ & $\begin{array}{c}\text { California, Colorado, Connecticut, Idaho, Maryland, } \\
\text { Massachusetts, Minnesota, Rhode Island, Vermont, } \\
\text { and Washington }\end{array}$ & HealthPocket & All sites \\
\hline Cost sharing & $\begin{array}{l}\text { California, Connecticut, Idaho, Maryland, Vermont, and } \\
\text { Washington }\end{array}$ & HealthSherpa & All sites \\
\hline $\begin{array}{l}\text { Total estimated out- } \\
\text { of-pocket costs }\end{array}$ & California, Idaho, Kentucky, and Rhode Island & Consumers' Checkbook & All sites \\
\hline \multicolumn{4}{|l|}{ Plan quality rating } \\
\hline $\begin{array}{l}\text { Based on } \\
\text { established } \\
\text { metrics }\end{array}$ & Connecticut & $\begin{array}{l}\text { Consumers' Checkbook } \\
\text { and HealthPocket }\end{array}$ & Medicare \\
\hline $\begin{array}{l}\text { Based on } \\
\text { surveys }\end{array}$ & California & 0 & 0 \\
\hline Other method & Kentucky, Maryland, and Minnesota & HealthPocket & 0 \\
\hline $\begin{array}{l}\text { Drug coverage } \\
\text { information }\end{array}$ & $\begin{array}{c}\text { California, Colorado, Idaho, Massachusetts, and } \\
\text { Vermont }\end{array}$ & 0 & All sites \\
\hline $\begin{array}{l}\text { Whether physician is } \\
\text { in network }\end{array}$ & 0 & Consumers' Checkbook & 0 \\
\hline
\end{tabular}

Table A.4. Sites That Offer Information on Provider Networks

\begin{tabular}{lccc}
\hline $\begin{array}{l}\text { Type of Provider Network } \\
\text { Information }\end{array}$ & State Sites & Aggregator Sites & Other \\
\hline $\begin{array}{l}\text { Links to plan's website for } \\
\text { provider information }\end{array}$ & $\begin{array}{c}\text { California; Connecticut; Hawaii; Idaho; } \\
\text { Massachusetts; Minnesota; Vermont; and } \\
\text { Washington, D.C. }\end{array}$ & $\begin{array}{c}\text { Consumers' } \\
\text { Checkbook and } \\
\text { HealthSherpa }\end{array}$ & $\begin{array}{c}\text { CalPERS and } \\
\text { Medicare }\end{array}$ \\
$\begin{array}{l}\text { Built-in tool for checking on } \\
\text { network status (physician or } \\
\text { hospital) }\end{array}$ & $\begin{array}{c}\text { Colorado, Kentucky, Maryland, and } \\
\text { Washington }\end{array}$ & HealthPocket & None \\
\hline
\end{tabular}


Table A.5. Sites That Offer User-Selected Sort and Filter Options

\begin{tabular}{|c|c|c|c|c|}
\hline \multirow[b]{2}{*}{ Plan Design Element } & \multicolumn{2}{|c|}{ Sorting $^{a}$} & \multicolumn{2}{|c|}{ Filtering $^{a}$} \\
\hline & State sites & Aggregator Sites & State sites & Aggregator Sites \\
\hline Premium & $\begin{array}{c}\text { California; Colorado; } \\
\text { Connecticut; Hawaii; } \\
\text { Idaho; Kentucky; } \\
\text { Maryland; } \\
\text { Massachusetts; } \\
\text { Minnesota; } \\
\text { Washington; and } \\
\text { Washington, D.C. }\end{array}$ & $\begin{array}{l}\text { Consumers' } \\
\text { Checkbook, } \\
\text { HealthPocket, and } \\
\text { HealthSherpa }\end{array}$ & $\begin{array}{c}\text { Colorado, } \\
\text { Connecticut, } \\
\text { Hawaii, Kentucky, } \\
\text { Maryland, } \\
\text { Massachusetts, } \\
\text { and Washington }\end{array}$ & $\begin{array}{l}\text { Consumers' } \\
\text { Checkbook and } \\
\text { HealthPocket }\end{array}$ \\
\hline Insurance carrier & $\begin{array}{c}\text { Connecticut, Hawaii, } \\
\text { Maryland }\end{array}$ & $\begin{array}{l}\text { Consumers' } \\
\text { Checkbook and } \\
\text { HealthPocket }\end{array}$ & $\begin{array}{c}\text { Colorado; } \\
\text { Connecticut; } \\
\text { Hawaii; Idaho; } \\
\text { Kentucky; } \\
\text { Maryland; } \\
\text { Massachusetts; } \\
\text { New York; Rhode } \\
\text { Island; Washington; } \\
\text { and Washington, } \\
\text { D.C. }\end{array}$ & $\begin{array}{l}\text { Consumers' } \\
\text { Checkbook, } \\
\text { HealthPocket, and } \\
\text { HealthSherpa }\end{array}$ \\
\hline Deductible & $\begin{array}{c}\text { Colorado; } \\
\text { Connecticut; Idaho; } \\
\text { Kentucky; Maryland; } \\
\text { Massachusetts; } \\
\text { Minnesota; } \\
\text { Washington; and } \\
\text { Washington, D.C. }\end{array}$ & $\begin{array}{l}\text { HealthPocket and } \\
\text { HealthSherpa }\end{array}$ & $\begin{array}{c}\text { Colorado; } \\
\text { Connecticut; Idaho; } \\
\text { Kentucky; } \\
\text { Maryland; } \\
\text { Massachusetts; } \\
\text { Minnesota; } \\
\text { Washington; and } \\
\text { Washington, D.C. }\end{array}$ & $\begin{array}{l}\text { Consumers' } \\
\text { Checkbook and } \\
\text { HealthPocket }\end{array}$ \\
\hline $\begin{array}{l}\text { Estimated out-of-pocket } \\
\text { costs }\end{array}$ & $\begin{array}{l}\text { California, Idaho, } \\
\text { and Kentucky }\end{array}$ & $\begin{array}{l}\text { Consumers' } \\
\text { Checkbook }\end{array}$ & Kentucky & $\begin{array}{l}\text { Consumers' } \\
\text { Checkbook }\end{array}$ \\
\hline $\begin{array}{l}\text { Maximum out-of-pocket } \\
\text { costs }\end{array}$ & $\begin{array}{l}\text { Idaho and } \\
\text { Washington }\end{array}$ & HealthPocket & $\begin{array}{l}\text { Massachusetts and } \\
\text { Washington }\end{array}$ & HealthPocket \\
\hline Plan quality rating & $\begin{array}{l}\text { California, } \\
\text { Connecticut, } \\
\text { Kentucky, and } \\
\text { Maryland }\end{array}$ & $\begin{array}{l}\text { Consumers' } \\
\text { Checkbook and } \\
\text { HealthPocket }\end{array}$ & $\begin{array}{c}\text { Connecticut, } \\
\text { Maryland, and New } \\
\text { York }\end{array}$ & $\begin{array}{l}\text { Consumers' } \\
\text { Checkbook and } \\
\text { HealthPocket }\end{array}$ \\
\hline Metal tier & $\begin{array}{l}\text { Connecticut, } \\
\text { Maryland, and } \\
\text { Minnesota }\end{array}$ & HealthPocket & All sites & All sites \\
\hline $\begin{array}{l}\text { Plans that include specific } \\
\text { physician or hospital }\end{array}$ & Washington & 0 & $\begin{array}{l}\text { Colorado and } \\
\text { Kentucky }\end{array}$ & 0 \\
\hline
\end{tabular}

a Medicare is the only "other" site that provides user-selected sort and filter options, so we do not list it here. 
Abaluck, Jason, and Jonathan Gruber, "Choice Inconsistencies Among the Elderly: Evidence from Plan Choice in the Medicare Part D Program," American Economic Review, Vol. 101, No. 4, June 2011, pp. 1180-1210.

Abraham, Jean M., Roger Feldman, Caroline Carlin, and Jon Christianson, "The Effect of Quality Information on Consumer Health Plan Switching: Evidence from the Buyers Health Care Action Group," Journal of Health Economics, Vol. 25, No. 4, July 2006, pp. 762-781.

Access Health CT, home page, undated. As of May 6, 2016:

https://www.accesshealthct.com

Appelt, Kirstin, Jie Gao, Eric Johnson, and Ted von Glahn, "Choosing How to Choose: Can People Choose the Best Choice Architecture?”Advances in Consumer Research, Vol. 42, January 2014, pp. 395-396.

Apter, Andrea J., Michael K. Paasche-Orlow, Janine T. Remillard, Ian M. Bennett, Elana Pearl Ben-Joseph, Rosanna M. Batista, James Hyde, and Rima E. Rudd, "Numeracy and Communication with Patients: They Are Counting on Us," Journal of General Internal Medicine, Vol. 23, No. 12, December 2008, pp. 2117-2124.

Atanasov, Pavel, and Tom Baker, "Putting Health Back into Health Insurance Choice," Medical Care Research and Review, Vol. 71, No. 4, August 2014, pp. 337-355.

Baicker, Katherine, William J. Congdon, and Sendhil Mullainathan, "Health Insurance Coverage and Take-Up: Lessons from Behavioral Economics," Milbank Quarterly, Vol. 90, No. 1, March 2012, pp. 107-134.

Baker, Tom, Adrienne Beatty, Gabbie Nirenburg, and Janet Weiner, "Window Shopping on Healthcare.gov and the State-Based Marketplaces: More Consumer Support Is Needed," Leonard Davis Institute of Health Economics and Robert Wood Johnson Foundation, December 2014. As of May 3, 2016: http://www.rwjf.org/en/library/research/2014/12/window-shopping-on-healthcare-gov-andthe-state-based-marketplac.html

Barcellos, Silvia Helena, Amelie C. Wuppermann, Katherine Grace Carman, Sebastian Bauhoff, Daniel L. McFadden, Arie Kapteyn, Joachim K. Winter, and Dana Goldman, "Preparedness of Americans for the Affordable Care Act," Proceedings of the National Academy of Sciences of the United States of America, Vol. 111, No. 15, April 2014, pp. 5497-5502. 
Barnes, Andrew J., Yaniv Hanoch, and Thomas Rice, "Determinants of Coverage Decisions in Health Insurance Marketplaces: Consumers' Decision-Making Abilities and the Amount of Information in Their Choice Environment," Health Services Research, Vol. 50, No. 1, February 2015, pp. 58-80.

Barnes, Andrew J., Yaniv Hanoch, Stacey Wood, and Thomas Rice, “One Fish, Two Fish, Red Fish, Blue Fish: Effects of Price Frames, Brand Names, and Choice Set Size on Medicare Part D Insurance Plan Decisions," Medical Care Research and Review, Vol. 69, No. 4, February 2012, pp. 460-473.

Bhargava, Saurabh, George Loewenstein, and Justin Sydnor, Do Individuals Make Sensible (Health) Insurance Decisions? Evidence from a Menu with Dominated Options, Pittsburgh, Pa.: Carnegie Mellon University, working paper, February 2015.

Bordalo, Pedro, Nicola Gennaioli, and Andrei Shleifer, Salience Theory of Consumer Choice, Cambridge, Mass.: National Bureau of Economic Research Working Paper 17947, March 2012. As of May 3, 2016: http://www.nber.org/papers/w17947

Brockington, David, "A Low Information Theory of Ballot Position Effect," Political Behavior, Vol. 25, No. 1, March 2003, pp. 1-27.

Buchmueller, Thomas, "Price and the Health Plan Choices of Retirees," Journal of Health Economics, Vol. 25, No. 1, January 2006, pp. 81-101.

Bundorf, M. Kate, Rui Mata, Michael Schoenbaum, and Jay Bhattacharya, "Are Prescription Drug Insurance Choices Consistent with Expected Utility Theory?" Health Psychology, Vol. 32, No. 9, September 2013, pp. 986-994.

Bundorf, M. K., S. J. Singer, T. H. Wagner, and L. Baker, “Consumers' Use of the Internet for Health Insurance," American Journal of Managed Care, Vol. 10, No. 9, September 2004, pp. 609-616.

Bundorf, M. Kate, and Helena Szrek, "Choice Set Size and Decision Making: The Case of Medicare Part D Prescription Drug Plans," Medical Decision Making, Vol. 30, No. 5, September-October 2010, pp. 582-593.

California Public Employees' Retirement System, home page, updated May 4, 2016. As of May 4, 2016:

https://www.calpers.ca.gov/

CalPERS—See California Public Employees' Retirement System.

Centers for Medicare \& Medicaid Services, "Advanced Premium Tax Credits (APTC)," undated (a). As of May 6, 2016:

https://www.healthcare.gov/glossary/advanced-premium-tax-credit/ 
__, "Medicare Plan Finder," Medicare.gov, undated (b). As of May 4, 2016:

https://www.medicare.gov/find-a-plan/questions/home.aspx

Claxton, Gary, Matthew Rae, Nirmita Panchal, Anthony Damico, Nathan Bostick, Kevin

Kenward, and Heidi Whitmore, Employer Health Benefits: 2014 Annual Survey, Menlo Park, Calif.: Henry J. Kaiser Family Foundation and Health Research and Educational Trust, publication 8625, September 2014. As of May 3, 2016:

http://kff.org/health-costs/report/2014-employer-health-benefits-survey/

Connect for Health Colorado, home page, undated. As of May 6, 2016:

$\mathrm{http}: / /$ connectforhealthco.com/

Consumers' Checkbook, "Plan Comparison Tool 2016,” c. 2016. As of May 6, 2016:

https://www.healthplanratings.org/hie/

Covered California, home page, undated. As of May 6, 2016:

http://www.coveredca.com/

Cutler, David M., and Sarah J. Reber, "Paying for Health Insurance: The Trade-Off Between Competition and Adverse Selection," Quarterly Journal of Economics, Vol. 113, No. 2, May 1998, pp. 433-466.

Cutler, David M., and Richard J. Zeckhauser, "The Anatomy of Health Insurance," in Anthony J. Culyer and Joseph P. Newhouse, eds., Handbook of Health Economics, Vol. 1A, Part 3: Insurance Markets, Managed Care, and Contracting, Amsterdam: Elsevier, 2000, pp. 563643.

Dafny, Leemore, and David Dranove, "Do Report Cards Tell Consumers Anything They Don't Already Know? The Case of Medicare HMOs," RAND Journal of Economics, Vol. 39, No. 3, Autumn 2008, pp. 790-821.

Dafny, Leemore, Jonathan Gruber, and Christopher Ody, "More Insurers Lower Premiums: Evidence from Initial Pricing in the Health Insurance Marketplaces," American Journal of Health Economics, Vol. 1, No. 1, Winter 2015, pp. 53-81.

Dafny, Leemore, Kate Ho, and Mauricio Varela, "Let Them Have Choice: Gains from Shifting Away from Employer-Sponsored Health Insurance and Toward an Individual Exchange," American Economic Journal: Economic Policy, Vol. 5, No. 1, February 2013, pp. 32-58.

Day, Rosemary, and Pamela Nadash, "New State Insurance Exchanges Should Follow the Example of Massachusetts by Simplifying Choices Among Health Plans," Health Affairs, Vol. 31, No. 5, May 2012, pp. 982-989.

DC Health Link, home page, undated. As of May 6, 2016: https://dchealthlink.com/ 
DellaVigna, Stefano, "Psychology and Economics: Evidence from the Field," Journal of Economic Literature, Vol. 47, No. 2, 2009, pp. 315-372.

Einav, Liran, Amy Finkelstein, Stephen P. Ryan, Paul Schrimpf, and Mark R. Cullen, "Selection on Moral Hazard in Health Insurance," American Economic Review, Vol. 103, No. 1, February 2013, pp. 178-219.

Enroll UX 2014, home page, undated (a). As of May 6, 2016: http://www.ux2014.org/

—_, "About UX 2014," undated (b). As of May 2, 2016: http://www.ux2014.org/about-ux-2014

Ericson, Keith M., "Consumer Inertia and Firm Pricing in the Medicare Part D Prescription Drug Insurance Exchange," American Economic Journal: Economic Policy, Vol. 6, No. 1, February 2014, pp. 38-64.

Ericson, Keith, and Amanda Starc, "Heuristics and Heterogeneity in Health Insurance Exchanges: Evidence from the Massachusetts Connector," American Economic Review, Vol. 102, No. 3, May 2012, pp. 493-497.

— How Product Standardization Affects Choice: Evidence from the Massachusetts Health Insurance Exchange, Cambridge, Mass.: National Bureau of Economic Research, Working Paper 19527, October 2013. As of May 4, 2016:

http://www.nber.org/papers/w19527

—, Measuring Consumer Valuation of Limited Provider Networks, Cambridge, Mass.: National Bureau of Economic Research, Working Paper 20812, December 2014. As of May 4, 2016:

http://www.nber.org/papers/w20812

Feldman, Roger, Michael Finch, Bryan Dowd, and Steven Cassou, "The Demand for Employment-Based Health Insurance Plans," Journal of Human Resources, Vol. 24, No. 1, Winter 1989, pp. 115-142.

Frank, Richard G., and Karine Lamiraud, "Choice, Price Competition and Complexity in Markets for Health Insurance," Journal of Economic Behavior and Organization, Vol. 71, No. 2, August 2009, pp. 550-562.

Gabaix, Xavier, and David Laibson, "Shrouded Attributes, Consumer Myopia, and Information Suppression in Competitive Markets," Quarterly Journal of Economics, Vol. 121, No. 2, 2006, pp. 505-540.

Galesic, Mirta, and Rocio Garcia-Retamero, "Statistical Numeracy for Health: A Cross-Cultural Comparison with Probabilistic National Samples," Archives of Internal Medicine, Vol. 170, No. 5, March 8, 2010, pp. 462-468. 
Gibbs, Deborah A., Judith A. Sangl, and Barri Burrus, "Consumer Perspectives on Information Needs for Health Plan Choice," Health Care Financing Review, Vol. 18, No. 1, Fall 1996, pp. 55-73.

Greene, J., E. Peters, C. K. Mertz, and J. H. Hibbard, "Comprehension and Choice of a Consumer-Directed Health Plan: An Experimental Study," American Journal of Managed Care, Vol. 14, No. 6, June 2008, pp. 369-376.

Handel, Benjamin R., “Adverse Selection and Inertia in Health Insurance Markets: When Nudging Hurts," American Economic Review, Vol. 103, No. 7, December 2013, pp. 2643 2682.

Handel, Benjamin R., and Jonathan T. Kolstad, "Health Insurance for 'Humans': Information Frictions, Plan Choice, and Consumer Welfare," American Economic Review, Vol. 105, No. 8, August 2015, pp. 2449-2500.

Hanoch, Yaniv, and Thomas Rice, "Can Limiting Choice Increase Social Welfare? The Elderly and Health Insurance," Milbank Quarterly, Vol. 84, No. 1, 2006, pp. 37-73.

—, "The Economics of Choice: Lessons from the U.S. Health-Care Market," Health Expectations, Vol. 14, No. 1, March 2011, pp. 105-112.

Hanoch, Yaniv, Thomas Rice, Janet Cummings, and Stacey Wood, "How Much Choice Is Too Much? The Case of the Medicare Prescription Drug Benefit," Health Services Research, Vol. 44, No. 4, August 2009, pp. 1157-1168.

Hanoch, Yaniv, Stacey Wood, Andrew Barnes, Pi-Ju Liu, and Thomas Rice, "Choosing the Right Medicare Prescription Drug Plan: The Effect of Age, Strategy Selection, and Choice Set Size," Health Psychology, Vol. 30, No. 6, November 2011, pp. 719-727.

Harris-Kojetin, Lauren D., Jennifer D. Uhrig, Peyton Williams, Carla Bann, Elizabeth M. Frentzel, Lauren McCormack, Nancy Mitchell, and Nathan West, "The 'Choose with Care System': Development of Education Materials to Support Informed Medicare Health Plan Choices," Journal of Health Communication: International Perspectives, Vol. 12, No. 2 , 2007, pp. 133-156.

Hawai'i Health Connector, home page, undated. As of May 6, 2016:

http://www.hawaiihealthconnector.com/

HealthPocket, home page, undated. As of May 6, 2016:

https://www.healthpocket.com/

HealthSherpa, home page, undated. As of May 6, 2016:

https://www.healthsherpa.com/ 
HealthSource RI, home page, undated. As of May 6, 2016:

http://healthsourceri.com/

Heiss, Florian, Adam Leive, Daniel McFadden, and Joachim Winter, "Plan Selection in Medicare Part D: Evidence from Administrative Data," Journal of Health Economics, Vol. 32, No. 6, 2013, pp. 1325-1344.

Hibbard, Judith H., Jessica Greene, Shoshanna Sofaer, Kirsten Firminger, and Judith Hirsh, "An Experiment Shows That a Well-Designed Report on Costs and Quality Can Help Consumers Choose High-Value Health Care," Health Affairs, Vol. 31, No. 3, March 2012, pp. 560-568.

Hibbard, Judith H., J. J. Jewett, S. Engelmann, and M. Tusler, "Can Medicare Beneficiaries Make Informed Choices?” Health Affairs, Vol. 17, No. 6, November 1998, pp. 181-193.

Hibbard, Judith H., and E. Peters, "Supporting Informed Consumer Health Care Decisions: Data Presentation Approaches That Facilitate the Use of Information in Choice," Annual Review of Public Health, Vol. 24, 2003, pp. 413-433.

Iyengar, Sheena S., and Mark R. Lepper, "When Choice Is Demotivating: Can One Desire Too Much of a Good Thing?" Journal of Personality and Social Psychology, Vol. 79, No. 6, December 2000, pp. 995-1006.

Jacobson, Gretchen, Jennifer Huang, and Tricia Neuman, Medigap Reform: Setting the Context for Understanding Recent Proposals, Henry J. Kaiser Family Foundation, issue brief, January 13, 2014. As of May 4, 2016: $\mathrm{http} / / / \mathrm{kff}$.org/medicare/issue-brief/medigap-reform-setting-the-context/

Jin, Ginger Zhe, and Alan T. Sorensen, "Information and Consumer Choice: The Value of Publicized Health Plan Ratings," Journal of Health Economics, Vol. 25, No. 2, March 2006, pp. 248-275.

Johnson, Eric J., and Daniel Goldstein, “Do Defaults Save Lives?” Science, Vol. 302, No. 5649, November 21, 2003, pp. 1338-1339.

Johnson, Eric J., Ran Hassin, Tom Baker, Allison T. Bajger, and Galen Treuer, "Can Consumers Make Affordable Care Affordable? The Value of Choice Architecture," PLOS ONE, Vol. 8, No. 12, December 18, 2013, p. e81521.

King, Dominic, Felix Greaves, Ivo Vlaev, and Ara Darzi, “Approaches Based on Behavioral Economics Could Help Nudge Patients and Providers Toward Lower Health Spending Growth," Health Affairs, Vol. 32, No. 4, April 2013, pp. 661-668.

Kling, Jeffrey R., Sendhil Mullainathan, Eldar Shafir, Lee Vermeulen, and Marian Wrobel, "Comparison Friction: Experimental Evidence from Medicare Drug Plans," Quarterly Journal of Economics, Vol. 127, No. 1, February 2012, pp. 199-235. 
Kolstad, Jonathan T., and Michael E. Chernew, "Quality and Consumer Decision Making in the Market for Health Insurance and Health Care Services," Medical Care Research and Review, Vol. 66, No. 1, Suppl., February 2009, pp. 28S-52S.

Krieger, Miriam, and Stefan Felder, "Can Decision Biases Improve Insurance Outcomes? An Experiment on Status Quo Bias in Health Insurance Choice," International Journal of Environmental Research and Public Health, Vol. 10, No. 6, June 2013, pp. 2560-2577.

Krughoff, Robert, Walton Francis, and Robert Ellis, "Helping Consumers Choose Health Plans in Exchanges: Best Practice Recommendations," Health Affairs Blog, February 29, 2012. As of May 20, 2016:

http://healthaffairs.org/blog/2012/02/29/helping-consumers-choose-health-plans-inexchanges-best-practice-recommendations/

kynect, home page, undated. As of May 6, 2016:

https://kynect.ky.gov/

Li, Qian, and Pravin K. Trivedi, "Medicare Health Plan Choices of the Elderly: A Choice-withScreening Model," Journal of Business and Economic Statistics, Vol. 30, No. 1, January 2012, pp. 81-93.

Loewenstein, George, Joelle Y. Friedman, Barbara McGill, Sarah Ahmad, Suzanne Linck, Stacey Sinkula, John Beshears, James J. Choi, Jonathan Kolstad, David Laibson, Brigitte C. Madrian, John A. List, and Kevin G. Volpp, “Consumers' Misunderstanding of Health Insurance," Journal of Health Economics, Vol. 32, No. 5, September 2013, pp. 850-862.

Lynch, John G., Jr., and Dan Ariely, "Wine Online: Search Costs Affect Competition on Price, Quality, and Distribution," Marketing Science, Vol. 19, No. 1, 2000, pp. 83-103.

Madrian, Brigitte C., and Dennis F. Shea, "The Power of Suggestion: Inertia in 401(k) Participation and Savings Behavior," Quarterly Journal of Economics, Vol. 116, No. 4, November 2001, pp. 1149-1187.

Maher, Brendan S., "Some Thoughts on Health Care Exchanges: Choice, Defaults, and the Unconnected," Connecticut Law Review, Vol. 44, No. 4, April 2012, pp. 1099-1115. As of May 4, 2016: http://connecticutlawreview.org/articles/some-thoughts-on-health-care-exchanges-choicedefaults-and-the-unconnected/

Marquis, M. Susan, Melinda Beeuwkes Buntin, José J. Escarce, and Kanika Kapur, "The Role of Product Design in Consumers' Choices in the Individual Insurance Market," Health Services Research, Vol. 42, No. 6, Part 1, December 2007, pp. 2194-2223. 
Marquis, M. Susan, Melinda Beeuwkes Buntin, José J. Escarce, Kanika Kapur, Thomas A. Louis, and Jill M. Yegian, "Consumer Decision Making in the Individual Health Insurance Market," Health Affairs, Vol. 25, No. 3, May 2006, pp. W226-W234.

Maryland Health Connection, home page, undated. As of May 6, 2016: https:/www.marylandhealthconnection.gov/

Massachusetts Health Connector, home page, undated. As of May 6, 2016: https://www.mahealthconnector.org/

McWilliams, J. Michael, "Information Transparency for Health Care Consumers: Clear, but Effective?” Journal of General Internal Medicine, Vol. 28, No. 11, November 2013, pp. $1387-1388$.

McWilliams, J. Michael, Christopher C. Afendulis, Thomas G. McGuire, and Bruce E. Landon, "Complex Medicare Advantage Choices May Overwhelm Seniors-Especially Those with Impaired Decisionmaking," Health Affairs, Vol. 30, No. 9, August 2011, pp. 1786-1794.

Mikels, Joseph A., Andrew E. Reed, and Kosali I. Simon, "Older Adults Place Lower Value on Choice Relative to Young Adults," Journals of Gerontology, Series B: Psychological Sciences and Social Sciences, Vol. 64, No. 4, June 2009, pp. 443-446.

MNsure, home page, undated. As of May 6, 2016:

http://www.mnsure.org/

Monahan, Christine, Sarah J. Dash, Kevin Lucia, and Sabrina Corlette, What States Are Doing to Simplify Health Plan Choice in the Insurance Marketplaces, New York: Commonwealth Fund, issue brief, publication 1720, Vol. 34, December 2013. As of May 4, 2016 : http://www.commonwealthfund.org/publications/issue-briefs/2013/dec/simplify-health-planchoice

Naessens, James M., Mahmud Khan, Nilay D. Shah, Amy Wagie, Rebecca A. Pautz, and Claudia R. Campbell, "Effect of Premium, Copayments, and Health Status on the Choice of Health Plans," Medical Care, Vol. 46, No. 10, October 2008, pp. 1033-1040.

Nichols, Len M., Paul B. Ginsburg, Robert A. Berenson, Jon Christianson, and Robert E. Hurley, "Are Market Forces Strong Enough to Deliver Efficient Health Care Systems? Confidence Is Waning," Health Affairs, Vol. 23, No. 2, March 2004, pp. 8-21.

NY State of Health, home page, undated. As of May 6, 2016:

https://nystateofhealth.ny.gov/ 
O'Brien, Ellen, and Jack Hoadley, Medicare Advantage: Options for Standardizing Benefits and Information to Improve Consumer Choice, New York: Commonwealth Fund, issue brief, Vol. 33, publication 1117, April 2008. As of May 4, 2016:

http://www.commonwealthfund.org/publications/issue-briefs/2008/apr/medicare-advantage-options-for-standardizing-benefits-and-information-to-improve-consumer-choice

Pacific Business Group on Health, Consumer Choice of Health Plan Decision Support Rules for Health Exchanges: Installments I, II and III, 2012.

_- "Consumer Choice of Health Plan Decision Support Rules for Health Exchanges: Issue Brief-Top 5 Rules for Decision Support, and Strategies to Bridge the Gaps," c. 2013. As of May 4, 2016:

http://www.pbgh.org/storage/documents/PBGH_PlanChoiceBrief_Top5Rules_022113.pdf

Paez, Kathryn A., Coretta J. Mallery, HarmoniJoie Noel, Christopher Pugliese, Veronica E. McSorley, Jennifer L. Lucado, and Deepa Ganachari, "Development of the Health Insurance Literacy Measure (HILM): Conceptualizing and Measuring Consumer Ability to Choose and Use Private Health Insurance," Journal of Health Communication, Vol. 19, Supp. 2,

October 14, 2014, pp. 225-239.

PBGH-See Pacific Business Group on Health.

Peters, Ellen, Nathan Dieckmann, Anna Dixon, Judith H. Hibbard, and C. K. Mertz, "Less Is More in Presenting Quality Information to Consumers," Medical Care Research and Review, Vol. 64, No. 2, April 2007, pp. 169-190.

Peters, Ellen, Louise Meilleur, and Mary Kate Tompkins, Numeracy and the Affordable Care Act: Opportunities and Challenges, paper commissioned by the Roundtable on Health Literacy, Institute of Medicine, undated. As of May 4, 2016:

http://www.nationalacademies.org/hmd/ /media/Files/Activity\%20Files/PublicHealth/Health Literacy/Commissioned-Papers/

Numeracy-and-the-Affordable-Care-Act-Opportunities-and-Challenges.pdf

Politi, Mary C., Kimberly A. Kaphingst, Matthew Kreuter, Enbal Shacham, Melissa C. Lovell, and Timothy McBride, "Knowledge of Health Insurance Terminology and Details Among the Uninsured," Medical Care Research and Review, Vol. 71, No. 1, February 2014, pp. 8598.

Polsky, Daniel, Rebecca Stein, Sean Nicholson, and M. Kate Bundorf, "Employer Health Insurance Offerings and Employee Enrollment Decisions," Health Services Research, Vol. 40, No. 5, Pt. 1, October 2005, pp. 1259-1278. 
Public Law 111-148, Patient Protection and Affordable Care Act, March 23, 2010. As of May 4, 2016:

https://www.gpo.gov/fdsys/granule/PLAW-111publ148/PLAW-111publ148/contentdetail.html

Quincy, Lynn, What's Behind the Door: Consumer Difficulties Selecting Health Plans, Consumers Union, Health Policy Brief, January 2012a. As of May 3, 2016:

$\mathrm{http}$ //consumersunion.org/research/whats-behind-the-door-consumer-difficulties-selectinghealth-plans/

- Choice Architecture: Design Decisions That Affect Consumers' Health Plan Choices, Consumers Union, July 9, 2012b. As of May 4, 2016:

http://consumersunion.org/research/report-choice-architecture-design-decisions-that-affectconsumers-health-plan-choices/

Rice, Thomas, Gretchen Jacobson, Juliette Cubanski, and Tricia Neuman, “The Private Health Insurance Choices of Medicare Beneficiaries: How Much Does Price Matter?" Medical Care Research and Review, Vol. 71, No. 6, December 2014, pp. 661-689.

Romley, John A., Yuri Sanchez, John R. Penrod, and Dana P. Goldman, "Survey Results Show That Adults Are Willing to Pay Higher Insurance Premiums for Generous Coverage of Specialty Drugs," Health Affairs, Vol. 31, No. 4, April 2012, pp. 683-690.

Royalty, Anne Beeson, and Neil Solomon, "Health Plan Choice: Price Elasticities in a Managed Competition Setting," Journal of Human Resources, Vol. 34, No. 1, Winter 1999, pp. 1-41.

Samuelson, William, and Richard Zeckhauser, "Status Quo Bias in Decision Making," Journal of Risk and Uncertainty, Vol. 1, No. 1, March 1988, pp. 7-59.

Schram, Arthur, and Joep Sonnemans, "How Individuals Choose Health Insurance: An Experimental Analysis," working paper, 2008.

Schwartz, Barry, The Paradox of Choice: Why More Is Less, New York: Ecco, 2004.

Schwartz, Janet, Nortin M. Hadler, Dan Ariely, Joel C. Huber, and Thomas Emerick, "Choosing Among Employer-Sponsored Health Plans: What Drives Employee Choices?” Journal of Occupational and Environmental Medicine, Vol. 55, No. 3, March 2013, pp. 305-309.

Shepard, Mark, Hospital Network Competition and Adverse Selection: Evidence from the Massachusetts Health Insurance Exchange, working paper, 2015.

Simon, Herbert A., "A Behavioral Model of Rational Choice," Quarterly Journal of Economics, Vol. 69, No. 1, 1955, pp. 99-118.

- "Rational Choice and the Structure of the Environment," Psychological Review, Vol. 63, No. 2, March 1956, pp. 129-138. 
Sinaiko, Anna D., and Richard A. Hirth, "Consumers, Health Insurance and Dominated Choices," Journal of Health Economics, Vol. 30, No. 2, March 2011, pp. 450-457.

Spranca, M. D., M. N. Elliott, R. Shaw, and D. E. Kanouse, "Disenrollment Information and Medicare Plan Choice: Is More Information Better?" Health Care Financing Review, Vol. 28, No. 3, Spring 2007, pp. 47-59.

Strombom, Bruce A., Thomas C. Buchmueller, and Paul J. Feldstein, "Switching Costs, Price Sensitivity and Health Plan Choice," Journal of Health Economics, Vol. 21, No. 1, January 2002, pp. 89-116.

Szrek, Helena, and M. Kate Bundorf, "Enrollment in Prescription Drug Insurance: The Interaction of Numeracy and Choice Set Size," Health Psychology, Vol. 33, No. 4, April 2014, pp. 340-348.

Tanius, Betty E., Stacey Wood, Yaniv Hanoch, and Thomas Rice, “Aging and Choice: Applications to Medicare Part D," Judgment and Decision Making, Vol. 4, No. 1, February 2009, pp. 92-101.

Taylor, Erin A., Evan Saltzman, Sebastian Bauhoff, Rosalie L. Pacula, and Christine Eibner, "More Choice in Health Insurance Marketplaces May Reduce the Value of the Subsidies Available to Low-Income Enrollees," Health Affairs, Vol. 34, No. 1, January 2015, pp. 104110 .

Thaler, Richard H., and Cass R. Sunstein, Nudge: Improving Decisions About Health, Wealth, and Happiness, New Haven, Conn.: Yale University Press, 2008.

Tumlinson, Anne, Hannah Bottigheimer, Peter Mahoney, Elliot M. Stone, and Ann Hendricks, "Choosing a Health Plan: What Information Will Consumers Use?" Health Affairs, Vol. 16, No. 3, May-June 1997, pp. 229-238.

Ubel, Peter A., David A. Comerford, and Eric Johnson, "Healthcare.gov 3.0: Behavioral Economics and Insurance Exchanges," New England Journal of Medicine, Vol. 372, 2015, pp. 695-698.

Uhrig, Jennifer D., Lauren Harris-Kojetin, Carla Bann, and Tzy-Mey Kuo, "Do Content and Format Affect Older Consumers' Use of Comparative Information in a Medicare Health Plan Choice? Results from a Controlled Experiment," Medical Care Research and Review, Vol. 63, No. 6, December 2006, pp. 701-718.

ValuePenguin, "Affordable Care Act (Obamacare) Health Insurance Exchanges: Compare Health Insurance Exchange Plans," undated. As of May 6, 2016: http://www.valuepenguin.com/ppaca/exchanges 
Van den Berg, Bernard, Paula Van Dommelen, Piet Stam, Trea Laske-Aldershof, Tom Buchmueller, and Frederik T. Schut, "Preferences and Choices for Care and Health Insurance," Social Science and Medicine, Vol. 66, No. 12, June 2008, pp. 2448-2459.

Vermont Health Connect, home page, undated. As of May 6, 2016: https://portal.healthconnect.vermont.gov/VTHBELand/welcome.action

Washington Healthplanfinder, home page, undated. As of May 6, 2016: https://www.wahealthplanfinder.org

White, Chapin, Promoting Healthy Competition in Health Insurance Exchanges: Options and Trade-Offs, Washington, D.C.: National Institute for Health Care Reform, Policy Analysis 6, November 2011. As of May 4, 2016: http://www.nihcr.org/Healthy_Competition

Wong, Charlene A., David A. Asch, Cjloe M. Vinoya, Carol A. Ford, Tom Baker, Robert Town, and Raina M. Merchant, "The Experience of Young Adults on HealthCare.gov: Suggestions for Improvement," Annals of Internal Medicine, Vol. 161, No. 3, August 5, 2014, letter to the editor following p. 231.

Wood, Stacey, Yaniv Hanoch, Andrew Barnes, Pi-Ju Liu, Janet Cummings, Chandrima Bhattacharya, and Thomas Rice, "Numeracy and Medicare Part D: The Importance of Choice and Literacy for Numbers in Optimizing Decision Making for Medicare's Prescription Drug Program," Psychology and Aging, Vol. 26, No. 2, June 2011, pp. 295-307.

Your Health Idaho, home page, undated. As of May 6, 2016:

https://idahohix.yourhealthidaho.org/hix/ 